\title{
REVIEW
}

\section{Autonomic assessment of animals with spinal cord injury: tools, techniques and translation}

\author{
JA Inskip ${ }^{1,2,4}$, LM Ramer ${ }^{1,2,4}$, MS Ramer ${ }^{1,2}$ and AV Krassioukov ${ }^{1,3}$ \\ ${ }^{1}$ International Collaboration on Repair Discoveries, University of British Columbia, Vancouver, British Columbia, Canada; \\ ${ }^{2}$ Department of Zoology, University of British Columbia, Vancouver, British Columbia, Canada and ${ }^{3}$ Department of Medicine, \\ Division of Physical Medicine and Rehabilitation, University of British Columbia, Vancouver, British Columbia, Canada
}

\begin{abstract}
Study design: Literature review.
Objectives: To present a comprehensive overview of autonomic assessment in experimental spinal cord injury $(\mathrm{SCl})$.

Methods: A systematic literature review was conducted using PubMed to extract studies that incorporated functional motor, sensory or autonomic assessment after experimental SCl.

Results: While the total number of studies assessing functional outcomes of experimental $\mathrm{SCl}$ increased dramatically over the past 27 years, studies with motor outcomes dramatically outnumber those with autonomic outcomes. Within the areas of autonomic dysfunction (cardiovascular, respiratory, gastrointestinal, lower urinary tract, sexual function and thermoregulation), not all aspects have been characterized to the same extent. Studies focusing on bladder and cardiovascular function greatly outnumber those on sexual function, gastrointestinal function and thermoregulation. This review addresses the disparity between well-established motor-sensory testing presently used in experimental animals and the lack of standardized autonomic testing following experimental SCl. Throughout the review, we provide information on the correlation between existing experimental and clinically used autonomic tests. Finally, the review contains a comprehensive set of tables and illustrations to guide the reader through the complexity of autonomic assessment and dysfunctions observed following $\mathrm{SCl}$.

Conclusions: A wide variety of techniques exist to evaluate autonomic function in experimental animals with $\mathrm{SCl}$. The incorporation of autonomic assessment as outcome measures in experiments testing treatments or interventions for $\mathrm{SCl}$ should be considered a high, clinically relevant priority.

Spinal Cord (2009) 47, 2-35; doi:10.1038/sc.2008.61; published online 10 June 2008
\end{abstract}

Keywords: spinal cord injury; cardiovascular; respiratory; bladder; bowel; sexual

\section{Introduction}

Although it is generally appreciated that spinal cord injury (SCI) disrupts all types of communication between the brain and periphery below the lesion, the outcome of SCI is still commonly described in terms of motor function. The pervasive mental association between SCI and paralysis is reflected in recent headlines announcing a study on experimental SCI published in Nature Medicine. ${ }^{1}$ The headlines read 'Scientists move toward helping paralysis patients' $^{2}$ and 'paralysis cure'. ${ }^{3}$

In keeping with this perspective, an overwhelming number of clinical studies have focused on the effects of SCI on voluntary movement and the role of the somatic

Correspondence: Dr AV Krassioukov, International Collaboration on Repair Discoveries, University of British Columbia, 2469-6270 University Blvd., Vancouver, British Columbia, Canada V6T 1 Z4.

E-mail: krassioukov@icord.org

${ }^{4}$ These authors contributed equally to this work.

Received 20 February 2008; revised 5 May 2008; accepted 5 May 2008; published online 10 June 2008 nervous system. Despite the widespread effects of SCI on autonomic control, it is only recently that autonomic function following SCI has received significant attention in clinical research. ${ }^{4-6}$ The delay in addressing the autonomic effects of SCI has not only limited their appreciation among basic scientists and clinicians, but also efforts to develop new treatments or rehabilitation strategies targeting autonomic function following SCI. These shortcomings are not insignificant, as autonomic dysfunctions represent the primary causes of morbidity and mortality following SCI., ${ }^{7,8}$ In addition, individuals with SCI have identified recovery of autonomic functions as a high priority for improving their quality of life. ${ }^{9}$ Recent data demonstrate that autonomic function is not reliably predicted by the degree of residual motor or sensory function. ${ }^{10,11}$ Together these results suggest that there is an imbalance between clinical priorities and the general focus of SCI research.

A similar imbalance exists in animal research. This is highlighted by a systematic review of the animal SCI 
literature (Figure 1; see 'Methods'). We reviewed published studies of animals with experimental SCI, and identified studies with functional outcomes designed to evaluate motor, sensory or autonomic function. While the total number of studies increased dramatically over the past 27 years, published studies with motor outcomes dramatically outnumber those with sensory or autonomic outcomes. The disproportionate number of studies focusing on motor recovery after experimental SCI represents a significant mismatch between the clinical priorities of improved autonomic function and the direction of SCI research in animals.

When the functional autonomic outcomes are separated according to organ system dysfunction, it is immediately apparent that not all aspects of SCI-induced autonomic dysfunction have been examined to the same extent. The available data characterize mainly bladder and cardiovascular functions in SCI animals, whereas sexual function, gastrointestinal (GI) function and thermoregulation remain essentially uninvestigated. These findings are particularly alarming, as recovery of sexual function in particular has been identified by both paraplegics and quadriplegics as an urgent priority. ${ }^{9}$

There are several likely reasons for the paucity of research addressing autonomic dysfunctions following SCI. The complex organization of the autonomic nervous system, and its involvement in the control of almost every system in the body, makes it difficult to select appropriate functional tests. There is also some confusion surrounding the opera- tional definitions of autonomic dysfunctions that are present in animals following SCI. Finally, there may be a lack of agreement on (and awareness of) well-designed, clinically relevant tests that have been validated to evaluate autonomic functions in animals with SCI.

The main goal of this review is to provide the scientific community with an overview of the current methods used to assess the autonomic function of animals with SCI. For six aspects of autonomic function-cardiovascular function, respiratory function, GI function, lower urinary tract (LUT) function, sexual function and thermoregulation - we review the innervation of the system in humans and rats, the clinical implications of dysfunction following SCI and the tests or techniques that are currently available to evaluate function after experimental SCI. We also include functional tests that have been developed in other animal models, but that appear to be applicable to animals with SCI. Each test is reviewed in terms of its methodology, the type of information that it provides and the available data in animals with SCI. We hope to improve the understanding of functional tests used to evaluate autonomic function and to increase their incorporation in SCI experiments, particularly those studies testing potential therapeutic agents (see Table 9). We also hope that this review will be useful to veterinarians in clinical practice, to add to their arsenal of assessments of animals with naturally occurring SCI. Throughout the review we also highlight clinical assessments that are similar to the experimental methods we describe. The use of similar tests in the clinic and the laboratory is valuable because it facilitates
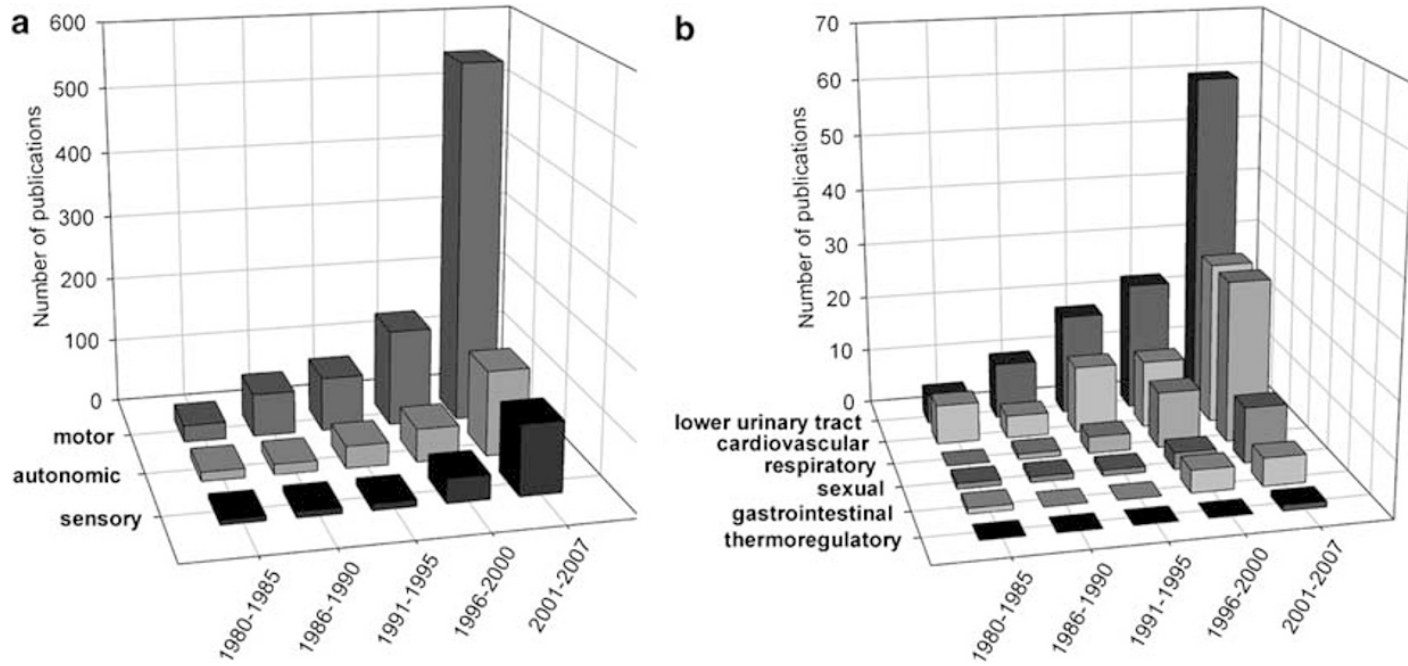

Figure 1 Autonomic dysfunction remains underrepresented in experimental spinal cord injury (SCI). (a) The total number of publications reporting the functional outcome in animal models of SCI has increased steadily since 1980. However, the rate of increase is dramatically different between studies characterizing function/dysfunction of different divisions of the nervous system. At every time period examined, published studies with motor outcomes far outnumber published studies investigating autonomic or sensory function. The disparity is particularly pronounced in the past 7 years, when studies incorporating a motor outcome outnumber publications with any autonomic outcome by more than four times. (b) When published data on autonomic function are categorized according to organ system dysfunction after SCl, it is clear that not every area is equally represented. Lower urinary tract (LUT) function/dysfunction is the best-characterized component of experimental $\mathrm{SCl}$, whereas experiments studying sexual, gastrointestinal and thermoregulatory function remain comparatively scant. However, when we compare the number of published studies characterizing motor outcome in the past 7 years (554) with the number of published studies characterizing LUT function in the same period (60), it is obvious that every aspect of SCI-related autonomic dysfunction should be considered a priority in animal research. 
Table 1 Search terms used to identify studies of motor, sensory and autonomic outcome of experimental SCI

\begin{tabular}{|c|c|c|c|c|c|c|c|}
\hline \multirow[t]{2}{*}{ Motor } & \multirow[t]{2}{*}{ Sensory } & \multicolumn{6}{|c|}{$\begin{array}{c}\text { Autonomic } \\
\text { Autonomic; sympathetic; parasympathetic }\end{array}$} \\
\hline & & Lower urinary tract & Cardiovascular & Respiratory & Sexual & Gastrointestinal & Thermoregulation \\
\hline Motor & Sensory & Urinary & Cardiovascular & Respiratory & Sexual & Gastrointestinal & Thermoregulation \\
\hline Movement & Sensation & Bladder & Blood pressure & Breathing & Uterus & Bowel & Sweating \\
\hline Walking & Touch & Micturition & Hypertension & Lung & Vagina & Colon & Piloerection \\
\hline Stepping & Proprioception & Renal & Hypotension & & Menstruation & & \\
\hline Locomotor & Pain & & Dysreflexia & & Menstrual & & \\
\hline Locomotion & Allodynia & & Heart & & Penis & & \\
\hline Postural & Hyperalgesia & & Arrhythmia & & Erection & & \\
\hline \multirow[t]{2}{*}{ Spasticity } & Dysaesthesia & & & & Ejaculation & & \\
\hline & Paresthesia & & & & & & \\
\hline
\end{tabular}

Each search term was used in combination with 'spinal cord injury'. Searches were limited to animal studies published in English within specified date ranges (Figure 1). Abstracts and manuscripts were reviewed to obtain the final publication count in each area: see Methods for details and Table 2 for inclusion/exclusion criteria.

the translation of our knowledge about autonomic function and dysfunction following SCI between the bench and the bedside.

\section{Methods: literature review}

A systematic literature review was conducted using PubMed to identify studies that incorporated functional assessment after experimental SCI. Each search was limited to animal studies published in English, and to specified publication date ranges. Search terms were always used in combination with 'spinal cord injury'. A separate search was performed using each of the terms listed in Table 1. The abstracts returned by each search were reviewed to identify studies with relevant functional outcomes; inclusion and exclusion criteria are listed in Table 2. If the outcome measure(s) used in the study were not evident from reading the abstract, the 'Methods' section of the paper was reviewed.

Publications were not counted twice in the same section (that is, no paper was counted as both locomotor and movement), but some were considered as spanning two sections (that is, some papers contained both motor and sensory functional assessments). All studies incorporating the functional outcome of interest were included, regardless of the objective of the study. For example, studies aimed at characterizing the effects of a treatment on pain after SCI that also included motor testing were counted as both motor and sensory. Finally, publications were categorized according to the intent of the outcome measure. For example, if authors used a ladder-walking test to assess locomotor function, the study was counted as motor (even though there are presumably proprioceptive components to the performance).

\section{Cardiovascular function}

Autonomic innervation of the cardiovascular system

In humans and animals with an intact neuraxis, both tonic neurogenic and reflex autonomic control of the cardiovascular system ensure adequate regional blood supply under a wide range of physiological conditions. The autonomic
Table 2 Criteria used to identify studies with relevant functional assessment after experimental $\mathrm{SCl}$

\begin{tabular}{|c|c|}
\hline Included & Excluded \\
\hline $\begin{array}{l}\text { All experimental models of } \mathrm{SCl} \\
\text { (for example, traumatic, } \\
\text { ischemic) in all species }\end{array}$ & $\begin{array}{l}\text { - Clinical (veterinary) SCI } \\
\text { - In vitro and ex vivo preparations } \\
\text { - Review articles }\end{array}$ \\
\hline $\begin{array}{l}\text { Studies incorporating functional } \\
\text { assessments of } \mathrm{SCl} \text {, including } \\
\text { those that: } \\
\text { - Characterize an outcome } \\
\text { measure } \\
\text { - Characterize function/ } \\
\text { dysfunction } \\
\text { - Use functional outcome to } \\
\text { assess manipulation or } \\
\text { treatment }\end{array}$ & $\begin{array}{l}\text { Studies detected by the search } \\
\text { criteria that contained no } \\
\text { functional assessments (For } \\
\text { example, motor neuron atrophy } \\
\text { after SCI) } \\
\text { - Studies that only monitored } \\
\text { vital signs during surgery or } \\
\text { treatment } \\
\text { - Electrophysiological studies of } \\
\text { individual neuron properties } \\
\text { (versus neurological function) } \\
\text { - Studies of spinal cord blood } \\
\text { flow/lesion perfusion or } \\
\text { microperfusion (versus systemic } \\
\text { cardiovascular function) } \\
\text { Studies testing the effects of } \\
\text { vasopressor therapy as a } \\
\text { treatment for SCI }\end{array}$ \\
\hline
\end{tabular}

Abstracts returned by literature searches were reviewed; if necessary, manuscripts were also reviewed to determine what outcome measures were included in the study. Studies were included/excluded according to the listed criteria.

innervation of the cardiovascular system has important ramifications for the pattern of cardiovascular dysfunction that emerges after SCI. Here we review the most relevant features of cardiovascular innervation (Figure 2), the details of which have been extensively reviewed elsewhere. ${ }^{12,13}$

Clinical implications of cardiovascular dysfunction following SCI Unlike dysfunction of the LUT, which can be described in general terms for suprasacral SCI, cardiovascular dysfunction varies dramatically with level of injury, ${ }^{14,15}$ its severity determined by the relative loss of supraspinal control over spinal sympathetic outflow. ${ }^{16}$ Cervical SCI disrupts supraspinal connections to preganglionic sympathetic innervation of the heart and blood vessels, eliminating tonic excitatory input to these organs. If the injury occurs at T5 or above, 


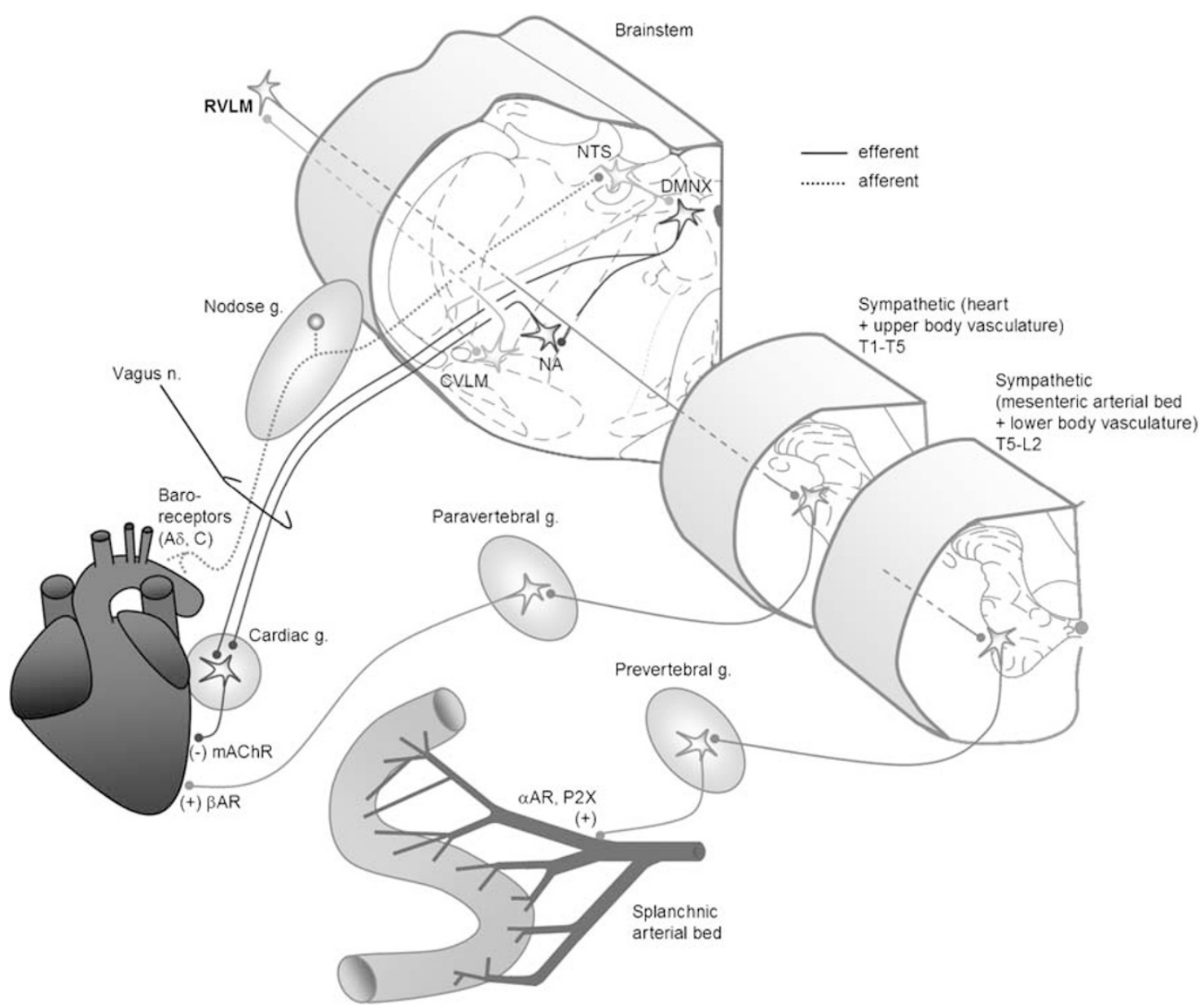

Figure 2 Autonomic innervation of the cardiovascular system. The major organs of the cardiovascular system are the heart and the blood vessels. The heart receives both parasympathetic and sympathetic innervation. Parasympathetic efferents travel to the heart in the vagus nerve, which exits the central nervous system (CNS) at the level of the medulla. The vagus nerve innervates the atria, nodes and Purkinje fibers via local cardiac ganglia, and vagal activity decreases heart rate, contractility and conduction velocity. Sympathetic activity has an opposite, stimulatory effect on the heart. All tissues of the heart receive sympathetic input from the upper thoracic (T1-T5) cord. Blood vessels are under sympathetic control, and vessels supplying the splanchnic region-the liver, spleen and intestines - are most important in cardiovascular control. The splanchnic bed is densely innervated, highly compliant and contains approximately one-fourth of the total blood volume in humans at rest. ${ }^{403}$ As such, it is the primary capacitance bed in the body. Sympathetic outflow to the splanchnic bed exits the thoracolumbar cord (T5-L2) and provides tonic vasoconstriction. The relative amount of sympathetic and parasympathetic activity governing cardiovascular control is determined (in part) by information from two types of afferents: baroreceptors and chemoreceptors. Baroreceptors in the aortic arch, carotid sinus and coronary arteries detect changes in arterial pressure, and chemoreceptors in the carotid bodies respond to changes in partial pressures of oxygen and carbon dioxide in the blood. Baroreceptor activity is the primary drive for rapid blood pressure adjustment. Baroreceptor afferents travel primarily in the vagus nerve and the glossopharyngeal nerve to reach the medulla. Abbreviations: AR, adrenergic receptors; CVLM, caudal ventrolateral medulla; DMNX, dorsal vagal motor nerve; g, ganglion; mAChR, muscarinic cholinergic receptors; NA, nucleus ambiguous; $n$, nerve; NTS, nucleus of the solitary tract; P2X, purinergic receptors; RVLM, rostral ventrolateral medulla; $(+)$ denotes excitatory synapses; $(-)$ denotes inhibitory synapses.

supraspinal control over sympathetic innervation of the splanchnic vascular bed is lost, jeopardizing blood pressure control. For this reason, injuries at and above T5-T6 are most likely to precipitate severe cardiovascular dysfunction. ${ }^{14,17}$

The acute phase of clinical SCI is marked by neurogenic shock, a period of profoundly altered cardiovascular control. ${ }^{18}$ This phenomenon is particularly pronounced following cervical SCI, which frequently induces severe hypotension and bradycardia. ${ }^{14,17}$ After neurogenic shock resolves, basal cardiovascular parameters remain altered in people with cervical and high-thoracic SCI. ${ }^{19}$ People with mid-thoracic SCI typically have elevated heart rates, ${ }^{20}$ whereas people with higher injuries often present with low heart rate and resting blood pressure. ${ }^{21}$ Cervical SCI also abolishes circadian blood pressure rhythms ${ }^{22-24}$ and blunts the cardiovascular responses to exercise. ${ }^{25}$ In addition to low resting blood pressure, many people with high SCI experience orthostatic hypotension $(\mathrm{OH})$, a decrease in blood pressure that occurs with assumption of a sitting position. ${ }^{26}$ These individuals are also prone to autonomic dysreflexia (AD), episodes of paroxysmal hypertension, often accompanied by baroreflex-mediated bradycardia, induced by sensory stimulation below the level of the injury. ${ }^{17}$ As a group, cardiovascular disorders are the most common underlying or contributing causes of death in people with SCI. ${ }^{8,27}$ 
Assessment of cardiovascular function following experimental SCI SCI alters the connectivity of autonomic circuits between the brainstem and spinal cord that governs cardiovascular control and modifies sympathetic intraspinal and neurovascular transmission resulting in altered vascular smooth muscle responses. ${ }^{28-34}$ These phenomena (as well as others) are likely to contribute to SCI-induced cardiovascular dysfunction. Here we focus on the systemic cardiovascular outcome of experimental SCI. Several aspects of SCI-induced cardiovascular dysfunction have been successfully modeled in experimental animals. Cardiovascular parameters of animals with SCI are monitored from direct arterial blood pressure measurements: indirect measurements of blood pressure (collected using a tail cuff, for example) have never been used in animals with SCI. Arterial blood pressure is taken either directly from a fluid-filled cannula or via radiotelemetric monitoring of animals with chronically implanted cannulae.

Short-term cardiovascular assessment using fluid-filled cannulae The bulk of available cardiovascular data from animals with SCI has been collected using arterial cannulae implanted acutely prior to data collection. Typically, the cannula is placed in one carotid or femoral artery hours or days before data collection, although it is possible to maintain cannulae for at least 1 week with daily flushing. Cannulae are filled with heparin solution to preserve patency and tunneled subcutaneously for externalization. After arterial cannulae are implanted, animals are housed singly to protect cannulae from cage-mate chewing. Cardiovascular parameters can be monitored directly in conscious animals in their home cage by connecting the cannulae to a pressure transducer: this method has been used frequently to study many types of cardiovascular dysfunction in animals with SCI.

The aspect of cardiovascular dysfunction that has been best characterized in rodent models of SCI is AD, episodic hypertension that has been described in both rats and mice, and is induced by visceral and somatic stimuli (see Table 3 for detailed references). The nature of rodent $\mathrm{AD}$ and its inciting stimuli is very similar to that described in humans. Rats, like humans, typically experience AD when SCI occurs at or above T5-T6. In one study, bladder filling induced AD in rats with severe contusion SCI at T4, but not in rats with severe T10 contusion. ${ }^{68}$ The most common experimental stimulus for $\mathrm{AD}$ is colorectal distension (CRD), in which a balloon catheter is inserted into the colon through the anus in the conscious animal. ${ }^{28}$ Air is infused into the balloon to mimic the pressure of several fecal boli in the colon. Distension is typically maintained for $1 \mathrm{~min}$, and arterial pressure is monitored before, during and after CRD.

Formerly considered to be associated with chronic SCI, AD may also emerge during the acute stages in both animals and humans. ${ }^{74}$ Rats with complete transection of the spinal cord at T5 develop $\mathrm{AD}$ in response to CRD as early as $24 \mathrm{~h}$ after injury. ${ }^{28}$ The severity of AD subsequently decreases during the first post-injury week, and $\mathrm{AD}$ is relatively mild at 7 days following $\mathrm{T} 5 \mathrm{SCI}{ }^{28,38}$ Thereafter, the severity of $\mathrm{AD}$ increases. Although the actual rise in blood pressure varies with the level and severity of injury, as well as the experimental conditions, the majority of experiments are conducted at least 2 weeks after SCI when AD is pronounced. This well-characterized model has been used extensively to identify mechanisms contributing to the development of $\mathrm{AD}$; still, only a few studies have examined the severity of $\mathrm{AD}$ as an outcome measure when testing therapies for SCI (Table 9).

Compared to its hypertensive counterpart, $\mathrm{OH}$ has received little attention in experimental SCI. Some clues to mechanisms of $\mathrm{OH}$ are provided by animal models of microgravity-induced cardiovascular deconditioning, in which microgravity is simulated by hindlimb unloading (HU). ${ }^{75-77}$ Animals exposed to HU experience a pronounced drop in blood pressure when subjected to head-up tilt. ${ }^{78}$ Considering this, we are currently developing an animal model of $\mathrm{OH}$ after SCI. We have recently observed $\mathrm{OH}$ in rats with complete transection injury at T3-T4 (JAI, LMR and AVK, unpublished observations). When these unanesthetized rats are subjected to passive head-up tilt 1 month after injury, they experience a pronounced drop in blood pressure (Figure 3); uninjured rats subjected to the same maneuver exhibit either a rise in blood pressure or very little change.

Blood pressure data collected directly from arterial cannulae have also been used to monitor animals in the early phases of recovery from SCI. Neurogenic shock is generally considered to be less pronounced in experimental animals than in human SCI. This notion might stem from the fact that the overwhelming majority of experiments are performed in animals with thoracic SCI. Animals with cervical SCI may experience neurogenic shock that is more comparable to the clinical situation. Rats with complete transection between C7 and T1 developed both hypotension and bradycardia. ${ }^{79}$ Mean arterial pressure fell precipitously (by approximately $30 \mathrm{~mm} \mathrm{Hg}$ ) in the first $24 \mathrm{~h}$ after injury, and slowly recovered to preinjury levels (around $100 \mathrm{~mm} \mathrm{Hg}$ ) by 9 days after injury. Heart rate also decreased dramatically (from about 360 b.p.m. to about 300 b.p.m.) and remained significantly lower than preinjury heart rate for 9 days (the duration of the study). Owing to the challenges involved in animal care, there are very few data on animals with high, severe SCI. These animal models are currently being developed (for example Pearse et al. ${ }^{80}$ ) and should facilitate our understanding of cardiovascular control following cervical SCI.

Cardiovascular data collected from animals with acutely implanted arterial cannulae have also been subjected to spectral analysis. This type of analysis exploits the relationship between frequency of spontaneous fluctuations in cardiovascular parameters and the activity of systems (local, sympathetic and parasympathetic) governing cardiovascular control. Spectral analysis has been validated in humans, ${ }^{81,82}$ $\operatorname{dogs}^{82-84}$ and rats, ${ }^{85}$ and provides indices of autonomic nervous system activity from relatively short segments of continuous recordings of blood pressure (and in humans, electrocardiogram signals). Spectral analysis has been applied to examine blood pressure variation in rats with acute SCI. ${ }^{70}$ At 1 and 6 days after complete transection at T4-T5, rats exhibited reduced power in the low-frequency range, 
Table 3 Overview of studies characterizing or targeting cardiovascular dysfunction after experimental SCI

\begin{tabular}{|c|c|c|c|c|}
\hline Technique used & Species & Injury model & Time range post-injury & References \\
\hline \multicolumn{5}{|l|}{ Acute arterial cannulation } \\
\hline \multirow[t]{12}{*}{ Basal cardiovascular parameters } & \multirow[t]{8}{*}{ Rat } & \multirow[t]{2}{*}{ T1-T4 clip compression } & $<4 \mathrm{~h}$ & $35-37$ \\
\hline & & & 1.5 months & 38 \\
\hline & & \multirow[t]{2}{*}{ C6/7 Tx; T2 Tx; T9 Tx } & $4 \mathrm{~h}$ & 38 \\
\hline & & & $\leqslant 1$ week & 39 \\
\hline & & \multirow[t]{2}{*}{ T4-T7 Tx } & $0 \mathrm{~h}-6$ weeks & 40 \\
\hline & & & $\leqslant 1$ week & 41 \\
\hline & & T5-T8 contusion & $<1 \mathrm{~h}$ & $42-44$ \\
\hline & & T9 clip compression & $1,2 \mathrm{~h}$ & 45 \\
\hline & Rat, cat & C7 Tx (ligature crush) & $<1 \mathrm{~h}$ & 46 \\
\hline & Cat & T6 contusion & $\leqslant 24 \mathrm{~h}$ & 47 \\
\hline & Dog & C4 Tx & $<1 \mathrm{~h}$ & 48 \\
\hline & Monkey & T5 balloon compression & & 49 \\
\hline \multicolumn{5}{|l|}{ Autonomic dysreflexia } \\
\hline \multirow[t]{11}{*}{ Colorectal distension } & \multirow[t]{2}{*}{ Mouse } & T2 clip compression & 2 weeks & 50 \\
\hline & & T2 Tx & 2 weeks & $50-52$ \\
\hline & \multirow[t]{9}{*}{ Rat } & \multirow[t]{2}{*}{$\mathrm{C} 7-\mathrm{T} 1 ; \mathrm{C} 8 \mathrm{Tx}$} & 3 days & 53,54 \\
\hline & & & $2-3$ months & 55 \\
\hline & & \multirow[t]{3}{*}{ T4-T5 clip compression } & $\leqslant 1$ week & 38,56 \\
\hline & & & 2-4 weeks & $38,57-59$ \\
\hline & & & 4-6 weeks & 38,59 \\
\hline & & \multirow[t]{4}{*}{ T3-T5 Tx } & $\leqslant 24 \mathrm{~h}$ & $40,60,61$ \\
\hline & & & $\leqslant 1$ week & $28,40,60$ \\
\hline & & & 2-4 weeks & $28,34,40,60-65$ \\
\hline & & & $2-3$ months & 55 \\
\hline \multirow[t]{4}{*}{ Bladder distension } & \multirow[t]{4}{*}{ Rat } & \multirow[t]{2}{*}{ C7-T1 Tx } & $24 \mathrm{~h}$ & 66 \\
\hline & & & $\leqslant 1$ week & 67 \\
\hline & & T4 contusion & 4 weeks & 68 \\
\hline & & T5 Tx & $\leqslant 1$ week & 28 \\
\hline \multirow[t]{3}{*}{ Somatic stim. } & \multirow[t]{2}{*}{ Mouse } & T2 clip compression & 2 weeks & 50 \\
\hline & & $\mathrm{T} 2 \mathrm{Tx}$ & & $50-52$ \\
\hline & Rat & T4 clip compression & $2-6$ weeks & 59 \\
\hline Vag.-cerv. stim. & Rat & $\mathrm{T7} \mathrm{Tx}$ & $1-3$ weeks & 69 \\
\hline Spectral analysis & Rat & T1-T5 Tx & $\leqslant 1$ week & 70,71 \\
\hline \multirow[t]{5}{*}{ Telemetric monitoring } & \multirow[t]{5}{*}{ Rat } & C7-T1 Tx & $2-3$ months & 55 \\
\hline & & \multirow{3}{*}{ T4-5 Tx } & $\leqslant 24 \mathrm{~h} \leqslant 1$ week & 40 \\
\hline & & & 4-6 weeks & 40,72 \\
\hline & & & $2-3$ months & 73 \\
\hline & & T4 clip compression & 1.5 months & 38 \\
\hline
\end{tabular}

Abbreviations: stim., stimulation; Tx, transection; vag.-cerv., vaginocervical.

Studies have been classified by the technique used to assess cardiovascular function. Studies employing a combination of techniques are referenced under both headings. Studies using similar experimental animals, injury models and time range of study post-injury are grouped together.

indicative of reduced sympathetic tone (or increased parasympathetic tone ${ }^{85}$ ) that affects blood pressure control. There are currently no data applying spectral analysis to more chronic experimental SCI. However, as this analysis is related to clinical measures of autonomic control following human $\mathrm{SCI}^{86}$ it represents a readily translatable tool for autonomic assessment in experimental animals and humans with SCI.

Advantages/disadvantages. Blood pressure measurements collected directly from fluid-filled cannulae provide highresolution cardiovascular data with a relatively modest investment in equipment. However, preserving catheter patency for repeated measurements in the same animals can present a challenge. For this reason, this method typically only provides a snapshot of information about cardiovascular function in each animal (that is, taken at a single time point). The presence of investigators at the time of data collection, as well as possible effects of recent surgery for cannula implantation, may contribute to stress in the animals during data collection.

\section{Telemetric monitoring of cardiovascular parameters}

Telemetric monitoring provides continuous physiological information about the cardiovascular function of conscious, freely moving animals over a long time course. This technique was first applied to animals with SCI in our laboratory (Figure 4), ${ }^{38}$ and allowed us to characterize changes in resting blood pressure and heart rate in rats during recovery from high-thoracic SCI. Rats were instrumented with a telemetric transducer (catheter implanted into the descending aorta) 1 month prior to SCI, and arterial pressure data were transmitted as a radiofrequency signal to a receiver under the cage. The recovery time after transducer implantation was critical, as the effects of simultaneous 

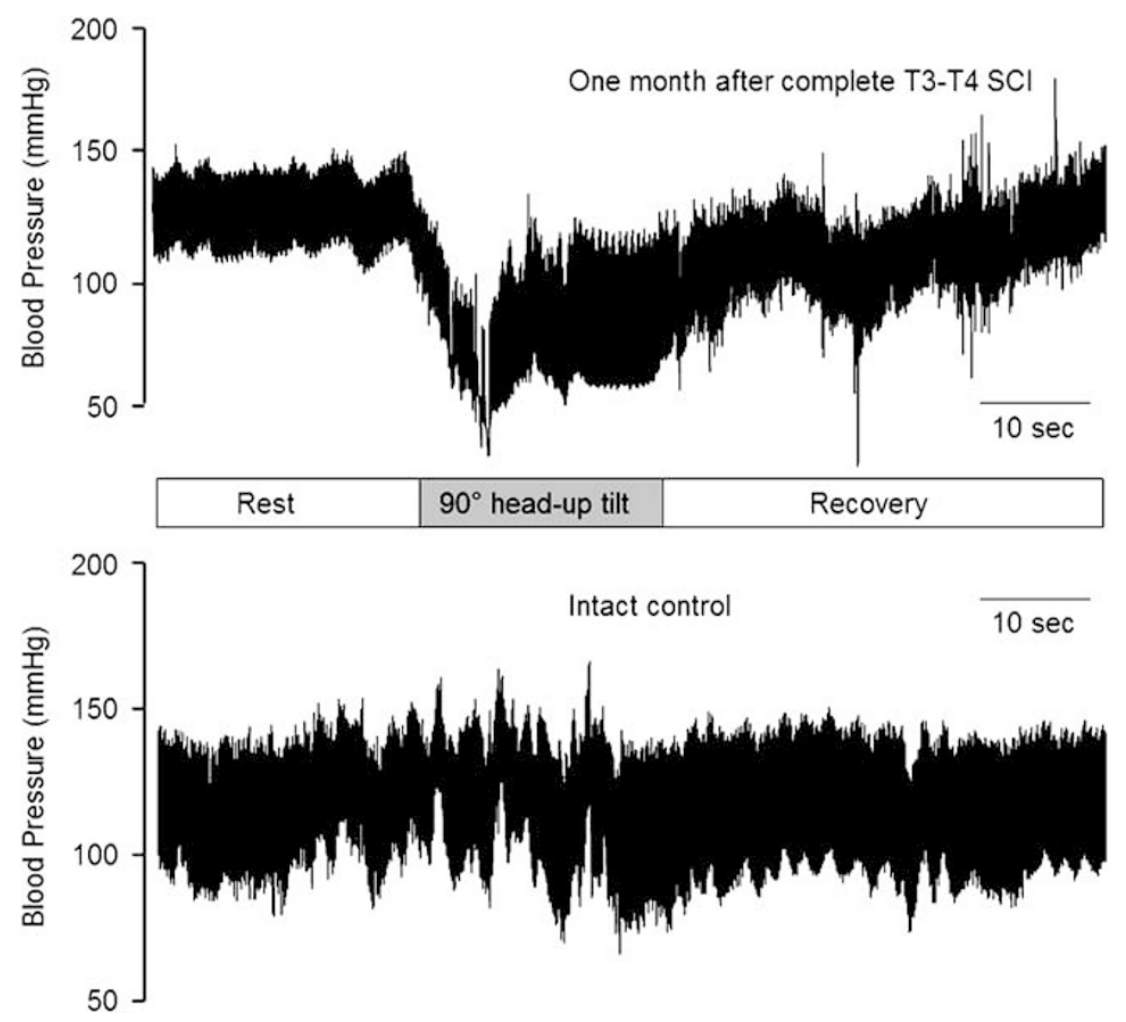

Figure 3 Representative tracings using fluid-filled cannulae to assess blood pressure during head-up tilt. One month after complete T3-T4 transection injury, conscious rats with a left carotid artery cannulation subjected to a passive $90^{\circ}$ head-up tilt experienced a pronounced drop in blood pressure. Uninjured rats subjected to the same maneuver exhibited either a rise in blood pressure or very little change (JAI, LMR and AVK, unpublished observations).

transducer implantation and SCI can impede blood supply to the hindlimbs. ${ }^{38}$

Telemetric monitoring of animals with SCI suggests that SCI-induced alterations in basal cardiovascular control are similar between rats and humans. Rats with T5 clip compression SCI experience transient hypotension and persistent tachycardia following injury. ${ }^{38,87}$ Telemetric monitoring revealed that blood pressure recovered to preinjury levels by $48 \mathrm{~h}$ after SCI, and remained equivalent to preinjury levels for at least 6 weeks following injury. Heart rate was increased relative to preinjury levels by 3 days after SCI, and remained elevated for at least 6 weeks. Diurnal fluctuations in blood pressure and heart rate returned approximately 5 days after injury. ${ }^{38}$ Interestingly, recent telemetric data demonstrate that rats with more rostral injuries (complete T4 transection) experience persistent hypotension and tachycardia, with altered basal blood pressure and heart rate for at least 6 weeks following SCI. ${ }^{40}$ Thus, it seems that in rats, as in humans, severity of cardiovascular dysfunction varies with both level and severity of SCI. Radiotelemetry has also been used to investigate $\mathrm{AD}$ induced by CRD, which is similar in progression between rats with T5 clip compression and rats with T4 complete transection (Figure 4). ${ }^{38,40}$

Advantages/disadvantages. As data collection is continuous, telemetric monitoring is extremely informative. Since it avoids the potential stressors of intra-arterial catheterization, catheter maintenance, or restraint for catheter connection, telemetry can be considered the gold standard for cardiovascular assessment in conscious experimental animals. It does not eliminate stress due to handling when animals must be loosely restrained for cardiovascular measurements (such as during CRD to induce AD), so this remains a consideration in telemetric studies. Most significantly, adopting telemetric monitoring entails considerable investment in equipment. Perhaps for this reason, data in animals with SCI remain scant (Table 3).

\section{Respiratory function}

Innervation of the respiratory system

Coordinated activity of somatic (diaphragm and accessory respiratory skeletal muscles) and autonomic (smooth muscles of the bronchial tree) nervous systems is crucial for normal respiration. Here we review efferent and afferent innervation as it pertains to respiratory dysfunction that emerges following SCI (Figure 5). For simplicity, we omit many important aspects, and the interested reader is directed to comprehensive reviews on the subject (for example, see Brading $^{12}$ and Canning and Fischer ${ }^{88}$ ).

Clinical implications of respiratory dysfunction following SCI Respiratory dysfunction after SCI is determined by relative loss of descending autonomic innervation to the respiratory 

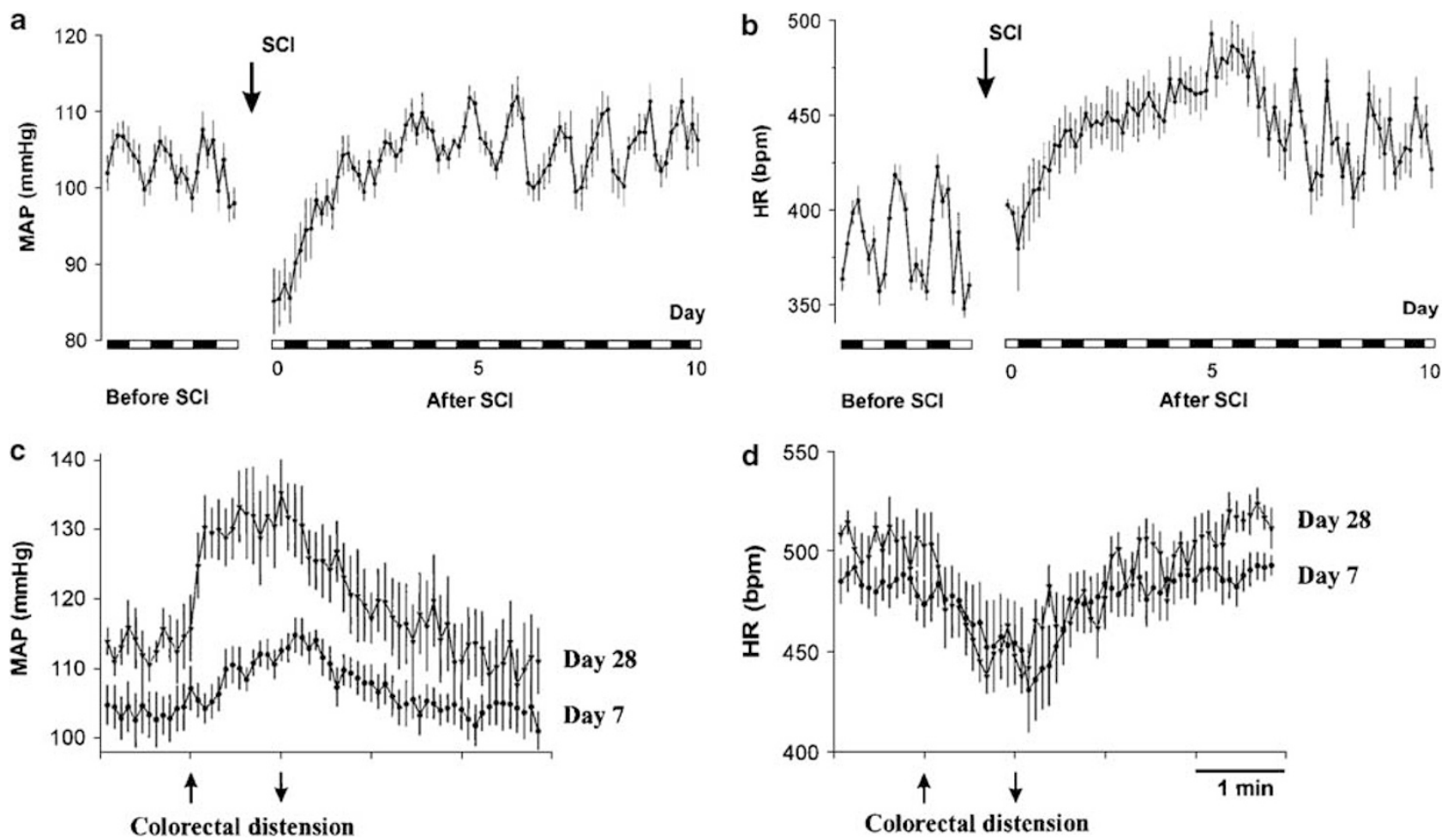

Figure 4 Use of telemetric monitoring to assess basal cardiovascular parameters (a, b) and autonomic dysreflexia (c, d) after experimental spinal cord injury $(\mathrm{SCl})$. Rats were instrumented with radiotelemetric pressure transducers and cannulae were implanted into the descending aorta 1 month prior to T5 clip compression SCl. $(\mathbf{a}, \mathbf{b})$ Telemetric monitoring permitted data collection in freely moving rats for 3 days prior to $\mathrm{SCl}$ (to establish reliable uninjured baseline responses) and for the first 10 days following $\mathrm{SCl}$. Mean values ( \pm s.e. $\mathrm{m}$.) of $3 \mathrm{~h}$ intervals for five rats are shown, and light and dark periods are indicated on the $x$ axes. (c, d) Autonomic dysreflexia (AD) was examined at 7 and 28 days following $\mathrm{SCl}$. Average responses ( \pm s.e.m.) to colorectal distension in five rats are shown. This figure is reprinted from Mayorov et al. ${ }^{38}$

muscles. Injuries above C3 paralyze the diaphragm, and ventilatory support is typically required to sustain life. After C3-C5 SCI, the diaphragm is partially denervated, and inspiration is compromised; still, most individuals with C4-C5 SCI do not require artificial ventilation (or can be weaned during recovery ${ }^{89}$ ). In lower cervical SCI, innervation of the primary (and some accessory) inspiratory muscles is preserved, but ventilation is still impaired, because denervated intercostal muscles do not coordinate chest expansion with diaphragm descent. ${ }^{90}$ Finally, any SCI above L1-L2 denervates abdominal muscles, reducing the effectiveness of coughing.

The clinical ramifications of respiratory dysfunctions following SCI are severe, and encompass pneumonia, atelectasis, bronchitis, reduced lung volumes and compliance, sleep apnea and respiratory insufficiency or dyspnea, particularly during exercise. ${ }^{91-95}$ The incidence and severity of respiratory dysfunction increases with the level of SCI. Respiratory complications are the leading cause of death in acute SCI. ${ }^{96}$ In chronic SCI, respiratory dysfunction contributes significantly to mortality, ${ }^{8}$ and is associated with reduced quality of life. ${ }^{97}$

Assessment of respiratory function following experimental SCI The most common experimental model used to study SCIinduced respiratory dysfunction is rat cervical hemisection.
This injury reliably disrupts innervation to one-half of the diaphragm. Recently, cervical hemicontusion models have been developed that also induce respiratory deficits due to hemidiaphragm paralysis. ${ }^{98,99}$ Data from both injury models have increased our understanding of endogenous plastic processes that might improve respiratory function following SCI (Table 4; reviewed in Zimmer et al. ${ }^{134}$ ). A few studies have also examined the potential for regenerative therapies to restore diaphragm function (Table 9). The obvious limitation of these models is that they are incomplete injuries, and thus do not model all aspects of clinical SCI. As more models of severe cervical SCI are developed, our understanding of respiratory dysfunction after SCI is likely to improve. Fortunately, outcome measures used to assess respiratory function are similar between experimental and clinical SCI, facilitating translation of these data.

\section{Phrenic nerve conduction}

Phrenic nerve conduction testing is used clinically for planning phrenic nerve or diaphragmatic pacing for assisted activation of the diaphragm. ${ }^{135-137}$ In animals, phrenic nerve responses during spontaneous breathing or spinal cord stimulation are examined in anesthetized, paralyzed (mechanically ventilated) animals. ${ }^{101-103,121,122}$ These data have been used extensively to characterize respiratory 


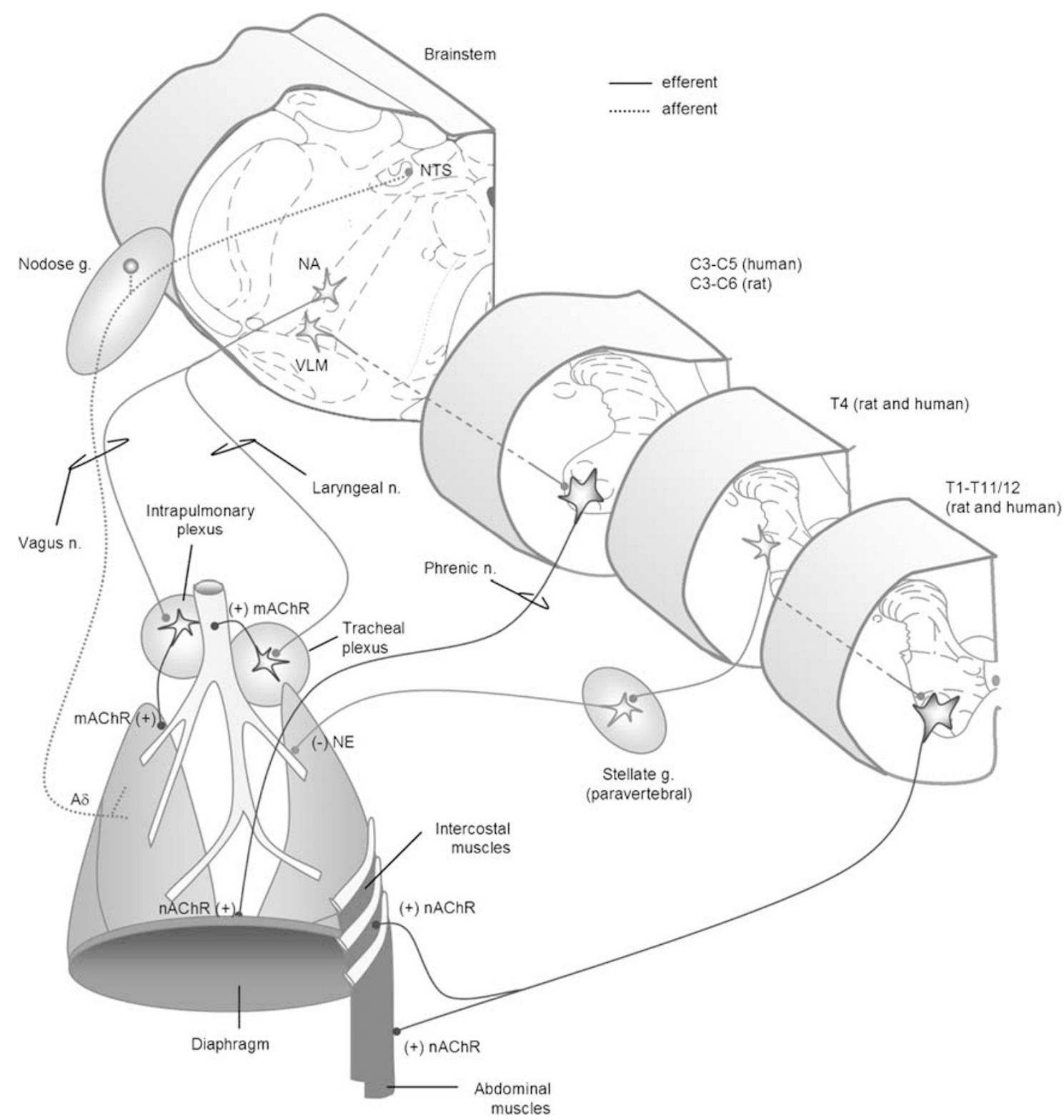

Figure 5 Innervation of the respiratory system. The main respiratory muscles are the diaphragm, intercostals and abdominals. The diaphragm is the major inspiratory muscle and is innervated by phrenic motor neurons that lie in the cervical spinal cord (C3-C5 in humans; C3-C6 in rats $^{404}$ ). Innervation of respiratory intercostal and abdominal muscles exits the thoracolumbar spinal cord, from T1-T11 and T7-L2, respectively. Activity of these muscles (as well as that of accessory muscles) is modulated by autonomic premotor neurons in the VLM, which project to motor neurons in the spinal cord. The airways receive both parasympathetic and sympathetic inputs. The parasympathetic nervous system provides the most important innervation to the smooth muscle of the airways, and is thus most important in controlling its diameter. Preganglionic parasympathetic neurons originate in the NA, and innervate the trachea and the bronchi via the laryngeal and vagus nerves (respectively). Parasympathetic innervation is predominately cholinergic and its action is excitatory, reducing airway diameter (via mAChR). Sympathetic innervation of smooth muscle is comparatively scant. Preganglionic sympathetic axons exit at T4 and travel to paravertebral ganglia, and post-ganglionic adrenergic fibers elicit bronchodilation, acting through $\beta$-AR. The airways also have extensive afferent innervation. The most important afferents regulating respiration are vagal $A \delta$, with cell bodies in the nodose ganglia and central axons projecting to the NTS. Abbreviations: A $\delta$, mechanoreceptors; $\beta$-AR, $\beta$-adrenergic receptors; $C$, cervical spinal cord; $g$, ganglion; $L$, lumbar spinal cord; mAChR, muscarinic cholinergic receptors; NA, nucleus ambiguous; nAChR, nicotinic cholinergic receptors; NE, norepinephrine; $n$, nerve; NTS, nucleus of the solitary tract; T, thoracic spinal cord; VLM, ventrolateral medulla; $(+)$ denotes excitatory synapses; $(-)$ denotes inhibitory synapses.

plasticity after SCI, particularly during the crossed phrenic phenomenon (CPP). ${ }^{134,138}$

The CPP relies on a functionally latent bulbospinal pathway that innervates the diaphragm bilaterally. When the hemidiaphragm is paralyzed by C2 hemisection, hypoxia induced by contralateral phrenic nerve section activates the latent pathway to restore diaphragmatic function. This pathway also becomes spontaneously active over time following SCI, but this spontaneous return of activity may not be sufficient to restore diaphragmatic function. ${ }^{104} \mathrm{~A}$ series of phrenic nerve function studies has revealed that systemic delivery of xanthines (adenosine receptor 
Table 4 Overview of studies characterizing or targeting respiratory dysfunction after experimental SCI

\begin{tabular}{|c|c|c|c|c|}
\hline Technique used & Species & Injury model & Time range post-injury & References \\
\hline \multirow[t]{8}{*}{ Phrenic nerve conduction } & \multirow[t]{8}{*}{ Rat } & \multirow[t]{2}{*}{ C2 hemicontusion } & 1 week & 99 \\
\hline & & & 4-6 weeks & 99,100 \\
\hline & & \multirow{5}{*}{ C2 hemisection } & $\leqslant 24 \mathrm{~h}$ & $101-118$ \\
\hline & & & $\leqslant 1$ week & $104,116,117,119,120$ \\
\hline & & & $2-4$ weeks & $103,119,121-124$ \\
\hline & & & 4-8 weeks & 121,125 \\
\hline & & & 2-4 months & $116,117,126$ \\
\hline & & C4/5 contusion & 2-11 weeks & 100 \\
\hline \multirow[t]{3}{*}{ Pneumotachometry } & Rat & C2 hemisection & $1-2$ months & 127,128 \\
\hline & Dog & T2, T4, T8 (seg. epid.) & Immediate & 129 \\
\hline & Turtle & D8-D10 Tx & 4,8 weeks & 130 \\
\hline \multirow[t]{7}{*}{ Diaphragm EMG } & \multirow[t]{5}{*}{ Rat } & \multirow[t]{4}{*}{$\mathrm{C} 2$ hemisection } & $\leqslant 24 \mathrm{~h}$ & $105,117,131$ \\
\hline & & & $\leqslant 1$ week & 119 \\
\hline & & & 2-4 weeks & 119 \\
\hline & & & 90 days & 117 \\
\hline & & C2 hemicontusion & 7 days, 1 month & 99 \\
\hline & Dog & T2, T4, T8 (seg. epid.) & Immediate & 129 \\
\hline & Mouse & C2 hemisection & $1-48 \mathrm{~h}$ & 132 \\
\hline \multirow[t]{3}{*}{ Plethysmography } & \multirow[t]{3}{*}{ Rat } & C2 hemisection & $2,3,5$ weeks & 122 \\
\hline & & C4/5 hemicontusion & $24 \mathrm{~h}, 1,2,4,6$ weeks & 98 \\
\hline & & T8 contusion & $24 \mathrm{~h}, 7$ days & 133 \\
\hline
\end{tabular}

Abbreviations: EMG, electromyography; seg. epi., segmental epidural; Tx, transection.

Studies have been classified by the technique used to assess respiratory function. Studies employing a combination of techniques are referenced under both headings. Studies using similar experimental animals, injury models and time range of study post-injury are grouped together.

antagonists) can activate this pathway without phrenic nerve section, to restore respiratory drive to phrenic motor neurons following SCI. ${ }^{105-107,123,126}$ These data, and preliminary clinical experience, suggest that xanthine treatment may represent a viable therapeutic option in weaning individuals with SCI from ventilatory support. ${ }^{139}$

Phrenic nerve recording has also been used to test the efficacy of olfactory ensheathing cell (OEC) transplantation in improving the respiratory outcome of experimental SCI ${ }^{140,141}$ (Table 9). In these experiments, rats with high cervical hemisection (that abolished ipsilateral phrenic nerve activity) received OEC transplantation at the time and site of injury. In one study, rats that received OECs recovered spontaneous respiratory rhythm in the ipsilateral phrenic nerve by 2 months after SCI. ${ }^{140}$ In another set of experiments, ipsilateral phrenic nerve activity recovered to approximately $80 \%$ of contralateral nerve activity by 3-6 months post-SCI. ${ }^{141}$ In the latter set of experiments, the authors transected the contralateral spinal cord to demonstrate that a significant proportion of this recovery was due to ipsilateral projections. However, the underlying mechanism of recovery is not known.

\section{Pneumotachometry}

Pneumotachometry is the evaluation of the respiratory volumes and rate that can be readily applied in conjunction with phrenic nerve recording. This type of assessment was important in identifying altered breathing patterns in rats with unilateral cervical SCI. ${ }^{127}$ Rats with C2 hemisection exhibit a reduced expiratory volume and an increased respiratory rate to preserve total (minute) ventilation. ${ }^{127}$
Pneumotachography was also applied to verify the functional significance of crossed phrenic pathways. ${ }^{128}$

\section{Diaphragmatic electromyography}

Similar to clinical practice, electromyography (EMG) of the diaphragm can be performed in conjunction with phrenic nerve conduction studies in animals with SCI. For example, rats that received OECs at the time of $\mathrm{C} 2$ hemisection recovered both ipsilateral phrenic nerve activity and ipsilateral diaphragm activity 3-6 months after treatment and injury. ${ }^{141}$ A recent study used diaphragmatic EMG to test the effect of administering a $\mathrm{N}$-methyl-D-aspartic acid (NMDA) receptor antagonist (MK-801) in acute cervical SCI. ${ }^{131}$ In these experiments, i.p. MK-801 administration after C2 hemisection was associated with both recovery of ipsilateral diaphragm function and upregulation of NMDA receptor subunit NR2A.

Advantages/disadvantages (phrenic nerve conduction, pneumotachometry and diaphragmatic EMG). Although diaphragmatic EMG, phrenic nerve recordings and pneumotachometric evaluations have clinical correlates, they are much more invasive procedures in the experimental laboratory than in the clinical setting. These experiments are technically demanding and terminal preparations. Although they provide a quantitative and informative index of diaphragmatic function, other outcome measures may be more suitable when respiratory function is not the sole or primary focus of an experiment. 


\section{Plethysmography}

An alternative outcome measure for assessing respiratory function in experimental SCI is whole-body plethysmography (WBP), in which respiratory function is determined in conscious animals, without invasive instrumentation. Prior to experimentation, rats are typically trained to become acclimated to the plethysmography chamber to prevent confounds of stress. In a recent study, WBP was used to characterize respiratory function in rats with a C5 hemicontusion SCI. ${ }^{98}$ These rats exhibited respiratory deficits that are reminiscent of clinical SCI: ${ }^{142}$ specifically, their ability to augment tidal volume in response to hypercapnic challenge was impaired 4 weeks after severe SCI. This technique has also been used to verify the altered breathing pattern induced by $\mathrm{C} 2$ hemisection previously reported in anesthetized rats. ${ }^{122}$ Although spirometry is more commonly used in the clinic, WBP has recently been validated for respiratory evaluation of people with SCI. ${ }^{143,144}$

Advantages/disadvantages. The most obvious advantage of WBP is that it is not a terminal experiment. Rather, respiratory data can be collected in the same animals at different time points following SCI. It does not provide a direct index of diaphragm function, but does provide clinically relevant indices of respiratory function in experimental animals. As it also requires less technical expertise than other methods, WBP may represent an attractive method for many laboratories investigating respiratory dysfunction after experimental SCI.

\section{Gastrointestinal function}

Innervation of the gastrointestinal system

The GI system control involves a complex interaction between the somatic nervous system (anal sphincters), both divisions of the autonomic nervous system, and the unique intrinsic enteric nervous system (ENS). The ENS controls the secretion, motility, blood flow, storage and evacuation of the GI tract, and its basic organization and function is similar across species. The autonomic nervous system modulates the intrinsic activity of the ENS, and is especially important at the proximal and distal ends of the GI tract (Figure 6). More detailed information about the interactions between the autonomic nervous system and ENS can be found in recent reviews. ${ }^{145-147}$

Clinical impact of gastrointestinal dysfunctions following SCI Although the ENS does have some intrinsic functional capacity, this is significantly impaired when it loses central coordination following SCI. The disruption of autonomic innervation to the GI tract is primarily revealed by abnormal motor function as opposed to changes in secretory or absorptive function. ${ }^{148}$ GI problems are prevalent in both the acute and chronic periods following SCI, and are a significant cause of rehospitalization and morbidity. ${ }^{149-153}$ Although there is some controversy over the effect of SCI on the upper GI tract, there is evidence of gastric dilation, delayed gastric emptying (GE), gastric ulceration and prolonged orocecal transit time (OCTT) following SCI. ${ }^{154-157}$ The most common complications are lower GI tract dysfunctions and most research has focused on their identification and resolution. These typically present as constipation, compaction and fecal incontinence, and can trigger both physical and psychological problems that restrict lifestyle choices and disrupt rehabilitation and overall quality of life of individuals with SCI. ${ }^{158,159}$

The term 'neurogenic bowel' describes the loss of neuronal control to the colon, and resulting dysfunction. ${ }^{160}$ The neurogenic bowel can be divided into two main types, each with characteristic colonic dysfunctions; supraconal lesions result in damage to descending supraspinal pathways (upper motor neuron bowel syndrome) and infraconal (cauda equina or pelvic nerve lesions) damage to motor and parasympathetic innervation to the colon (lower motor neuron bowel syndrome). ${ }^{160}$ The upper motor neuron bowel, or hyperreflexive bowel, is associated with spastic activity in the colon and external anal sphincter (EAS), which interferes with the voluntary ability to defecate but leaves the bowel reflex intact - the basis for bowel emptying using chemical or mechanical stimuli. The lower motor neuron, or areflexive, bowel is associated with a relaxed colon, perturbed peristalsis, slow stool propulsion and constipation. ${ }^{160}$

\section{Assessment of gastrointestinal function following experimental} SCI

Given that SCI primarily affects GI motor control, the majority of GI assessments following SCI consist of tests of functional motility or contractile activity. This section focuses on functional GI assessments used in experimental animal models (Table 5), some of which have been used as outcome measures for assessing autonomic function of the GI tract in humans following SCI and for testing clinically relevant therapies for restoring GI function.

\section{Gastrointestinal transit with oral markers}

GI transit can be assessed in experimental animals by segmental dye recovery along the GI tract following oral marker delivery. ${ }^{170,171}$ In the experimental animal, a nontoxic, nonabsorbable dye is administered by gavage feeding to the stomach. After the desired time interval, animals are euthanized, clamps are secured between each GI segment and marker recovery is detected by spectrophotometry to quantify the amount of dye in each segment, an indicator of movement through the GI tract. ${ }^{170}$

Dye recovery has been used as an outcome measure in rats with SCI at various levels. ${ }^{161,172}$ Rats with cervical or thoracic spinal cord transection showed increased dye recovery in the stomach and decreased recovery in the small intestine throughout the first week after injury, indicating decreased GE and overall GI transit. ${ }^{161}$ However, after 10 days post-SCI, there were no differences in dye recovery between the stomach and intestine, indicating that there is a recovery of GE and overall GI transit. ${ }^{164}$ Unlike humans, these rats also showed concurrent spontaneous recovery of bowel function. ${ }^{172}$ A follow-up study revealed that large bowel empty- 


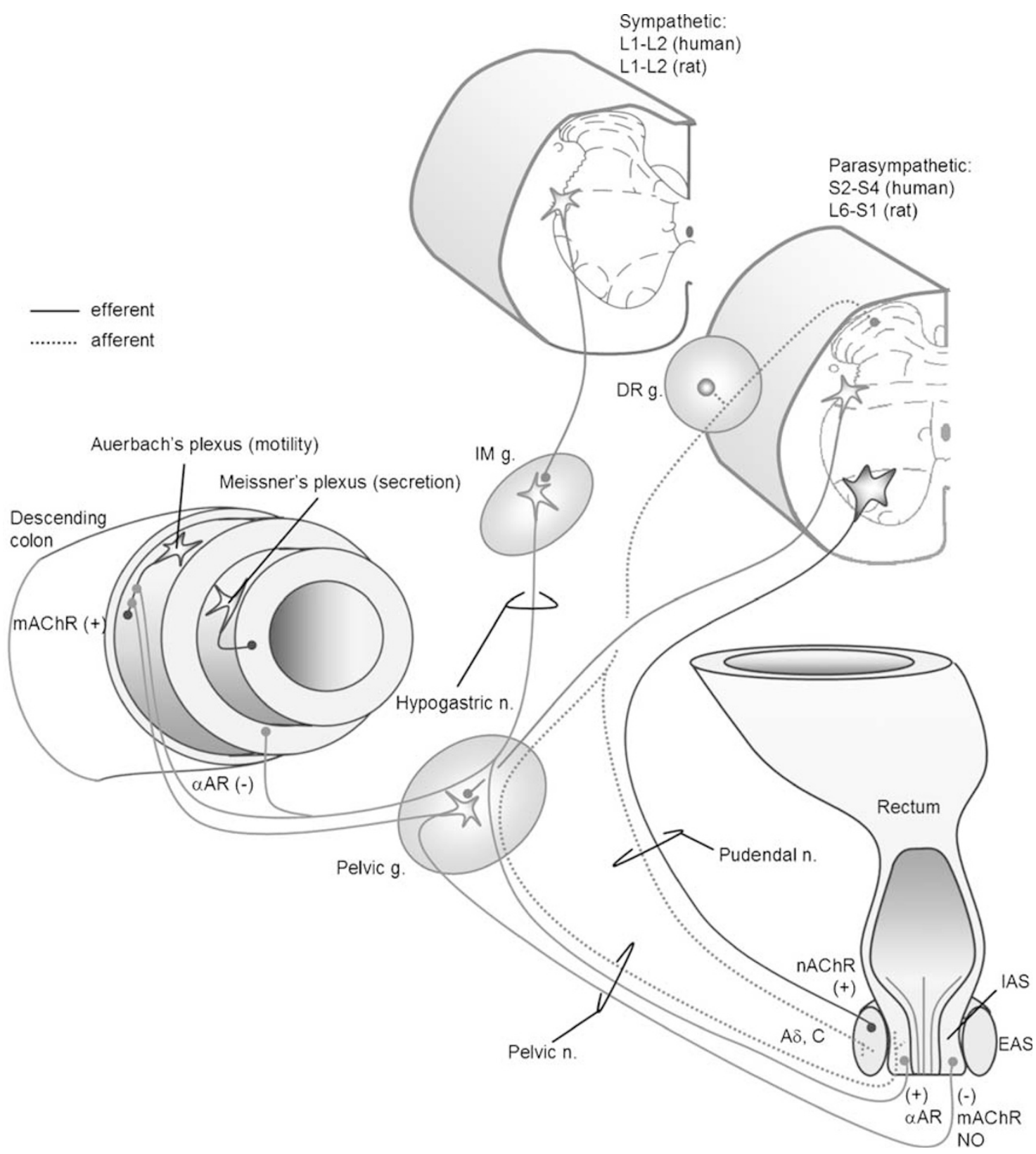

Figure 6 Innervation of the distal gastrointestinal (GI) tract. The ENS is composed of two main ganglionated plexuses that lie between the longitudinal and circular muscle layers (myenteric or Auerbach's plexus) and within the submucosal layer of the Gl tract (submucosal or Meissner's plexus). The myenteric plexus is continuous throughout the entire length of the $\mathrm{Gl}$ tract, and is primarily involved in the coordination of smooth muscle activity, whereas the submucosal plexus is present primarily in the small and large intestines, where it controls secretion and absorption. ${ }^{145}$ Autonomic innervation of the $\mathrm{Gl}$ tract is required to modulate the intrinsic activity of the enteric nervous system (ENS). This modulation is especially important in the distal GI tract (illustrated here), where the ANS coordinates storage and evacuation by regulating colon motility and resting anal sphincter tone. ${ }^{405,406}$ Parasympathetic innervation of the distal colon and rectum originates in the sacral cord (S2-S4), whereas the upper Gl tract (to the level of the splenic flexure) is innervated by the vagus nerve (not illustrated here). Preganglionic parasympathetic neurons synapse directly on Auerbach's plexus that enhances smooth muscle activity (via mAChR). Sympathetic innervation is mainly postganglionic, and arises from paravertebral and prevertebral ganglia of the abdominal and pelvic cavities - celiac, superior and inferior mesenteric and pelvic ganglia. Sympathetic neurons in prevertebral ganglia inhibit muscle and secretory activity indirectly, by noradrenergic modulation of activity in both the Meissner and Auerbach's plexuses. The IAS receives both sympathetic and parasympathetic innervation, whereas the EAS is innervated by somatic fibers traveling in the pudendal nerve (S2-S4 in humans, L6-S1 in rats). Afferent information from this area travels in both the pelvic and pudendal nerves. Abbreviations: A $\delta$, $C$, mechanosensitive primary afferents; $\alpha \mathrm{AR}, \alpha$-adrenergic receptors; DR g, dorsal root ganglion; EAS, external anal sphincter; g, ganglion; IAS, internal anal sphincter; IM g, inferior mesenteric ganglion; mAChR, muscarinic cholinergic receptors; $n$, nerve; nAChR, nicotinic cholinergic receptors; NO, nitric oxide; ( +) denotes excitatory synapses; $(-)$ denotes inhibitory synapses. 
Table 5 Overview of studies characterizing or targeting gastrointestinal dysfunction after experimental SCl

\begin{tabular}{|c|c|c|c|c|}
\hline Technique used & Species & Injury model & Time range post-injury & References \\
\hline \multirow[t]{5}{*}{ GI transit with oral markers } & \multirow[t]{4}{*}{ Rat } & \multirow[t]{3}{*}{ T4-T5 Tx } & 30 min-7 days & 161 \\
\hline & & & 1 day & 162,163 \\
\hline & & & $1-30$ days & 164 \\
\hline & & C7-T1 Tx & 30 min; $6 \mathrm{~h} ; 1,3,7$ days & 161 \\
\hline & Cat & T4 hemostat clamp & $1-2$ weeks & 165 \\
\hline \multirow[t]{3}{*}{ Manometry } & Rat & $\mathrm{T} 4 \mathrm{Tx}$ & 1 day-2 weeks & 166 \\
\hline & Cat & T4 hemostat clamp & $1-2$ weeks & 165 \\
\hline & Dog & T10 Tx & 2-6 weeks & 167 \\
\hline \multirow[t]{3}{*}{ EMG } & \multirow[t]{3}{*}{ Rat } & \multirow[t]{2}{*}{ T9-T10 Tx } & $\leqslant 24 h$ & 168 \\
\hline & & & 2 days-6 weeks & 168,169 \\
\hline & & T9-T10 contusion & 2 days-6 weeks & 169 \\
\hline
\end{tabular}

Abbreviations: EMG, electromyography; GI, gastrointestinal; Tx, transection.

Studies have been classified by the technique used to assess gastrointestinal function. Studies employing a combination of techniques are referenced under both headings. Studies using similar experimental animals, injury models and time range of study post-injury are grouped together.

ing prevented the development of delayed GE and GI transit following SCI. ${ }^{162}$ Although the effects of SCI on the upper GI tract are clinically still somewhat controversial, with some groups reporting GE delays and others demonstrating normal GE, ${ }^{155-157,173}$ these results suggest that delayed GE is in fact secondary to lower GI delayed motility. ${ }^{162}$ This corroborates previous research showing that the GE reflex is mediated by vagovagal reflexes and is not disrupted by sympathetic denervation of the upper GI tract. ${ }^{174,175}$

Visualization techniques, similar to orally administered radionucleotides used to assess GI motility clinically, ${ }^{156,176,177}$ can also be applied in the experimental setting. Video fluoroscopy has been recently used to assess the functional benefits of colonic electrical stimulation as a treatment to improve colonic transit in rats ${ }^{178,179}$ and SCI cats. ${ }^{165}$ These results suggest that colonic transit times are improved with the use of colonic electrical stimulation. ${ }^{180}$ Magnetic resonance imaging (MRI) has also been used to visualize GI motility by detection of solid food labeled with trace amounts of nontoxic iron oxide particles in rats. ${ }^{181}$

Advantages/disadvantages. Oral marker delivery for evaluation of GI transit can require training and animal habituation, particularly if gavage feeding is required. The detection of the markers can be performed as a terminal preparation, or by indirect visualization. The latter type of detection techniques (MRI or X ray) are attractive as they could be easily combined with sensory or motor outcomes; however, these techniques are more expensive and technically demanding.

\section{Electromyography}

EMG recording of EAS activity has been used as a tool to investigate the physiology and pathophysiology of the EAS in rats with SCI. ${ }^{168}$ This preparation allows for the measurement of both baseline EMG activity in the EAS and the contractions stimulated by EAS distension. ${ }^{168}$ Animals are restrained in a supine position using a loose-fitting cylinder, or masking tape, to secure their torso, hind limbs and tail. ${ }^{168,169}$ Temporary bipolar EMG electrodes are implanted in the EAS, with the external wire attached to the tail and connected to a preamplifier. After recording baseline EAS EMG activity, EAS distension is initiated with a plastic probe (used to mimic fecal bolus), and the resultant EAS contractions are recorded. ${ }^{168}$ Anesthetics are not normally used in this assessment, as they significantly attenuate EAS hyperreflexia.

This technique has also been used to assess functional recovery of autonomic reflexes after the period of spinal shock, and the development of hyperreactive autonomic reflexes. ${ }^{169}$ EAS hyperreflexia, reflected in prolonged burst duration of EAS activity, developed 2 days post-contusion at T9-T10 and resolved to preoperative levels, not significantly different from controls, by 6 weeks post-injury. In contrast, spinally transected animals developed EAS hyperreflexia 7 days post-injury and did not demonstrate any EAS reflex recovery. ${ }^{169}$ This research demonstrates the sensitivity of EAS EMG recording and its potential as an objective assessment of pelvic autonomic reflexes.

EMG recording from the jejunum has been recently adapted for use with telemetry, allowing for recording in awake and mobile rats. ${ }^{182}$ In this technique, an EMG transmitter is implanted dorsally between the shoulder blades and connected to the electrodes in the jejunum. ${ }^{182}$

Advantages/disadvantages. EMG is technically demanding, usually terminal, and requires both training and specialized equipment. However, it represents the most sensitive and direct evaluation of the activity in the GI tract.

\section{Manometry}

Manometry, the measurement of pressure changes within different parts of the GI tract, has also been used to assess colonic motility in rats following SCI. ${ }^{166}$ Similar to the clinical technique ${ }^{183-185}$ a fluid-filled catheter is inserted into the colon and is attached to recording probes at different regions along the colon; however, in the rat these probes are secured with ligatures to allow for chronic 
recording. ${ }^{166}$ To quantify motor activity, a motility index can be calculated that incorporates the amplitude, duration, frequency and number of contractions. Using this technique, spinally transected rats showed a reduction of distal colonic motility acutely after injury, which returned to preoperative values after 7 days. ${ }^{186}$ Unfortunately, the combined motility index does not provide an indication of the functional motility in the colon-an important consideration given that one of the main problems following SCI is the lack of coordinated peristalsis rather than lack of overall contractile activity. ${ }^{155}$ However, when used in combination with oral marker delivery, the effects of reduced motility can be more clearly assessed. ${ }^{165,179,187}$

\section{Strain gauge transducers}

Strain gauge transducers have also been used to continuously record gastric, small intestinal and colonic motility in awake rats. ${ }^{188}$ In contrast to manometry, this technique measures the pressure changes on the extraluminal surface of the GI tract. ${ }^{189-191}$ Although each transducer has only uniaxial sensitivity, by placing transducers at right angles to each other in the same segment, both longitudinal and circular contractile muscle activities can be recorded-a good indicator of coordinated motility. ${ }^{189}$ This technique has been used to model postoperative GI tract paresis, ${ }^{188}$ assess neurochemical effects on GI motility ${ }^{192}$ and examine the functional effects of altered pacemaker activity in the gut. ${ }^{193}$ Although this technique has not yet been used in experimental SCI, its relative noninvasiveness and capacity for chronic use makes it a promising way to measure functional GI motility.

Advantages/disadvantages (manometry and strain gauge transducers). Both manometry and strain gauge techniques require a fairly significant investment in training and equipment. Manometry is ideal for acute measurements, but its use is restricted to the colon. The use of strain gauges is surgically demanding, but does not interfere with normal GI motility, and is therefore preferable for chronic recording. ${ }^{194}$

\section{Hydrogen breath test}

Hydrogen breath tests are commonly used to assess the pathophysiology of clinical GI disorders. As there is no bodily source of hydrogen other than that produced by bacterial metabolism in the cecum, an increase in hydrogen expiration following carbohydrate administration indicates the arrival of the nutrient bolus in the cecum, and can be used as a measure of OCTT. ${ }^{195-197}$ Using this test, individuals with SCI show significantly delayed OCTT compared to controls - an effect that is more pronounced in quadriplegic than paraplegic patients. ${ }^{198}$ Although this technique has also been validated in feline, canine and rodent models, ${ }^{195,199,200}$ it has not yet been used in experimental SCI. However, it may prove to be a useful outcome measure to assess GI function following SCI - at both the bench and the bedside.
Advantages/disadvantages. The hydrogen breath test is minimally invasive and could easily be used in conjunction with other assessments in SCI animals. It can be used at repeated intervals in the same animals. However, specialized equipment is necessary for detection of hydrogen in the breath.

\section{Urinary bladder function}

Innervation of the lower urinary tract

Although interspecies differences exist, the basic organization and innervation of the LUT is similar among common experimental species and humans (Figure 7). In general terms, storage of urine is sympathetically mediated, whereas micturition is elicited by parasympathetic activation: however, normal LUT function requires the coordinated activity of the sympathetic, parasympathetic and somatic nervous systems. Here we provide only the basic scheme of LUT innervation, as neural control of the LUT and associated reflexes are comprehensively reviewed elsewhere. ${ }^{201-207}$

\section{Clinical implications of lower urinary tract dysfunction following SCI}

The manifestation of LUT dysfunction after SCI is similar in experimental animals, ${ }^{67,208}$ (Table 6) and humans, ${ }^{205,206,268-270}$ and is broadly termed neurogenic bladder. The initial period following SCI is marked by bladder areflexia and urinary retention. When SCI occurs at or below the sacral level (that is, infraconal; a lower motoneuron injury) bladder areflexia persists. If the lesion extends rostrally to the thoracolumbar region to involve sympathetic preganglionic neurons, the bladder neck may also become hypoactive. Suprasacral (supraconal) SCI (an upper motor neuron lesion) typically produces hyperreflexia of the smooth (detrusor) muscle of the bladder and tonic activation of the striated urethral sphincter. Therefore, sphincter contractions are dyssynergic with detrusor contractions. Detrusor hyperreflexia and detrusor-sphincter dyssynergia result from both a loss of tonic supraspinal inhibition and the emergence of aberrant spinal reflexes. The clinical profile of LUT dysfunction is highly variable between individuals with SCI, but can be generally described in terms of impaired continence (most common in supraconal SCI), impaired emptying (most severe in infraconal SCI) and impaired sensation of bladder filling (a component of dysfunction for most people with SCI). Clinically, complications of LUT dysfunction remain the leading cause of rehospitalization among people with SCI. ${ }^{271}$

\section{Assessment of lower urinary tract function following experimental SCI}

SCI induces profound changes in bladder innervation, particularly afferent, circuitry, ${ }^{206,217,272,273}$ morphology ${ }^{209,213,274}$ and structure, ${ }^{275-278}$ all of which likely contribute to neurogenic bladder. We limit this discussion to functional assessments only, with an emphasis on tests used in clinical SCI. Although an animal model of cauda equina/conus medullaris injury (lumbosacral ventral root avulsion in rat) has been recently developed, ${ }^{279,280}$ available experimental data describe 


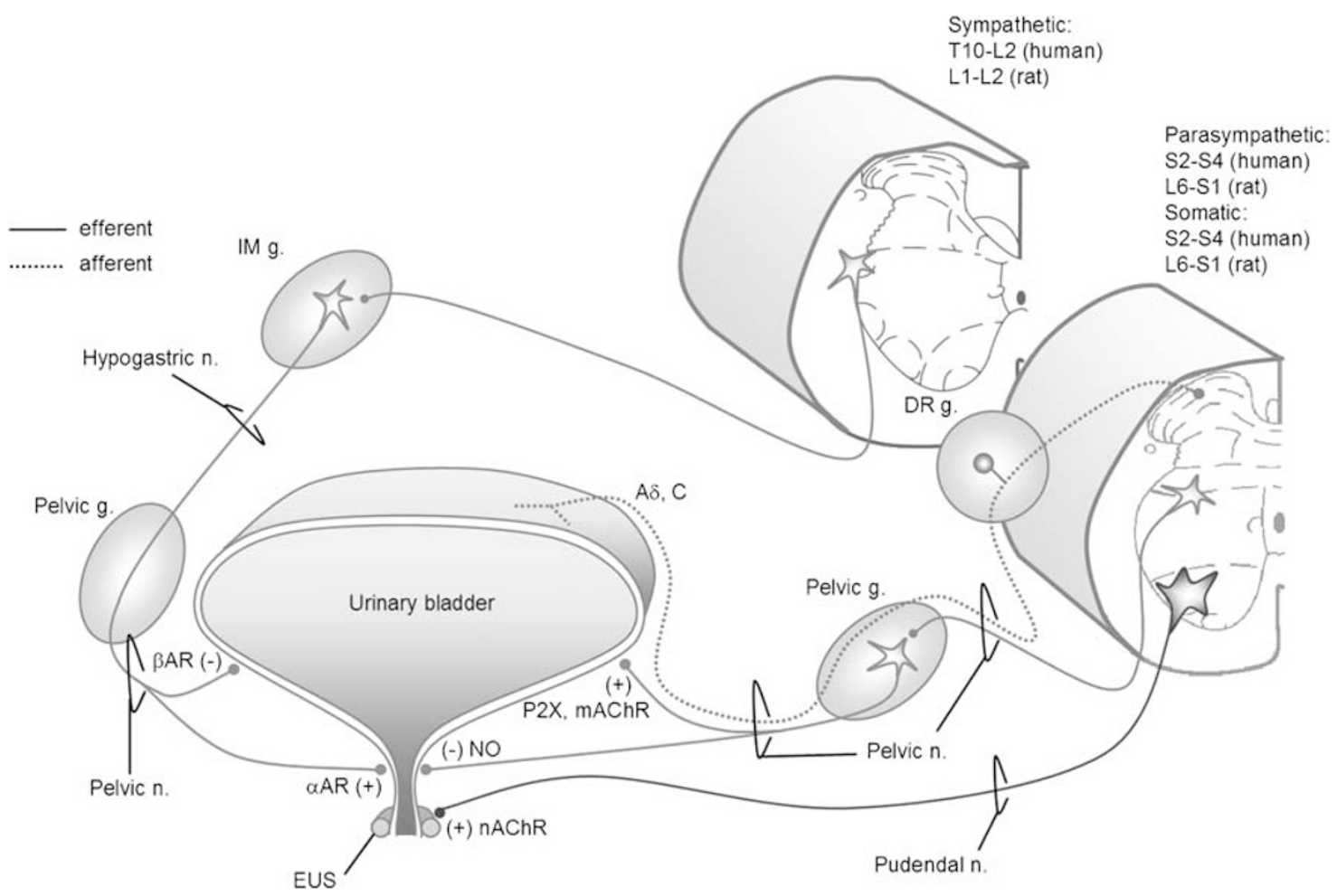

Figure 7 Innervation of the lower urinary tract (LUT). The LUT is comprised of the bladder, urethral sphincter and urethra. The LUT receives the bulk of its innervation from three nerves. The hypogastric nerve carries sympathetic innervation to the LUT; contributing spinal nerves exit the spinal cord (SC) between L1 and L2. Muscle activity for storage is mediated by $\alpha$-AR expressed in the trigone, bladder neck and urethra (excitatory), and by $\beta$-AR expressed in the bladder dome (inhibitory). The pelvic nerve contains parasympathetic input originating in the sacral cord (L6-S1 in rat ${ }^{407}$ ) and controls micturition via cholinergic muscarinic receptors (mAChR) expressed throughout the LUT. The human pudendal nerve exits the sacral SC, and provides somatic innervation to the striated muscles of the external urethral sphincter; in rats, the pudendal nerve originates in the L6-S1 cord. In addition to their efferent function, each of these nerves carries afferent input from the LUT. Information about bladder distension is carried by mechanosensitive afferents $(A \delta, C)$ found primarily in the pelvic nerve. These afferents signal the coordinated switch between storage and micturition. The pudendal and hypogastric nerves mostly contain nociceptive afferents, which are not depicted here. Abbreviations: AR, adrenergic receptors; DR g, dorsal root ganglion; EUS, external urinary sphincter; g, ganglion; IM g, inferior mesenteric ganglion; $L$, lumbar spinal cord; $m A C h R$, muscarinic cholinergic receptors; $n$, nerve; $n A C h R$, nicotinic cholinergic receptors; NO, nitric oxide; P2X, purinergic receptor; S, sacral spinal cord; $(+)$ denotes excitatory synapses; $(-)$ denotes inhibitory synapses.

bladder dysfunction following supraconal (not infraconal) SCI. Although SCI-induced LUT dysfunction has been well-characterized in experimental animals, few studies have included LUT assessment as an outcome measure in testing therapies for SCI (Table 9).

Cystometric urodynamic analysis

The most common method for assessing LUT function in experimental animals is cystometric urodynamic analysis. Cystometry can be performed using a urethral or transvesical catheter implanted into the bladder dome: although the latter method is more invasive, it does not partially obstruct the urethra and permits EMG of the external urethral sphincter (see 'External urinary sphincter electromyography') to be performed concurrently. Cystometry is routinely conducted in both conscious and anesthetized animals, with the caveat that anesthesia does affect micturition reflexes, ${ }^{281}$ particularly in animals with chronic SCI. ${ }^{235,236,257}$ This undesirable effect may be partially addressed by reducing the dose of anesthetic. ${ }^{236}$ Whether transvesical or transure- thral, conscious or unconscious, cystometry in experimental animals is essentially similar to clinical cystometry: the bladder is filled with saline while recording intravesical pressure to examine the relationship between bladder volume and pressure during filling and micturition.

Detrusor hyperreflexia and detrusor-sphincter dyssynergia create a similar urodynamic pattern in rats ${ }^{209,237,218}$ and humans ${ }^{206,269,282,283}$ with suprasacral SCI. Post-injury cystometrograms are characterized by increases in volume threshold for inducing micturition, pressure during micturition, volume expelled during micturition and residual volume after micturition. In addition, spinal-cord-injured rats and humans often exhibit nonvoiding detrusor contractions during bladder filling, a hallmark of detrusor hyperreflexia. Rats assessed via conscious transvesical cystometry 2-3 weeks after complete thoracic (T8-T10) spinal transection had larger volume thresholds for micturition (1.43 versus $0.34 \mathrm{ml}$ ), larger micturition pressures (48 versus $26 \mathrm{~mm} \mathrm{Hg}$ ), increased voided volumes $(0.72$ versus $0.31 \mathrm{ml})$ and increased residual volumes ( 0.71 versus $0.03 \mathrm{ml}$ ) compared to uninjured controls. $^{218}$ 
Table 6 Overview of studies characterizing or targeting lower urinary tract dysfunction after experimental SCI

\begin{tabular}{|c|c|c|c|c|}
\hline Technique used & Species & Injury model & Time range post-injury & References \\
\hline \multirow[t]{22}{*}{ Cystometry } & \multirow[t]{11}{*}{ Rat } & \multirow[t]{3}{*}{ T8-T10 contusion } & $\leqslant 1$ week & 209-211 \\
\hline & & & 2-4 weeks & $209,211,212$ \\
\hline & & & 8 weeks & 210,213 \\
\hline & & \multirow[t]{6}{*}{ T8-T11 Tx } & Immediate & 214 \\
\hline & & & $24 \mathrm{~h}$ & 215,216 \\
\hline & & & $\leqslant 1$ week & 217 \\
\hline & & & $2-4$ weeks & $209,214,216-234$ \\
\hline & & & $4-8$ weeks & $225,231,235-245$ \\
\hline & & & $8-12$ weeks & $232,246,247$ \\
\hline & & T12 heat injury & 1 month & 248 \\
\hline & & $\mathrm{L} 3 / 4 ; \mathrm{L} 6 / \mathrm{S} 1 \mathrm{Tx}$ & Immediate; 2-5 weeks & 214 \\
\hline & Rabbit & $\mathrm{T} 10 \mathrm{Tx}$ & $1,2,7-21$ days & 249 \\
\hline & \multirow[t]{8}{*}{ Cat } & C6-T1 Tx & 10 weeks & 250 \\
\hline & & T1 clip compression & $2-3,5-7$ weeks & 251 \\
\hline & & $\mathrm{T} 8 \mathrm{Tx}$; $\mathrm{T} 8$ contusion & 3 weeks & 252 \\
\hline & & $\mathrm{T} 10 \mathrm{~d}$. fun. $\mathrm{Tx}$ & Immediate & 253 \\
\hline & & $\mathrm{T} 10-\mathrm{T} 12 \mathrm{Tx}$ & $\leqslant 24 \mathrm{~h}$ & 254 \\
\hline & & & $2-4$ weeks & 255,256 \\
\hline & & & 4-8 weeks & $255-261$ \\
\hline & & & $6-12$ months & 257,260 \\
\hline & \multirow[t]{2}{*}{ Dog } & \multirow[t]{2}{*}{ T8-T11 Tx } & $1-8$ weeks & 262 \\
\hline & & & $1-8$ months & 263,264 \\
\hline \multirow[t]{17}{*}{ External urinary sphincter EMG } & \multirow[t]{10}{*}{ Rat } & \multirow{3}{*}{ T8 contusion } & $\leqslant 1$ week & 209,213 \\
\hline & & & 2 weeks & 209 \\
\hline & & & 6-8 weeks & 210,213 \\
\hline & & \multirow[t]{3}{*}{ T8-T9 Tx } & Immediate & 214 \\
\hline & & & 2-4 weeks & 209,214 \\
\hline & & & 4-6 weeks & $214,241,243$ \\
\hline & & \multirow[t]{3}{*}{ T8-T11 Tx } & $2-4$ weeks & 219 \\
\hline & & & 4-8 weeks & $236,237,239,240$ \\
\hline & & & $8-12$ weeks & 246 \\
\hline & & $\mathrm{L} 3 / 4 ; \mathrm{L} 6 / \mathrm{S} 1 \mathrm{Tx}$ & Immediate; $2-5$ weeks & 214 \\
\hline & Rabbit & $\mathrm{T} 10 \mathrm{Tx}$ & $1,2,7-21$ days & 249 \\
\hline & \multirow[t]{4}{*}{ Cat } & C6-T1 Tx & 10 weeks & 250 \\
\hline & & $\mathrm{T} 1$ clip compression & $2-3,5-7$ weeks & 251 \\
\hline & & T9-T12 Tx & 2-4 weeks & 256 \\
\hline & & & $6-8$ weeks & $253,258,261$ \\
\hline & \multirow[t]{2}{*}{ Dog } & \multirow[t]{2}{*}{ T8-T10 Tx } & $1-8$ weeks & 251 \\
\hline & & & $1-8$ months & 264 \\
\hline \multirow[t]{5}{*}{ Bladder volume } & \multirow[t]{4}{*}{ Rat } & \multirow[t]{3}{*}{ T8; T9/10 contusion } & $\leqslant 1$ week & $213,265,266$ \\
\hline & & & 2-4 weeks & $265-267$ \\
\hline & & & $4-6$ weeks & 265,266 \\
\hline & & $\mathrm{T} 10 \mathrm{Tx}$ & $0-20$ days & 217 \\
\hline & Cat & $\mathrm{T} 8 \mathrm{Tx}$; $\mathrm{T} 8$ contusion & 2 weeks & 252 \\
\hline \multirow[t]{3}{*}{ Videofluoroscopy } & \multirow[t]{2}{*}{ Cat } & C6-T1 Tx & 10 weeks & 250 \\
\hline & & $\mathrm{T} 1$ clip compression & 2-7 weeks & 251 \\
\hline & Dog & T8-T9 Tx & $1-8$ weeks & 262 \\
\hline Pressure recording (c. spongiosus) & Rat & T9/10 contusion & $\leqslant 1$ week; $2-4$ weeks & 266 \\
\hline
\end{tabular}

Abbreviations: compr., compression; c. spongiosus, corpus spongiosus; d. fun., dorsolateral funiculus; EMG, electromyography; Tx, transection.

Studies have been classified by the technique used to assess lower urinary tract (LUT) function. Studies employing a combination of techniques are referenced under both headings. Studies using similar experimental animals, injury models and time range of study post-injury are grouped together.

Preclinical urodynamic analysis has been used extensively to characterize mechanisms of and identify therapeutic candidates for bladder dysfunction following SCI (Table 6). Such experiments continue to be informative even after treatments enter clinical practice: for example, rats were recently treated with botulinum-A to examine the effects of acute versus delayed therapy following SCI. ${ }^{238}$ To date, only a few experimental studies testing regenerative, plasticitypromoting or protective treatments for SCI have incorporated urodynamic analysis as an outcome measure (Table 9). In one such study, rats that received transplants of immortalized neural stem cells at the site of thoracic SCI (T8 contusion) exhibited reduced micturition pressure and reduced residual urine compared to untreated controls. ${ }^{284}$ 
Two subsequent studies in the same injury model demonstrated that transplantation of neural precursor cells ${ }^{285}$ or genetically modified fibroblasts ${ }^{286}$ accelerated recovery from bladder areflexia and reduced micturition pressure and the number of nonvoiding detrusor contractions.

\section{External urinary sphincter electromyography}

In both clinical and experimental assessment of SCI, external urethral sphincter EMG (EUS EMG) can be performed in conjunction with cystometry to provide a direct measurement of detrusor-sphincter dyssynergia. Wire electrodes are inserted into the muscle of the EUS, and EUS activity during bladder filling and micturition is recorded. The data are typically expressed as mean EMG activity, mean EMG power frequency, mean EMG-spiking activity (ESA) and durations of activity or contractions. ${ }^{213,236}$ Also, the relationship between EUS EMG amplitude and detrusor contractions is examined to determine the extent of coordination between detrusor and sphincter activities. Changes in EUS EMG throughout the micturition cycle can be examined by power spectrum analysis using the fast Fourier transform algorithm. ${ }^{213}$

In rats ${ }^{209,213,237}$ and humans ${ }^{206,269,287,288}$ with suprasacral SCI, EUS EMG reveals sphincter activity that is not associated with detrusor contraction or micturition. In rats, the micturition-induced increase in external sphincter activity (dESA) is lost following thoracic SCI: as dESA is negatively correlated with SCI severity, it can be used as an index of detrusor-sphincter dyssynergia. ${ }^{213}$ Other intriguing indices of bladder-sphincter synergy have been identified by analyzing fractal dimensions and power spectra of EUS EMG and cystometrograms. ${ }^{239,240}$ Akin to urodynamic analysis, EUS EMG has been used as an outcome measure in mechanistic studies of LUT dysfunction in experimental SCI (Table 6). However, this technique is rarely included in preclinical studies that assess the functional benefits of therapies for SCI (Table 9).

Advantages/disadvantages (Cystometric urodynamic analysis and External urinary sphincter electromyography). Cystometry and EUS EMG applied in combination definitely represent the most informative and clinically relevant assessment of LUT function following SCI. However, these are invasive, technically demanding procedures that can only be performed at a single time point (that is, at the end of the experiment). Laboratories that lack expertise in these techniques may wish to adopt another method of monitoring bladder function after SCI.

\section{Functional bladder volume}

In rats, increases in bladder volume are proportional to severity of SCI. ${ }^{213,274}$ Bladder volume is estimated by measuring the volume of urine expressed at micturition, either by using a metabolic cage ${ }^{267,284-286}$ or by measuring the volume of urine that can be manually expressed. ${ }^{289}$ Bladder volume has been used as an outcome measure in experiments testing chondroitinase (a bacterial enzyme) as a regenerative therapy for $\mathrm{SCI}^{289}$ In these experiments, intrathecal chondroitinase treatment reduced the volume of urine that could be manually expressed in rats with moderate thoracic SCI.

An attractive alternative to estimating bladder function by expressed urine is transabdominal ultrasound, which has been recently used in rat SCI. ${ }^{265}$ In this study, a handheld digital ultrasound imaging system was used to measure bladder volume following severe thoracic (T10) contusion. Bladder volume was $3.51 \pm 0.47 \mathrm{ml}$ (compared to $0.089 \pm 0.04 \mathrm{ml}$ in uninjured rats) on day 4 post-injury and decreased to $1.83 \pm 0.50 \mathrm{ml}$ by day 8 ; it did not change significantly for the duration of the experiment (46 days). The authors found that ultrasonic measurements of bladder volume were comparable to estimates based on manual expression of urine.

Advantages/disadvantages. Measurements of volume of urine per micturition represent a cost-saving alternative for monitoring bladder function, but are tedious and lack precision. Transabdominal ultrasound is noninvasive, less stressful than other methods, does not disrupt concomitant motor and sensory testing and permits assessment in the same animals throughout the recovery period. As this is a common clinically used test, it could be recommended for more frequent use in animal experiments. This method will require some investment in technology and training.

\section{Videofluoroscopy}

In videofluoroscopy, the bladder is filled with radio-opaque medium and imaged by X-ray video recording. This approach is commonly used to evaluate a variety of organ functions in the clinical setting. Fluoroscopy has been used in preclinical investigations of electrical stimulation to improve bladder function following SCI (Table 6). These studies characterize the effects of sacral spinal stimulation, ${ }^{262}$ direct bladder stimulation, ${ }^{251,290}$ and more recently, neuroprosthetic microstimulators targeting the bladder wall and plexus ${ }^{291,292}$ in dogs and cats with SCI.

Advantages/disadvantages. Videofluoroscopy is a clinically relevant technique and provides useful information for specific applications (those mentioned above) in larger species; however, it has never been used in rodent SCI. It also requires specialized equipment and expertise that is not likely to be available to most investigators.

\section{Corpus spongiosum pressure recording}

Another method of examining LUT function that has been recently developed involves telemetric monitoring of pressure within the corpus spongiosum of the penis (CSP). ${ }^{266,293}$ Traditionally used to study sexual function in experimental animals $^{294-296}$ (see 'Sexual function'), CSP pressure has been recently validated for assessing LUT function in spinal-cordinjured rats. ${ }^{293}$ In this study, the authors found that volume of urine expelled per micturition was highly correlated with micturition duration recorded by CSP pressure: thus, telemetric CSP pressure monitoring can provide information about voiding volume and frequency of micturition in freely 
moving, conscious animals throughout their recovery from SCI. At 21 days after thoracic (T10) contusion, rats with telemetric pressure monitoring had micturition CSP pressure waveforms that were increased in duration, mean pressure and peak frequency compared to those observed before SCI. ${ }^{266}$

Advantages/disadvantages. Pressure recording from erectile tissue is technically challenging, but has the benefits of being able to be used chronically and in unanesthetized, freely moving animals. It is of particular interest for outcome assessment post-SCI because it allows for simultaneous recording of micturition and erection events - both of which are perturbed following SCI.

\section{Sexual function}

Innervation of the pelvic organs and genitalia

The autonomic innervation of the pelvic organs is essentially similar across mammalian species, and generally similar between males and females. ${ }^{297}$ Here we review only the most pertinent features of tissue innervation in the pelvic organs and genitalia (Figure 8). More detailed reviews can be found elsewhere. ${ }^{298-300}$

The role of the autonomic nervous system in sexual function Normal sexual function requires a combination of local spinal reflexes and descending cortical control. ${ }^{300,301}$ Genital arousal is a combined neurovascular and neuromuscular response that can be initiated reflexively or psychogenically. In both sexes, reflex sexual arousal results from increased parasympathetic activity, which causes nitric-oxidemediated vasodilation, ${ }^{302-304}$ accompanied by inhibition of sympathetic adrenergic activity. Together these two changes lead to an increase in genital blood flow, engorgement of erectile tissues and intracavernous pressure increase and, in women, lubrication of the vaginal surface. Unlike reflex arousal, psychogenic arousal appears to be facilitated by the sympathetic nervous system. ${ }^{305-308}$ In the male rat, and probably also in humans, the contraction of the somatic striated perineal muscles (bulbospogiosus and ichiocavernosus) also contributes to penile rigidity during erection. $^{309-312}$

Sexual climax appears to be mediated by a spinal reflex: ${ }^{313}$ in response to genital stimulation, anesthetized, acutely spinalized rats show a urethrogenital response similar to that seen in human sexual climax..$^{307,314-316}$ This reflex includes clonic contractions of the perineal muscles, rhythmic firing of the cavernous nerve, penile erections and ejaculation in the male, and rhythmic vaginal and uterine contractions in the female. ${ }^{316}$ This response is mediated by efferent output from hypogastric and pelvic nerves, suggesting that both parasympathetic and sympathetic nervous systems are involved. ${ }^{317}$ With regards to the autonomic nervous system, ejaculation itself is considered to be a sympathetically mediated event; ${ }^{318}$ however, normal anterograde ejaculation requires the coordination of both the somatic and sympathetic nervous systems.

The autonomic nervous system also has a role in the maintenance of reproductive capacity, although there is comparatively little research in this area. ${ }^{319}$ The activity of the epidydimis, whose main functions include sperm transport ${ }^{320,321}$ and fluid resorption, ${ }^{319}$ is primarily regulated by the sympathetic nervous system, with particularly important innervation arising from the inferior mesenteric ganglion. ${ }^{320,321}$

\section{Clinical impact of sexual dysfunctions following SCI}

Low sexual satisfaction and sexual dysfunction are both well documented after SCI, and the resolution of these problems has been identified as a high priority. ${ }^{9,322}$ The disruption to autonomic circuits following SCI can result in a number of different sexual changes and the sexual function subgroup of the ASIA/ISCOS working group is currently developing international autonomic standards for documenting these changes. ${ }^{323}$ Here we focus primarily on changes in sexual function rather than reproductive function. The effect of SCI on sexual function is highly dependent on injury level and the most commonly affected sexual responses are arousal and orgasm.

Individuals with upper motor neuron lesions, and preserved S2-S5 roots, generally have preserved reflex genital arousal, as the reflexes mediating erection are located in the spinal cord. However, these individuals generally are unable to initiate genital arousal psychogenically. On the other hand, lower level SCI (infraconal or cauda equina) tends to disrupt reflex vasocongestion, but can leave sympathetically mediated psychogenic arousal intact. ${ }^{306,307}$ These psychogenic erections are comparable in duration, rigidity and tumescence to the preserved reflex erections in men with higher lesions. ${ }^{306}$

Many women with SCI maintain the ability to reach orgasm. However, men often have difficulty maintaining erection, ejaculating and sensing orgasm. As a result, male reproductive function is significantly affected by SCI. Penile vibratory stimulation and electroejaculation have been used to successfully manage infertility in many cases. ${ }^{324-326}$ Most women maintain reproductive capacity, and are able to become pregnant and undergo normal pregnancy after a short period of amenorrhea acutely after SCI. ${ }^{327,328}$

$\mathrm{AD}$ must also be included in the discussion of sexual function, as it can be triggered by sexual activity and sperm retrieval in those with injuries above $\mathrm{T} 5 .^{329-334}$ During periods of $\mathrm{AD}$, blood pressure can reach levels that are potentially life threatening. However, despite these extreme blood pressure levels, the symptoms of $\mathrm{AD}$ are not always subjectively detected by the individual (termed silent AD). ${ }^{335}$ Therefore, it is imperative that blood pressure be assessed in both private sexual activity and during sperm retrieval procedures to assure that patients are not at risk. ${ }^{335}$ Interestingly, although $\mathrm{AD}$ interferes with sexual activity for some individuals, the symptoms of $\mathrm{AD}$ during sexual activity can also be perceived as pleasurable or arousing. ${ }^{333,336}$ 


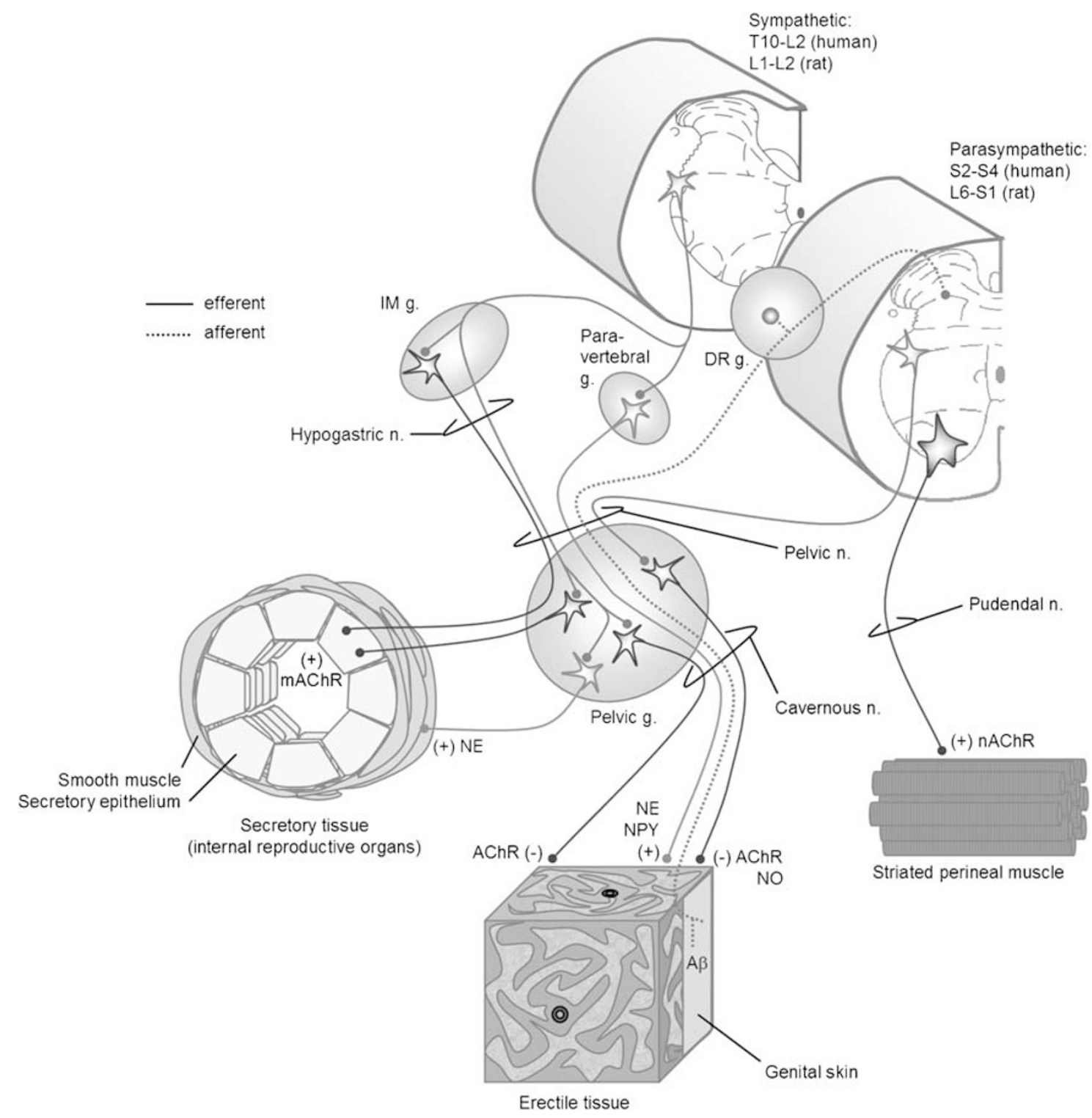

Figure 8 Innervation of the pelvic organs and genitalia. In the pelvic organs and genitalia there are three main tissue types: secretory, erectile and striated muscle. The majority of the autonomic innervation to these tissues comes from the bilateral pelvic ganglia (PG), which contains both sympathetic and parasympathetic neurons. Parasympathetic preganglionic neurons originate in the sacral cord (S2-S4 in humans; L6-S1 in rodents) and travel in the pelvic nerve to the PG. Sympathetic innervation originates in the lumbar cord (L1-L2) and travels via the hypogastic nerves to innervate the PG - in rodents, sympathetic nerves also travel to the PG via the pelvic nerve, which is mixed sympathetic and parasympathetic. Unlike human PG, which form a diffuse plexus on either side of the prostate (men) or cervix (women), rat PG are more condensed, and form two true ganglia. In both sexes, the largest nerve exiting from the PG is the cavernous nerve (also called penile nerve in males). In humans, somatic innervation of the striated perineal muscles, which include the ischiocavernosus, bulbocavernosus and levator ani, originates in the sacral cord (S2-4), whereas in the rats, this is shifted rostrally (L6-S1). Afferent information from the pelvic organs is relayed to the spinal cord via the 'genitospinal' nerves (pelvic, hypogastric and pudendal; for simplicity, only the pelvic nerve is illustrated here) and sensory pathways ascend bilaterally in the dorsal quadrant of the spinal cord. ${ }^{408}$ ' Abbreviations: AChR, cholinergic receptors; DR g, dorsal root ganglion; g, ganglion; IM g, inferior mesenteric ganglion; n, nerve; nAChR, nicotinic cholinergic receptors; NE, norepinephrine; NO, nitric oxide; NPY, neuropeptide $\mathrm{Y} ;(+)$ denotes excitatory synapses; $(-)$ denotes inhibitory synapses.

Assessment of sexual response and reproductive function following experimental SCI

Although the subjective responses from human studies are indispensable to fully elucidate sexual functioning following $\mathrm{SCI}^{337}$ physiological data can be obtained from experimental animal models regarding normal sexual function ${ }^{338}$ and recovery of autonomic circuits after injury. ${ }^{266}$ Spinal transection models have been used to study the neurophysiology of spinal sex reflexes in the absence of supraspinal control, ${ }^{316}$ and to study infertility post-SCI. ${ }^{339-341}$ However, sexual function has been rarely used as an outcome measure in testing therapies for SCI (Table 7). Like human research, 
Table 7 Overview of studies characterizing or targeting sexual dysfunction after experimental SCI

\begin{tabular}{|c|c|c|c|c|c|}
\hline Technique used & Species & Sex & Injury model & Time range post-injury & References \\
\hline \multirow[t]{3}{*}{ Behavioral scoring } & Rat & M & Mid-T Tx & 28-52 days & 342 \\
\hline & & & T8-T9 Tx & $1-7$ days & 343 \\
\hline & & & T6 Tx & 3,4 weeks & 344 \\
\hline \multicolumn{6}{|l|}{ Pressure recording } \\
\hline c. cavernosus & & M & T8-T9 Tx & 2 weeks & 345 \\
\hline c. spongiosus & & M & T10 contusion & $\leqslant 1$ week, $2-4$ weeks & 266 \\
\hline Doppler flowmetry & & $\mathrm{F}$ & $\mathrm{T} 10 \mathrm{Tx}$ & 6-8 weeks & 346 \\
\hline Epididymal sperm transport & & M & T9 contusion & 10 days & 347 \\
\hline
\end{tabular}

Abbreviations: c. cavernosus, corpus cavernosus; c. spongiosus, corpus spongiosus; Tx, transection.

Studies have been classified by the technique used to assess sexual function. Studies using similar experimental animals, injury models and time range of study post-injury are grouped together.

experimental animal research has been dominated by the study of male sexual function, and there are comparably few validated experimental animal models of female sexual function. $^{348}$ This section focuses on functional assessments of autonomically mediated components of sexual and reproductive function, with a focus on those that have been used in experimental SCI.

\section{Ex copula visual scoring}

Visual scoring has long been used to assess sexual function in experimental animals. This semi-quantitative technique includes observation, grading and quantification of sexual arousal and copulatory events (mounts, intromissions and ejaculations in the male; lordosis in the female animals). ${ }^{349}$ Ex copula tests have been primarily used in experimental SCI models, as functional copulatory behavior is unrealistic given the associated motor deficits. Animals are generally tested in a supine position with their legs and torso restrained by straps. ${ }^{350}$

To test reflex sexual function, penile reflexes are elicited by the retraction of the penile sheath and light pressure on the base of the penis, ${ }^{351}$ mechanical stimulation of the urethra ${ }^{316,352}$ or by electrical stimulation of the dorsal penile nerve. ${ }^{343}$ The stereotyped responses occur in clusters and include erections (reddening of the glans), cups (flaring of the glans into a trumpet shape) and flips (anteroflexions of the glans of varying lengths). ${ }^{351,353,344}$ After SCI, these reflex erections occur more quickly and more frequently than in uninjured animals. ${ }^{342}$

Visual scoring can also be used to investigate psychogenic erectile function. Penile reflexes triggered by central stimulation of the medial preoptic area (a brain region with a wellestablished role in the facilitation of sexual behavior) revealed that the capacity for centrally mediated erections is preserved in a rat model of cauda equina injury. ${ }^{350}$ As erectile function has been traditionally associated with parasympathetic activation, this research revealed that the presence of thoracolumbar sympathetic activity is sufficient to mediate erection, and likely forms a component of normal erectile function. ${ }^{350}$ Similar results have also been found clinically. ${ }^{354}$

Like many of the other assessment methods described herein, visual scoring is most valuable when used in conjunction with other physiological measures, such as EMG recording. Together, these two techniques have been recently used as outcome measures for assessing the effects of pharmacological manipulation to facilitate penile reflexes and ejaculation after experimental SCI. ${ }^{344}$ Similarly, the combination of visual scoring and blood pressure recording following penile reflex stimulation in a rodent model of SCI could be used to address the important clinical issue of vibrostimulation-triggered $\mathrm{AD}$ in men undergoing fertility treatment (JAI, LMR and AVK, unpublished observations).

\section{Corpus spongiosum and cavernosus pressure recording}

During erection, dilation of arteries and erectile tissue relaxation increase blood flow and result in increased intrapenile pressure. Pressure recording of the corpus cavernosum (CC) or corpus spongiosum (CSP) has been used to study sexual function and erectile function in intact rats, ${ }^{294,355,356}$ and is the most common assessment of erectile function used in preclinical trials. ${ }^{356}$ In this technique, the CC or CSP is catheterized using a polyethylene tubing, or a hypodermic needle attached to tubing, connected to a pressure transducer. ${ }^{345}$ The parameters that are commonly measured include the baseline, peak and plateau pressures, total area under the curve, as well as erection latency and total number of erections. ${ }^{356}$ These outcome measures have been used to characterize the sexual response changes that occur after SCI and the effectiveness of drugs in restoring normal responses.

Recent validation in rats with SCI showed that CSP pressure recording is a reliable method to evaluate erectile function over extended periods of time in conscious and freely moving animals as well as in restrained animals. ${ }^{266,293}$ Akin to previous reports using reflex erection tests on SCI rats, ${ }^{311,351}$ SCI rats exhibited shorter time to first observed erectile event compared to baseline values. ${ }^{266}$ CSP pressure recording was sensitive to early changes in SCI rats: the number of CSP pressure peaks increased in SCI rats as early as 1 day post-injury, even though at this time the total number of erectile events was not different from baseline values. ${ }^{266}$ Furthermore, SCI rats had many more CSP pressure peaks per erectile event, revealing that although erections may be qualitatively similar after SCI, their physiology may be significantly altered. ${ }^{266}$ Pressure recording has been recently 
used as an outcome measure for evaluating the effectiveness of pharmacological manipulation to restore erectile capacity after SCI. ${ }^{345}$

Advantages/disadvantages. Described above; see Urinary bladder function ('Assessment of lower urinary tract function following experimental SCI' and 'Corpus spongiosum pressure recording').

\section{Perineal muscle electromyography}

Physiological responses and the role of perineal muscles can be measured during sexual behavior using EMG recording. This technique was used in the discovery of the urethrogenital reflex, a model used to study human sexual climax. ${ }^{316}$ In the men, wire electrodes are placed in the bulbospongiosus muscle, which is attached to the CSP; in women, this recording is usually taken from the smooth muscle of the vagina. $^{316}$ In both sexes, mechanical stimulation of the urethra elicits clonic contractions of the perineal muscles and rhythmic cavernous muscle activity, with expulsion of the urethral contents in the men. ${ }^{316}$ This technique has been validated in uninjured rats as well as spinalized, anesthetized animals. $^{316,357}$

Advantages/disadvantages. Like EMG in other systems, perineal EMG is generally a terminal preparation and is conducted on anesthetized animals. However, it offers a readily quantifiable measure of the sexual response.

\section{Flowmetry}

As signs of female genital arousal are quite subtle, experimental research in this area relies heavily on physiological recording. Vaginal photoplethysmography offers a reliable clinical measurement of vaginal blood volume and pulse amplitude. ${ }^{307,358-360}$ Experimentally, vaginal blood flow recording by laser Doppler flowmetry has been recently established as a method to investigate sexual arousal in rats. ${ }^{348,361,362}$ In this technique, capillary blood flow is measured by a surface probe, placed on the ventral surface of the vagina or clitoral glans, which is connected to a flowmeter. ${ }^{346,348,361}$ Using a bipolar hook electrode, electrostimulation is applied to the clitoral nerve or pelvic plexus to elicit a vascular response. ${ }^{361}$

After suprasacral SCI, unlike male rats, female rats exhibited decreased response to electrostimulation; only $50 \%$ of animals showed increased clitoral blood flow, and even then, the increase was weak and nonsustained. ${ }^{346}$ In contrast, uninjured female rats showed immediate and sustained increases in both clitoral and vaginal capillary blood flow. ${ }^{361}$ Recently, this technique has been used as a functional outcome to evaluate the effectiveness of pharmacological agents to restore sexual arousal following experimental SCI. ${ }^{346}$

Advantages/disadvantages. This technique offers a new way to investigate the underrepresented issue of female sexual dysfunction following SCI. Flowmetry itself is noninvasive, but it is often used in combination with nerve stimulation, in invasive and terminal preparations. It is conducted in anesthetized animals, as the recording is very sensitive to movement.

\section{Epididymal sperm transport assay}

Unlike the techniques described above, which assess sexual function, this assay is utilized to assess reproductive function following SCI. Epididymal sperm transport is assessed by labeling of spermatozoa followed by quantification of labeled sperm throughout the length of the epididymis. ${ }^{347}$ This technique offers an indirect way to assess the preservation of sympathetic innervation to the epididymis, as sperm transport through the epididymis is sympathetically mediated. ${ }^{320,321}$ Following SCI, rats show decreased epididymal sperm transport. ${ }^{347}$

Advantages/disadvantages. This assay is a terminal preparation that demands some level of technical skill - for both the injection of the label and the epididymal dissection.

\section{Thermoregulatory function}

\section{Autonomic control of thermoregulatory effectors}

The thermoregulatory role of the autonomic nervous system is primarily mediated by the sympathetic nervous system and its vasomotor, sudomotor and pilomotor effectors. Although each of these effectors can also be activated by emotional stimuli, for the purposes of this review, we focus only on their thermoregulatory function. The preganglionic neurons of these effectors are cholinergic, and lie in the thoracolumbar cord (T1-L2); the ganglionic neurons are also cholinergic, and lie in the paravertebral ganglia.

Vasomotor efferents that innervate cutaneous vascular beds regulate the amount of heat that is dissipated to the surrounding environment. Unlike the visceral vasoconstrictors, cutaneous vasoconstrictors are not under strong baroreflex control, but are strongly affected by core temperature changes. Some areas of the skin are more specialized to perform thermoregulatory roles; areas with arteriovenous anastamoses allow for quick transfer of blood from the arteries to veins. Although the location of anastamoses varies from species to species, their function is similar.

In contrast to most sympathetic efferents, sudomotor efferents are cholinergic. When activated, these neurons act via muscarinic receptors to increase sweat gland secretion. In humans, there are two types of sudomotor neurons, apocrine or eccrine. Eccrine glands (present over the entire skin surface, with especially high levels on the palms, soles, face and axillae) are primarily used for diffuse thermoregulatory sweating; apocrine glands are associated with hair follicles, and are present in the genital, axillary and mammary regions. Unlike humans, rats only have apocrine glands, present on the plantar and palmar paw surfaces. These glands are activated by psychogenic rather than thermal stimuli, and do not have a role in thermoregulation. ${ }^{363}$

Pilomotor neurons are noradrenergic, and innervate piloerector muscles, which are found throughout the hairy skin of experimental animals and skin of humans. When 
these muscles contract, they raise their associated hairs and ultimately augment insulation. The rostrocaudal innervation pattern of piloerector muscles is similar to that of the sensory dermatomes.

Clinical implications of thermoregulatory dysfunction after SCI SCI can disrupt the descending sympathetic input, leaving large areas of skin and associated blood vessels, sweat glands and hair follicles disconnected from supraspinal sympathetic control. ${ }^{364}$ As a result, sympathetic mechanisms do not respond adequately to adjust core temperature and maintain equilibrium. The resulting thermoregulatory instability in both the acute and chronic periods can be severely debilitating.

Clinically, there are three main phenomena associated with temperature dysregulation reported following SCI: poikilothermia, acute hyperthermia and exercise-induced hyperthermia. ${ }^{5}$ Poikilothermia is also called 'environmental fever', but can refer to both the hypo- and hyperthermia experienced by individuals with SCI as a result of the ambient environment that they are exposed to. 'Quad fever' is used to refer to hyperthermia present in the first few weeks or months after SCI that is unrelated to infection or other identifiable causes.

In general, individuals with high injuries are predisposed to more severe temperature dysregulation than those with lower injuries. ${ }^{365,366}$ However, even individuals with lowlevel SCI can exhibit up to a 50\% reduction in whole-body sweating capacity compared to able-bodied controls-a reduction that correlates with their reduced skin surface area for sweating. ${ }^{367,368}$ Although there is some evidence of increased productivity of sweat glands above the injury as a mechanism of compensation for decreased sweating below the injury, ${ }^{369}$ individuals with SCI remain at a significant risk for heat illness due to increased heat storage. ${ }^{370}$ Heat storage is particularly problematic in wheelchair athletes, ${ }^{371}$ but recent evidence suggests that precooling or cooling during exercise can reduce the development of a high core temperature. ${ }^{372,373}$

As well as being at increased risk for thermoregulatory dysfunction, individuals with high-thoracic and cervical injuries are also at risk for $\mathrm{AD}$. During periods of $\mathrm{AD}$, when reflex sympathetic adrenergic vasoconstriction below the level of injury elevates systemic blood pressure, reflex sympathetic cholinergic activity can also cause excessive sweating. In combination with thermoregulatory dysfunc- tion, profuse sweating can contribute to a lowering of body temperature, which can result in hypothermia. ${ }^{374}$

\section{Assessment of thermoregulatory function following experimental SCI}

In this section we focus primarily on functional tests of thermoregulatory control that are currently employed in experimental SCI research. These studies most commonly aim to characterize the thermoregulatory changes that occur after SCI, and a small number of them test approaches to mitigate these dysfunctions (Table 8). Molecular approaches to thermoregulation are beyond the scope of this review and have been recently reviewed elsewhere. ${ }^{377,378}$

\section{Core temperature recording}

Core temperature recording provides a rough indication of the thermoregulatory capacity. Clinically, this type of information is easy to obtain, as it is part of routine care of individuals following SCI. In animals, core temperature is also quite easily obtained using a rectal thermometer. Acutely after cervical and high-thoracic SCI, rat core temperatures decline significantly and are vulnerable to changes in ambient environmental temperatures. ${ }^{40,379}$ Although the use of heating mats and raised environmental temperatures can be used to maintain body temperature in the acute setting, ${ }^{379}$ at 6 weeks post-injury core temperatures remained significantly lower in SCI rats compared to preoperative levels. ${ }^{40}$

Advantages/disadvantages. Core temperature recording is minimally stressful for SCI animals with limited colorectal sensation. The tools are easily available and the technique itself requires minimal training. However, investigators must be aware that rectal probe insertion could induce $\mathrm{AD}$, which can alter core temperature. ${ }^{40,374}$

\section{Cutaneous temperature recording}

Cutaneous temperature recording provides a simple indirect way to investigate cutaneous vasoconstrictor activity. Despite the fact that skin blood flow is important in heat loss during exercise in individuals with $\mathrm{SCI}{ }^{380}$ there has been little research investigating cutaneous blood flow after experimental animal SCI. ${ }^{40}$ The skin of the tail is the most important thermoregulatory organ in the rodent, and has been targeted in many investigations of thermoregulatory function. ${ }^{381,382}$ Infrared thermography can be used to record the surface temperature of the rat tail and hindlimb. ${ }^{40,383,384}$

Table 8 Overview of studies characterizing or targeting thermoregulatory dysfunction after experimental SCl

\begin{tabular}{llll}
\hline Technique used & Species & Injury model & Time range post-injury \\
\hline Core temperature recording & Rats & $\mathrm{C} 6 / 7 \mathrm{Tx}$ & $6 \mathrm{~h}$ \\
Infrared thermography & & $\mathrm{T} 4 \mathrm{Tx}$ & 1 day-6 weeks \\
Flowmetry & & $\mathrm{T} 2 ; \mathrm{T} 9 \mathrm{Tx}$ & $1 \mathrm{~h}-7$ days \\
Microneurography & $\mathrm{T} 12-\mathrm{T} 13 \mathrm{Tx}$ & $0-72 \mathrm{~h}$ & 375 \\
\hline
\end{tabular}

Abbreviation: Tx, transection.

Studies have been classified by the technique used to assess thermoregulatory function. Studies employing a combination of techniques are referenced under both headings. Studies using similar experimental animals, injury models and time range of study post-injury are grouped together. 
Following SCI, the skin temperature of the mid-tail and the hindpaw increased. These changes correlated with the decrease in core temperature, suggesting that the two are potentially related. ${ }^{40}$

Advantages/disadvantages. Cutaneous temperature recording is noninvasive, causes no stress to the animals and can be used chronically. However, specialized equipment is required for both the data acquisition and analysis.

\section{Flowmetry}

Blood flow recording provides a noninvasive way to assess sympathetic vasomotor pathways following SCI. Clinically, this method has been used to show that individuals with high SCI have reduced skin vasoconstriction in response to cutaneous cold compared to controls, and reduced vasodilation in response to local heating below the injury. ${ }^{385,386}$ This method is also used in experimental animal research, where ultrasound flow probes are surgically implanted around the artery, tissue or organ of interest, and flow is recorded using a flowmeter. ${ }^{39,382}$ Hong and colleagues have recently looked at organ system microcirculation, including the skin in the forepaw and hindpaw, after acute SCI at high and low thoracic levels. ${ }^{39}$ In the acute period, there was a significant decrease in forepaw blood flow, which may be related to changes in regional peripheral vascular resistance. ${ }^{39}$

Advantages/disadvantages. Flowmetry can be minimally invasive (when recording from the skin surface), but requires a significant investment in equipment. Although the equipment is quite sensitive to movements, caused by breathing for example, there are ways to reduce these artifacts. ${ }^{39}$

\section{Microneurography}

In vivo microneurography allows for the direct intraneural recording of sympathetic neuronal activity. ${ }^{387}$ Changes in sudomotor and vasoconstrictor activity can be recorded in response to thermoregulatory stimuli, or nerve activity can be evoked to investigate the function of the peripheral effectors. Microneurography has been recently used to assess whether therapeutic electrical stimulation can facilitate skin sympathetic nerve activity following SCI in rats. ${ }^{376}$

Advantages/disadvantages. Microneurography is both invasive and technically challenging. However, it provides a sensitive and direct measurement of sympathetic nerve activity.

\section{Sympathetic skin response}

Clinical sudomotor tests have proven successful in the identification and localization of autonomic nervous system lesions. ${ }^{388}$ The sympathetic skin response (SSR) is a widely used clinical technique that assesses the integrity of sympathetic cholinergic pathways. In humans, it is typically recorded from the palmar and plantar surfaces, areas rich in eccrine glands, and measures changes in skin conductance in response to electrical nerve stimulation. ${ }^{389}$ SSR has been suggested as one way to assess autonomic completeness of
SCI clinically, as it requires supraspinal input. ${ }^{390}$ However, no animal studies of SCI have included assessment of sudomotor function as an outcome measure of autonomic nervous system function.

Advantages/disadvantages. SSR is a noninvasive technique, but it has not yet been developed for use in animals.

\section{Visualization of sudomotor function}

The visualization of sudomotor function is used in both clinical and in experimental research. Thermoregulatory sweat testing with alizarin red has been used to define the extent of peripheral neuropathies. ${ }^{391,392}$ Preliminary results show that this technique can also be used as a tool to map the preserved function of cholinergic sympathetic pathways in individuals with SCI. ${ }^{393}$ The starch iodine technique is an analogous assessment that is used in rats to visualize sweat gland function. ${ }^{394,395}$

Advantages/disadvantages. This technique is minimally invasive and the results could be easily translated between the clinic and the experimental laboratory. However, in rodents, it can only inform about the presence or absence of sympathetic innervation of the palmar and plantar surfaces. Furthermore, it does not reveal any information about the thermoregulatory response.

\section{Conclusion}

Historically, SCI was synonymous with paralysis, and the ultimate goal of therapy was recovery of movement. Today, SCI is more correctly recognized as a potential disruption of all nervous system functions, including motor, sensory and autonomic. Although motor impairments are the most obvious manifestation of disability, they may not be the most catastrophic: injury to the spinal autonomic pathways results in functional deficits of the major organ systems, manifesting as bladder, gastrointestinal and sexual dysfunctions, and disordered cardiovascular function, thermoregulation and respiration. These aspects of autonomic dysfunction are fast emerging as priorities in clinical management of SCI. ${ }^{5,323}$

To address these priorities, discovery scientists must incorporate autonomic assessments as outcome measures in their experimental SCI research. Here we have reviewed a wide variety of techniques that are available to evaluate autonomic function in experimental animals, including some that have not yet been used in experimental SCI, but appear to be feasible. For some laboratories, incorporating autonomic assessment may involve adding new techniques to their existing battery of outcome measures. For others, collaboration may be required to attain the necessary expertise. In some cases, it might be necessary to add additional groups of animals to maintain scientific rigor.

Whatever the practical considerations of incorporating autonomic assessment, the gain - an improved understanding of autonomic dysfunction after SCI-is indisputably worth the effort. There is an urgent need to include 
Table 9 Overview of studies testing protective or regeneration/plasticity promoting therapy for $\mathrm{SCl}$

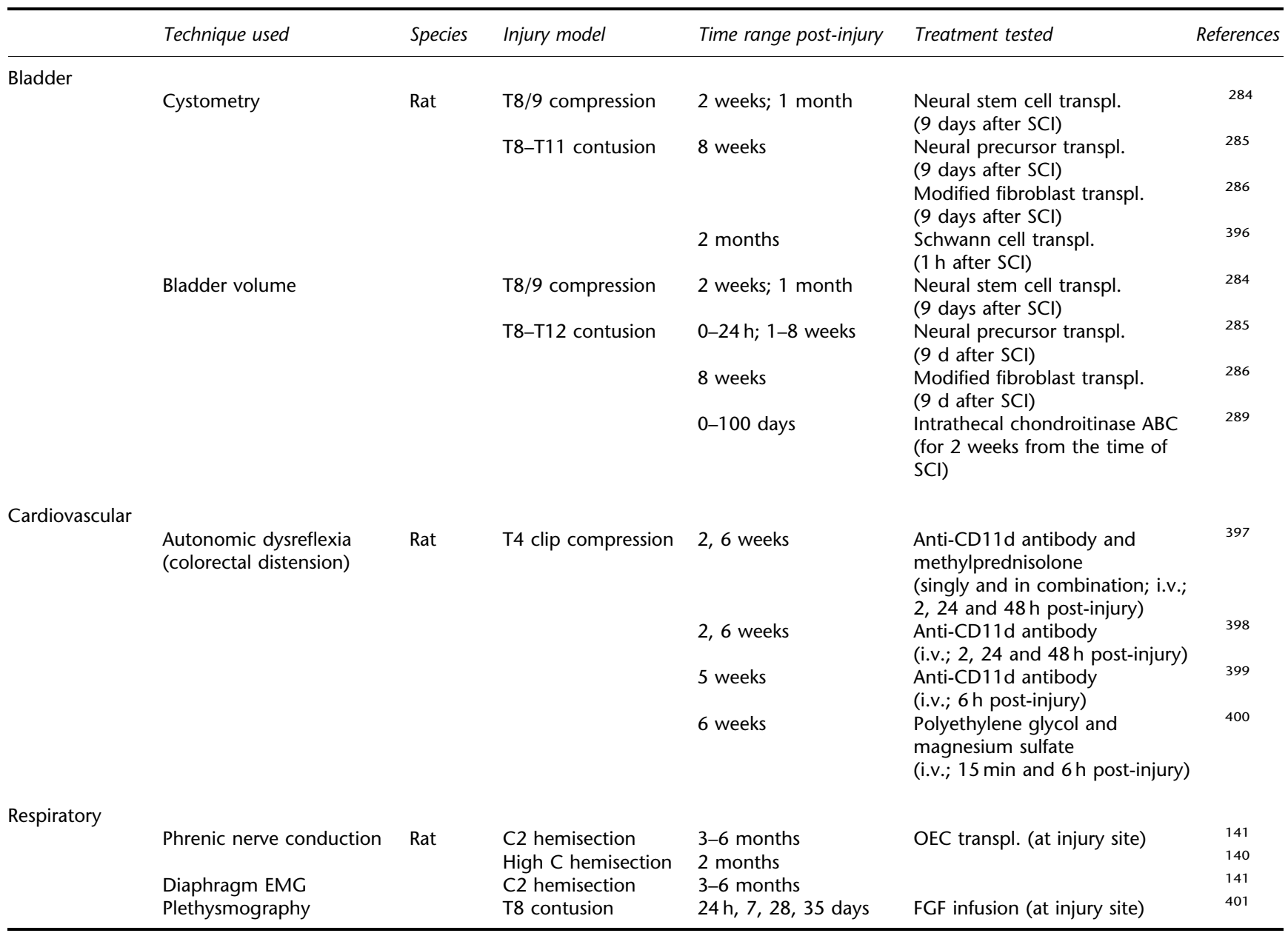

Abbreviations: EMG, electromyography; FGF, fibroblast growth factor; i.v., intravascular; OEC, olfactory ensheathing cells; transpl., transplantation; Tx, transection.

Studies have been classified by the autonomic system that they assess, as well as by the technique used to assess that system. Studies using similar experimental animals, injury models and time range of study post-injury are grouped together.

autonomic evaluations in experiments testing therapeutic (that is, regenerative or protective) agents after SCI, as there are very few experiments currently doing so (see Table 9).

At present, treatments are moving to clinical trial without any animal data that might predict their effects on autonomic function. ${ }^{402}$ If we continue to neglect autonomic function after SCI in the laboratory, the consequences for people with SCI could be disastrous.

\section{Acknowledgements}

We gratefully acknowledge the Heart and Stroke Foundation of BC and the Yukon (AVK and MSR), the Christopher Reeve Paralysis Foundation (AVK), the Rick Hansen Foundation (AVK and MSR), the Michael Smith Foundation for Health Research (JAI, LMR and MSR), the Canadian Institutes of Health Research (JAI and MSR) and the National Science and Engineering Research Council (LMR) for their support. We thank our colleagues at ICORD (International Collaboration on Repair Discoveries) for providing a supportive environment for our research.

\section{References}

1 Courtine G, Song B, Roy RR, Zhong H, Herrmann JE, Ao Y et al. Recovery of supraspinal control of stepping via indirect propriospinal relay connections after spinal cord injury. Nat Med 2008; 14: 69-74.

2 Dunham W. Scientists move toward helping paralysis patients. Reuters, 1-7-2008; http://www.reuters.com/article/scienceNews/ idUSN0428923520080107.

3 UCLA finds possible paralysis cure. Press TV. 1-9-2008; http:// www.presstv.ir/Detail.aspx?id $=38099 \&$ sectionid $=3510210$.

4 Sipski ML, Arenas A. Female sexual function after spinal cord injury. Prog Brain Res 2006; 152: 441-447.

5 Krassioukov AK, Karlsson AK, Wecht JM, Wuermser LA, Mathias CJ, Marino RJ. Assessment of autonomic dysfunction following spinal cord injury: rationale for additions to International Standards for Neurological Assessment. J Rehabil Res Dev 2007; 44: 103-112.

6 Weaver LC, Polosa C. Autonomic dysfunction after spinal cord injury. Prog Brain Res 2006; 152: 1-453. 
7 Soden RJ, Walsh J, Middleton JW, Craven ML, Rutkowski SB, Yeo JD. Causes of death after spinal cord injury. Spinal Cord 2000; 38: 604-610.

8 Garshick E, Kelley A, Cohen SA, Garrison A, Tun CG, Gagnon D et al. A prospective assessment of mortality in chronic spinal cord injury. Spinal Cord 2005; 43: 408-416.

9 Anderson KD. Targeting recovery: priorities of the spinal cordinjured population. J Neurotrauma 2004; 21: 1371-1383.

10 Ellaway PH, Anand P, Bergstrom EM, Catley M, Davey NJ, Frankel HL et al. Towards improved clinical and physiological assessments of recovery in spinal cord injury: a clinical initiative. Spinal Cord 2004; 42: 325-337.

11 Claydon VE, Krassioukov AV. Orthostatic hypotension and autonomic pathways after spinal cord injury. J Neurotrauma 2006; 23: 1713-1725.

12 Brading A. The Autonomic Nervous System and its Effectors. Blackwell: Oxford, UK, 1999.

13 Pang CC. Autonomic control of the venous system in health and disease: effects of drugs. Pharmacol Ther 2001; 90: 179-230.

14 Mathias C, Frankel H. The cardiovascular system in tetraplegia and paraplegia. In: Frankel HL (ed). Handbook of Clinical Neurology, 1992, pp 435-456.

15 Teasell RW, Arnold JM, Krassioukov A, Delaney GA. Cardiovascular consequences of loss of supraspinal control of the sympathetic nervous system after spinal cord injury. Arch Phys Med Rehabil 2000; 81: 506-516.

16 Furlan JC, Fehlings MG, Shannon P, Norenberg MD, Krassioukov AV. Descending vasomotor pathways in humans: correlation between axonal preservation and cardiovascular dysfunction after spinal cord injury. J Neurotrauma 2003; 20: 1351-1363.

17 Krassioukov A, Claydon VE. The clinical problems in cardiovascular control following spinal cord injury: an overview. Prog Brain Res 2006; 152: 223-229.

18 Atkinson PP, Atkinson JL. Spinal shock. Mayo Clin Proc 1996; 71: 384-389.

19 Mathias CJ. Orthostatic hypotension and paroxysmal hypertension in humans with high spinal cord injury. Prog Brain Res 2006; 152: 231-243.

20 Jacobs PL, Mahoney ET, Robbins A, Nash M. Hypokinetic circulation in persons with paraplegia. Med Sci Sports Exerc 2002; 34: 1401-1407.

21 Frankel HL, Michaelis LS, Golding DR, Beral V. The blood pressure in paraplegia. I. Paraplegia 1972; 10: 193-200.

22 Krum H, Louis WJ, Brown DJ, Jackman GP, Howes LG. Diurnal blood pressure variation in quadriplegic chronic spinal cord injury patients. Clin Sci (London) 1991; 80: 271-276.

23 Nitsche B, Perschak H, Curt A, Dietz V. Loss of circadian blood pressure variability in complete tetraplegia. J Hum Hypertens 1996; 10: 311-317.

24 Munakata M, Kameyama J, Kanazawa M, Nunokawa T, Moriai N, Yoshinaga K. Circadian blood pressure rhythm in patients with higher and lower spinal cord injury: simultaneous evaluation of autonomic nervous activity and physical activity. $J$ Hypertens 1997; 15: 1745-1749.

25 Van Loan MD, McCluer S, Loftin JM, Boileau RA. Comparison of physiological responses to maximal arm exercise among able-bodied, paraplegics and quadriplegics. Paraplegia 1987; 25: 397-405.

26 Claydon VE, Steeves JD, Krassioukov A. Orthostatic hypotension following spinal cord injury: understanding clinical pathophysiology. Spinal Cord 2006; 44: 341-351.

27 DeVivo MJ, Krause JS, Lammertse DP. Recent trends in mortality and causes of death among persons with spinal cord injury. Arch Phys Med Rehabil 1999; 80: 1411-1419.

28 Krassioukov AV, Weaver LC. Episodic hypertension due to autonomic dysreflexia in acute and chronic spinal cord-injured rats. Am J Physiol 1995; 268: H2077-H2083.

29 Yeoh M, McLachlan EM, Brock JA. Tail arteries from chronically spinalized rats have potentiated responses to nerve stimulation in vitro. J Physiol 2004; 556: 545-555.

30 McLachlan EM, Brock JA. Adaptations of peripheral vasoconstrictor pathways after spinal cord injury. Prog Brain Res 2006; 152: 289-297.
31 Krassioukov AV, Weaver LC. Morphological changes in sympathetic preganglionic neurons after spinal cord injury in rats. Neuroscience 1996; 70: 211-225.

32 Weaver LC, Cassam AK, Krassioukov AV, Llewellyn-Smith IJ. Changes in immunoreactivity for growth associated protein-43 suggest reorganization of synapses on spinal sympathetic neurons after cord transection. Neuroscience 1997; 81: 535-551.

33 Krassioukov AV, Fehlings MG. Effect of graded spinal cord compression on cardiovascular neurons in the rostro-ventrolateral medulla. Neuroscience 1999; 88: 959-973.

34 Krenz NR, Meakin SO, Krassioukov AV, Weaver LC. Neutralizing intraspinal nerve growth factor blocks autonomic dysreflexia caused by spinal cord injury. J Neurosci 1999; 19: 7405-7414.

35 Wallace MC, Tator CH. Spinal cord blood flow measured with microspheres following spinal cord injury in the rat. Can J Neurol Sci 1986; 13: 91-96.

36 Guha A, Tator CH. Acute cardiovascular effects of experimental spinal cord injury. J Trauma 1988; 28: 481-490.

37 Guha A, Tator $\mathrm{CH}$, Rochon J. Spinal cord blood flow and systemic blood pressure after experimental spinal cord injury in rats. Stroke 1989; 20: 372-377.

38 Mayorov DN, Adams MA, Krassioukov AV. Telemetric blood pressure monitoring in conscious rats before and after compression injury of spinal cord. J Neurotrauma 2001; 18: 727-736.

39 Guizar-Sahagun G, Velasco-Hernandez L, Martinez-Cruz A, Castaneda-Hernandez G, Bravo G, Rojas G et al. Systemic microcirculation after complete high and low thoracic spinal cord section in rats. J Neurotrauma 2004; 21: 1614-1623.

40 Laird AS, Carrive P, Waite PM. Cardiovascular and temperature changes in spinal cord injured rats at rest and during autonomic dysreflexia. J Physiol 2006; 577: 539-548.

41 Lahlou S. Enhanced hypotensive response to intravenous apomorphine in chronic spinalized, conscious rats: role of spinal dopamine $\mathrm{D}(1)$ and $\mathrm{D}(2)$ receptors. Neurosci Lett 2003; 349: 115-119.

42 Teng YD, Wrathall JR. Evaluation of cardiorespiratory parameters in rats after spinal cord trauma and treatment with NBQX, an antagonist of excitatory amino acid receptors. Neurosci Lett 1996; 209: 5-8.

43 Bravo G, Rojas-Martinez R, Larios F, Hong E, CastanedaHernandez G, Rojas $G$ et al. Mechanisms involved in the cardiovascular alterations immediately after spinal cord injury. Life Sci 2001; 68: 1527-1534.

44 Bravo G, Hong E, Rojas G, Guizar-Sahagun G. Sympathetic blockade significantly improves cardiovascular alterations immediately after spinal cord injury in rats. Neurosci Lett 2002; 319: 95-98.

45 Ceylan S, Ilbay K, Baykal S, Ceylan S, Sener U, Ozmenoglu M et al. Treatment of acute spinal cord injuries: comparison of thyrotropin-releasing hormone and nimodipine. Res Exp Med (Berl) 1992; 192: 23-33.

46 Faden AI, Jacobs TP, Holaday JW. Endorphin-parasympathetic interactions in spinal shock. J Auton Nerv Syst 1980; 2: 295-304.

47 Young W, Flamm ES, Demopoulos HB, Tomasula JJ, DeCrescito V. Effect of naloxone on posttraumatic ischemia in experimental spinal contusion. J Neurosurg 1981; 55: 209-219.

48 Albin MS, Bunegin L, Wolf S. Brain and lungs at risk after cervical spinal cord transection: intracranial pressure, brain water, blood-brain barrier permeability, cerebral blood flow, and extravascular lung water changes. Surg Neurol 1985; 24: 191-205.

49 Evans DE, Kobrine AI, Rizzoli HV. Cardiac arrhythmias accompanying acute compression of the spinal cord. J Neurosurg 1980; 52: 52-59.

50 Jacob JE, Gris P, Fehlings MG, Weaver LC, Brown A. Autonomic dysreflexia after spinal cord transection or compression in 129Sv, C57BL, and Wallerian degeneration slow mutant mice. Exp Neurol 2003; 183: 136-146.

51 Jacob JE, Pniak A, Weaver LC, Brown A. Autonomic dysreflexia in a mouse model of spinal cord injury. Neuroscience 2001; 108: 687-693.

52 Webb AA, Chan CB, Brown A, Saleh TM. Estrogen reduces the severity of autonomic dysfunction in spinal cord-injured male mice. Behav Brain Res 2006; 171: 338-349. 
53 Chiou-Tan FY, Lenz ML, Robertson CS, Grabois M. Pharmacologic treatment of autonomic dysreflexia in the rat. Am J Phys Med Rehabil 1994; 73: 251-255.

54 Chiou-Tan FY, Robertson CS, Chiou GC. Catecholamine assays in a rat model for autonomic dysreflexia. Arch Phys Med Rehabil 1998; 79: 402-404.

55 Collins HL, Dicarlo SE. TENS attenuates response to colon distension in paraplegic and quadriplegic rats. Am J Physiol Heart Circ Physiol 2002; 283: H1734-H1739.

56 Maiorov DN, Fehlings MG, Krassioukov AV. Relationship between severity of spinal cord injury and abnormalities in neurogenic cardiovascular control in conscious rats. J Neurotrauma 1998; 15: 365-374.

57 Weaver LC, Verghese P, Bruce JC, Fehlings MG, Krenz NR, Marsh DR. Autonomic dysreflexia and primary afferent sprouting after clip-compression injury of the rat spinal cord. I Neurotrauma 2001; 18: 1107-1119.

58 Marsh DR, Wong ST, Meakin SO, MacDonald JI, Hamilton EF, Weaver LC. Neutralizing intraspinal nerve growth factor with a trkA-IgG fusion protein blocks the development of autonomic dysreflexia in a clip-compression model of spinal cord injury. $J$ Neurotrauma 2002; 19: 1531-1541.

59 Marsh DR, Weaver LC. Autonomic dysreflexia, induced by noxious or innocuous stimulation, does not depend on changes in dorsal horn substance p. J Neurotrauma 2004; 21: 817-828.

60 Maiorov DN, Krenz NR, Krassioukov AV, Weaver LC. Role of spinal NMDA and AMPA receptors in episodic hypertension in conscious spinal rats. Am J Physiol 1997; 273: H1266-H1274.

61 Krassioukov AV, Johns DG, Schramm LP. Sensitivity of sympathetically correlated spinal interneurons, renal sympathetic nerve activity, and arterial pressure to somatic and visceral stimuli after chronic spinal injury. J Neurotrauma 2002; 19: $1521-1529$.

62 Landrum LM, Thompson GM, Blair RW. Does postsynaptic alpha 1-adrenergic receptor supersensitivity contribute to autonomic dysreflexia? Am J Physiol 1998; 274: H1090-H1098.

63 Bernet F, Leman S, Sequeira H. Autonomic dysreflexia increases plasma adrenaline level in the chronic spinal cord-injured rat. Neurosci Lett 2000; 286: 159-162.

64 Leman S, Sequeira H. Activation of adrenal preganglionic neurons during autonomic dysreflexia in the chronic spinal cord-injured rat. Auton Neurosci 2002; 98: 94-98.

65 Cameron AA, Smith GM, Randall DC, Brown DR, Rabchevsky AG. Genetic manipulation of intraspinal plasticity after spinal cord injury alters the severity of autonomic dysreflexia. $J$ Neurosci 2006; 26: 2923-2932.

66 Santajuliana D, Zukowska-Grojec Z, Osborn JW. Contribution of alpha- and beta-adrenoceptors and neuropeptide- $Y$ to autonomic dysreflexia. Clin Auton Res 1995; 5: 91-97.

67 Osborn JW, Taylor RF, Schramm LP. Chronic cervical spinal cord injury and autonomic hyperreflexia in rats. Am J Physiol 1990; 258: R169-R174.

68 Rivas DA, Chancellor MB, Huang B, Salzman SK. Autonomic dysreflexia in a rat model spinal cord injury and the effect of pharmacologic agents. Neurourol Urodyn 1995; 14: 141-152.

69 Sansone GR, Bianca R, Cueva-Rolon R, Gomez LE, Komisaruk BR. Cardiovascular responses to vaginocervical stimulation in the spinal cord-transected rat. Am J Physiol 1997; 273: R1361R1366.

70 Randall DC, Baldridge BR, Zimmerman EE, Carroll JJ, Speakman $\mathrm{RO}$, Brown DR et al. Blood pressure power within frequency range approximately $0.4 \mathrm{~Hz}$ in rat conforms to self-similar scaling following spinal cord transection. Am J Physiol Regul Integr Comp Physiol 2005; 288: R737-R741.

71 Baldridge BR, Burgess DE, Zimmerman EE, Carroll JJ, Sprinkle AG, Speakman RO et al. Heart rate-arterial blood pressure relationship in conscious rat before vs after spinal cord transection. Am J Physiol Regul Integr Comp Physiol 2002; 283: R748-R756.

72 Choi EA, Leman S, Vianna DM, Waite PM, Carrive P. Expression of cardiovascular and behavioural components of conditioned fear to context in T4 spinally transected rats. Auton Neurosci 2005; 120: 26-34.
73 Collins HL, Dicarlo SE. Acute exercise reduces the response to colon distension in $\mathrm{T}(5)$ spinal rats. Am J Physiol Heart Circ Physiol 2002; 282: H1566-H1570.

74 Krassioukov AV, Furlan JC, Fehlings MG. Autonomic dysreflexia in acute spinal cord injury: an under-recognized clinical entity. $J$ Neurotrauma 2003; 20: 707-716.

75 Delp MD, Holder-Binkley T, Laughlin MH, Hasser EM. Vasoconstrictor properties of rat aorta are diminished by hindlimb unweighting. J Appl Physiol 1993; 75: 2620-2628.

76 Vaziri ND, Ding Y, Sangha DS, Purdy RE. Upregulation of NOS by simulated microgravity, potential cause of orthostatic intolerance. J Appl Physiol 2000; 89: 338-344.

77 Vaziri ND. Nitric oxide in microgravity-induced orthostatic intolerance: relevance to spinal cord injury. J Spinal Cord Med 2003; 26: 5-11.

78 Tarasova O, Borovik A, Tsvirkoun D, Lebedev V, Steeves J, Krassioukov A. Orthostatic response in rats after hindlimb unloading: effect of transcranial electrical stimulation. Aviat Space Environ Med 2007; 78: 1023-1028.

79 Osborn JW, Taylor RF, Schramm LP. Determinants of arterial pressure after chronic spinal transection in rats. Am J Physiol 1989; 256: R666-R673.

80 Pearse DD, Lo Jr TP, Cho KS, Lynch MP, Garg MS, Marcillo AE et al. Histopathological and behavioral characterization of a novel cervical spinal cord displacement contusion injury in the rat. J Neurotrauma 2005; 22: 680-702.

81 de Boer RW, Karemaker JM, Strackee J. Relationships between short-term blood-pressure fluctuations and heart-rate variability in resting subjects. I: a spectral analysis approach. Med Biol Eng Comput 1985; 23: 352-358.

82 Pagani M, Lombardi F, Guzzetti S, Rimoldi O, Furlan R, Pizzinelli P et al. Power spectral analysis of heart rate and arterial pressure variabilities as a marker of sympatho-vagal interaction in man and conscious dog. Circ Res 1986; 59: 178-193.

83 Akselrod S, Gordon D, Madwed JB, Snidman NC, Shannon DC, Cohen RJ. Hemodynamic regulation: investigation by spectral analysis. Am J Physiol 1985; 249: H867-H875.

84 Rimoldi O, Pierini S, Ferrari A, Cerutti S, Pagani M, Malliani A. Analysis of short-term oscillations of R-R and arterial pressure in conscious dogs. Am J Physiol 1990; 258: H967-H976.

85 Cerutti C, Gustin MP, Paultre CZ, Lo M, Julien C, Vincent M et al. Autonomic nervous system and cardiovascular variability in rats: a spectral analysis approach. Am J Physiol 1991; 261: H1292-H1299.

86 Claydon VE, Krassioukov AV. Clinical correlates of frequency analyses of cardiovascular control after spinal cord injury. Am J Physiol Heart Circ Physiol 2008; 294: H668-H678.

87 Collins HL, Rodenbaugh DW, Dicarlo SE. Spinal cord injury alters cardiac electrophysiology and increases the susceptibility to ventricular arrhythmias. Prog Brain Res 2006; 152: 275-288.

88 Canning BJ, Fischer A. Neural regulation of airway smooth muscle tone. Respir Physiol 2001; 125: 113-127.

89 Wicks $A B$, Menter RR. Long-term outlook in quadriplegic patients with initial ventilator dependency. Chest 1986; 90 406-410.

90 Morgan MD, De Troyer A. The individuality of chest wall motion in tetraplegia. Bull Eur Physiopathol Respir 1984; 20: 547-552.

91 Mansel JK, Norman JR. Respiratory complications and management of spinal cord injuries. Chest 1990; 97: 1446-1452.

92 Winslow C, Rozovsky J. Effect of spinal cord injury on the respiratory system. Am J Phys Med Rehabil 2003; 82: 803-814.

93 Grandas NF, Jain NB, Denckla JB, Brown R, Tun CG, Gallagher ME et al. Dyspnea during daily activities in chronic spinal cord injury. Arch Phys Med Rehabil 2005; 86: 1631-1635.

94 Brown R, DiMarco AF, Hoit JD, Garshick E. Respiratory dysfunction and management in spinal cord injury. Respir Care 2006; 51: 853-868.

95 Leduc BE, Dagher JH, Mayer P, Bellemare F, Lepage Y. Estimated prevalence of obstructive sleep apnea-hypopnea syndrome after cervical cord injury. Arch Phys Med Rehabil 2007; 88: 333-337.

96 Berlly M, Shem K. Respiratory management during the first five days after spinal cord injury. J Spinal Cord Med 2007; 30 309-318. 
97 Jain NB, Sullivan M, Kazis LE, Tun CG, Garshick E. Factors associated with health-related quality of life in chronic spinal cord injury. Am J Phys Med Rehabil 2007; 86: 387-396.

98 Choi H, Liao WL, Newton KM, Onario RC, King AM, Desilets FC et al. Respiratory abnormalities resulting from midcervical spinal cord injury and their reversal by serotonin 1A agonists in conscious rats. J Neurosci 2005; 25: 4550-4559.

99 Baussart B, Stamegna JC, Polentes J, Tadie M, Gauthier P. A new model of upper cervical spinal contusion inducing a persistent unilateral diaphragmatic deficit in the adult rat. Neurobiol Dis 2006; 22: 562-574.

100 El Bohy AA, Schrimsher GW, Reier PJ, Goshgarian HG. Quantitative assessment of respiratory function following contusion injury of the cervical spinal cord. Exp Neurol 1998; 150: 143-152.

101 O'Hara Jr TE, Goshgarian HG. Quantitative assessment of phrenic nerve functional recovery mediated by the crossed phrenic reflex at various time intervals after spinal cord injury. Exp Neurol 1991; 111: 244-250.

102 Zhou SY, Goshgarian HG. Effects of serotonin on crossed phrenic nerve activity in cervical spinal cord hemisected rats. Exp Neurol 1999; 160: 446-453.

103 Fuller DD, Johnson SM, Olson Jr EB, Mitchell GS. Synaptic pathways to phrenic motoneurons are enhanced by chronic intermittent hypoxia after cervical spinal cord injury. $J$ Neurosci 2003; 23: 2993-3000.

104 Vinit S, Stamegna JC, Boulenguez P, Gauthier P, Kastner A. Restorative respiratory pathways after partial cervical spinal cord injury: role of ipsilateral phrenic afferents. Eur J Neurosci 2007; 25: 3551-3560.

105 Nantwi KD, El Bohy A, Goshgarian HG. Actions of systemic theophylline on hemidiaphragmatic recovery in rats following cervical spinal cord hemisection. Exp Neurol 1996; 140: $53-59$.

106 Nantwi KD, Goshgarian HG. Alkylxanthine-induced recovery of respiratory function following cervical spinal cord injury in adult rats. Exp Neurol 2001; 168: 123-134.

107 Bae H, Nantwi KD, Goshgarian HG. Recovery of respiratory function following $\mathrm{C} 2$ hemi and carotid body denervation in adult rats: influence of peripheral adenosine receptors. Exp Neurol 2005; 191: 94-103.

$108 \mathrm{Yu}$ XJ, Goshgarian HG. Aging enhances synaptic efficacy in a latent motor pathway following spinal cord hemisection in adult rats. Exp Neurol 1993; 121: 231-238.

109 Liou WW, Goshgarian HG. Quantitative assessment of the effect of chronic phrenicotomy on the induction of the crossed phrenic phenomenon. Exp Neurol 1994; 127: 145-153.

110 Hadley SD, Walker PD, Goshgarian HG. Effects of the serotonin synthesis inhibitor p-CPA on the expression of the crossed phrenic phenomenon $4 \mathrm{~h}$ following C2 spinal cord hemisection. Exp Neurol 1999; 160: 479-488.

111 El Bohy AA, Goshgarian HG. The use of single phrenic axon recordings to assess diaphragm recovery after cervical spinal cord injury. Exp Neurol 1999; 156: 172-179.

112 Zhou SY, Goshgarian HG. 5-Hydroxytryptophan-induced respiratory recovery after cervical spinal cord hemisection in rats. J Appl Physiol 2000; 89: 1528-1536.

113 Zhou SY, Basura GJ, Goshgarian HG. Serotonin(2) receptors mediate respiratory recovery after cervical spinal cord hemisection in adult rats. J Appl Physiol 2001; 91: 2665-2673.

114 Nantwi KD, Goshgarian HG. Actions of specific adenosine receptor A1 and A2 agonists and antagonists in recovery of phrenic motor output following upper cervical spinal cord injury in adult rats. Clin Exp Pharmacol Physiol 2002; 29: 915-923.

115 Basura GJ, Nantwi KD, Goshgarian HG. Theophylline-induced respiratory recovery following cervical spinal cord hemisection is augmented by serotonin 2 receptor stimulation. Brain Res 2002; 956: 1-13.

116 Zimmer MB, Goshgarian HG. Spinal activation of serotonin 1A receptors enhances latent respiratory activity after spinal cord injury. J Spinal Cord Med 2006; 29: 147-155.
117 Vinit S, Gauthier P, Stamegna JC, Kastner A. High cervical lateral spinal cord injury results in long-term ipsilateral hemidiaphragm paralysis. J Neurotrauma 2006; 23: 1137-1146.

118 James E, Nantwi KD. Involvement of peripheral adenosine A2 receptors in adenosine A1 receptor-mediated recovery of respiratory motor function after upper cervical spinal cord hemisection. I Spinal Cord Med 2006; 29: 57-66.

119 Nantwi KD, Goshgarian HG. Effects of chronic systemic theophylline injections on recovery of hemidiaphragmatic function after cervical spinal cord injury in adult rats. Brain Res 1998; 789: 126-129.

120 Zimmer MB, Goshgarian HG. GABA, not glycine, mediates inhibition of latent respiratory motor pathways after spinal cord injury. Exp Neurol 2007; 203: 493-501.

121 Golder FJ, Mitchell GS. Spinal synaptic enhancement with acute intermittent hypoxia improves respiratory function after chronic cervical spinal cord injury. J Neurosci 2005; 25: 2925-2932.

122 Fuller DD, Golder FJ, Olson Jr EB, Mitchell GS. Recovery of phrenic activity and ventilation after cervical spinal hemisection in rats. J Appl Physiol 2006; 100: 800-806.

123 Nantwi KD, Basura GJ, Goshgarian HG. Effects of long-term theophylline exposure on recovery of respiratory function and expression of adenosine A1 mRNA in cervical spinal cord hemisected adult rats. Exp Neurol 2003; 182: 232-239.

124 Bae H, Nantwi KD, Goshgarian H. Effects of carotid body excision on recovery of respiratory function in $\mathrm{C} 2$ hemisected adult rats. Exp Neurol 2005; 195: 140-147.

125 Doperalski NJ, Fuller DD. Long-term facilitation of ipsilateral but not contralateral phrenic output after cervical spinal cord hemisection. Exp Neurol 2006; 200: 74-81.

126 Nantwi KD, Basura GJ, Goshgarian HG. Adenosine A1 receptor mRNA expression and the effects of systemic theophylline administration on respiratory function 4 months after C2 hemisection. J Spinal Cord Med 2003; 26: 364-371.

127 Golder FJ, Reier PJ, Davenport PW, Bolser DC. Cervical spinal cord injury alters the pattern of breathing in anesthetized rats. $J$ Appl Physiol 2001; 91: 2451-2458.

128 Golder FJ, Fuller DD, Davenport PW, Johnson RD, Reier PJ, Bolser DC. Respiratory motor recovery after unilateral spinal cord injury: eliminating crossed phrenic activity decreases tidal volume and increases contralateral respiratory motor output. $J$ Neurosci 2003; 23: 2494-2501.

129 Skjodt NM, Farran RP, Hawes HG, Kortbeek JB, Easton PA. Simulation of acute spinal cord injury: effects on respiration. Respir Physiol 2001; 127: 3-11.

130 Johnson SM, Creighton RJ. Spinal cord injury-induced changes in breathing are not due to supraspinal plasticity in turtles (Pseudemys scripta). Am J Physiol Regul Integr Comp Physiol 2005; 289: R1550-R1561.

131 Alilain WJ, Goshgarian HG. MK-801 upregulates NR2A protein levels and induces functional recovery of the ipsilateral hemidiaphragm following acute $\mathrm{C} 2$ hemisection in adult rats. J Spinal Cord Med 2007; 30: 346-354.

132 Minor KH, Akison LK, Goshgarian HG, Seeds NW. Spinal cord injury-induced plasticity in the mouse-the crossed phrenic phenomenon. Exp Neurol 2006; 200: 486-495.

133 Teng YD, Bingaman M, Taveira-DaSilva AM, Pace PP, Gillis RA, Wrathall JR. Serotonin 1A receptor agonists reverse respiratory abnormalities in spinal cord-injured rats. J Neurosci 2003; 23: 4182-4189.

134 Zimmer MB, Nantwi K, Goshgarian HG. Effect of spinal cord injury on the respiratory system: basic research and current clinical treatment options. J Spinal Cord Med 2007; 30: 319-330.

135 McKinley WO. Late return of diaphragm function in a ventilator-dependent patient with a high cervical tetraplegia: case report, and interactive review. Spinal Cord 1996; 34: 626-629.

136 Oo T, Watt JW, Soni BM, Sett PK. Delayed diaphragm recovery in 12 patients after high cervical spinal cord injury. A retrospective review of the diaphragm status of 107 patients ventilated after acute spinal cord injury. Spinal Cord 1999; 37: 117-122. 
137 Strakowski JA, Pease WS, Johnson EW. Phrenic nerve stimulation in the evaluation of ventilator-dependent individuals with C4- and C5-level spinal cord injury. Am J Phys Med Rehabil 2007; 86: 153-157.

138 Goshgarian HG. The crossed phrenic phenomenon: a model for plasticity in the respiratory pathways following spinal cord injury. J Appl Physiol 2003; 94: 795-810.

139 Bascom AT, Lattin CD, Aboussouan LS, Goshgarian HG. Effect of acute aminophylline administration on diaphragm function in high cervical tetraplegia: a case report. Chest 2005; 127: 658-661.

$140 \mathrm{Li} \mathrm{Y,} \mathrm{Decherchi} \mathrm{P,} \mathrm{Raisman} \mathrm{G.} \mathrm{Transplantation} \mathrm{of} \mathrm{olfactory}$ ensheathing cells into spinal cord lesions restores breathing and climbing. I Neurosci 2003; 23: 727-731.

141 Polentes J, Stamegna JC, Nieto-Sampedro M, Gauthier P. Phrenic rehabilitation and diaphragm recovery after cervical injury and transplantation of olfactory ensheathing cells. Neurobiol Dis 2004; 16: 638-653.

142 Manning HL, Shea SA, Schwartzstein RM, Lansing RW, Brown R, Banzett RB. Reduced tidal volume increases 'air hunger' at fixed $\mathrm{P}_{\mathrm{CO} 2}$ in ventilated quadriplegics. Respir Physiol 1992; 90: 19-30.

143 Schilero GJ, Grimm D, Lesser M. Comparison of lung volume measurements in individuals with spinal cord injury by two different methods. J Spinal Cord Med 2004; 27: 443-447.

144 Schilero GJ, Grimm DR, Bauman WA, Lenner R, Lesser M. Assessment of airway caliber and bronchodilator responsiveness in subjects with spinal cord injury. Chest 2005; 127: 149-155.

145 Furness JB. The Enteric Nervous System. Blackwell: Oxford, UK, 2006.

146 Thompson DG. Neurogastroenterology: imaging of the sensory and motor control of the GI tract. I Psychosom Res 2006; 61: 301-304.

147 Phillips RJ, Powley TL. Innervation of the gastrointestinal tract: patterns of aging. Auton Neurosci 2007; 136: 1-19.

148 Camilleri M, Bharucha AE. Gastrointestinal dysfunction in neurologic disease. Semin Neurol 1996; 16: 203-216.

149 Miller LS, Staas Jr WE, Herbison GJ. Abdominal problems in patients with spinal cord lesions. Arch Phys Med Rehabil 1975; 56: 405-408.

150 Cosman BC, Stone JM, Perkash I. Gastrointestinal complications of chronic spinal cord injury. J Am Paraplegia Soc 1991; 14: 175-181.

151 Menter R, Weitzenkamp D, Cooper D, Bingley J, Charlifue S, Whiteneck G. Bowel management outcomes in individuals with long-term spinal cord injuries. Spinal Cord 1997; 35: 608-612.

152 Savic G, Short DJ, Weitzenkamp D, Charlifue S, Gardner BP. Hospital readmissions in people with chronic spinal cord injury. Spinal Cord 2000; 38: 371-377.

153 Middleton JW, Lim K, Taylor L, Soden R, Rutkowski S. Patterns of morbidity and rehospitalisation following spinal cord injury. Spinal Cord 2004; 42: 359-367.

154 Kewalramani LS. Neurogenic gastroduodenal ulceration and bleeding associated with spinal cord injuries. J Trauma 1979; 19: 259-265.

155 Fealey RD, Szurszewski JH, Merritt JL, DiMagno EP. Effect of traumatic spinal cord transection on human upper gastrointestinal motility and gastric emptying. Gastroenterology 1984; 87: 69-75.

156 Segal JL, Milne N, Brunnemann SR. Gastric emptying is impaired in patients with spinal cord injury. Am J Gastroenterol 1995; 90: 466-470.

$157 \mathrm{Kao} \mathrm{CH}$, Ho YJ, Changlai SP, Ding HJ. Gastric emptying in spinal cord injury patients. Dig Dis Sci 1999; 44: 1512-1515.

158 Glickman S, Kamm MA. Bowel dysfunction in spinal-cordinjury patients. Lancet 1996; 347: 1651-1653.

159 Krogh K, Nielsen J, Djurhuus JC, Mosdal C, Sabroe S, Laurberg S. Colorectal function in patients with spinal cord lesions. Dis Colon Rectum 1997; 40: 1233-1239.

160 Stiens SA, Bergman SB, Goetz LL. Neurogenic bowel dysfunction after spinal cord injury: clinical evaluation and rehabilitative management. Arch Phys Med Rehabil 1997; 78: S86-102.

161 Gondim FA, Alencar HM, Rodrigues CL, da Graca JR, dos Santos AA, Rola FH. Complete cervical or thoracic spinal cord transections delay gastric emptying and gastrointestinal transit of liquid in awake rats. Spinal Cord 1999; 37: 793-799.

162 Gondim FA, Rodrigues CL, Lopes Jr AC, Leal PR, Camurca FL, Freire CC et al. Effect of preinjury large bowel emptying on the inhibition of upper gastrointestinal motility after spinal cord injury in rats. Dig Dis Sci 2003; 48: 1713-1718.

163 Gondim FA, Rodrigues CL, da Graca JR, Camurca FD, de Alencar HM, dos Santos AA et al. Neural mechanisms involved in the delay of gastric emptying and gastrointestinal transit of liquid after thoracic spinal cord transection in awake rats. Auton Neurosci 2001; 87: 52-58.

164 Rodrigues CL, Gondim FA, Leal PR, Camurca FD, Freire CC, dos Santos AA et al. Gastric emptying and gastrointestinal transit of liquid throughout the first month after thoracic spinal cord transection in awake rats. Dig Dis Sci 2001; 46: 1604-1609.

165 Bruninga K, Riedy L, Keshavarzian A, Walter J. The effect of electrical stimulation on colonic transit following spinal cord injury in cats. Spinal Cord 1998; 36: 847-853.

166 Meshkinpour H, Harmon D, Thompson R, Yu J. Effects of thoracic spinal cord transection on colonic motor activity in rats. Paraplegia 1985; 23: 272-276.

167 Chang SM, Yu GR, Diao YM, Zhang MJ, Wang SB, Hou CL. Sacral anterior root stimulated defecation in spinal cord injuries: an experimental study in canine model. World J Gastroenterol 2005; 11: $1715-1718$.

168 Holmes GM, Rogers RC, Bresnahan JC, Beattie MS. External anal sphincter hyperreflexia following spinal transection in the rat. J Neurotrauma 1998; 15: 451-457.

169 Holmes GM, Van Meter MJ, Beattie MS, Bresnahan JC. Serotonergic fiber sprouting to external anal sphincter motoneurons after spinal cord contusion. Exp Neurol 2005; 193: 29-42.

170 Goodman RD, Lewis AE, Schuck EA, Greenfield MA. Gastrointestinal transit. Am J Physiol 1952; 169: 236-241.

171 Reynell PC, Spray GH. The simultaneous measurement of absorption and transit in the gastro-intestinal tract of the rat. J Physiol 1956; 131: 452-462.

172 Gondim FA, da Graca JR, de Oliveira GR, Rego MC, Gondim RB, Rola FH. Decreased gastric emptying and gastrointestinal and intestinal transits of liquid after complete spinal cord transection in awake rats. Braz J Med Biol Res 1998; 31: 1605-1610.

173 Zhang RL, Chayes Z, Korsten MA, Bauman WA. Gastric emptying rates to liquid or solid meals appear to be unaffected by spinal cord injury. Am J Gastroenterol 1994; 89: 1856-1858.

174 Forster ER, Green T, Dockray GJ. Efferent pathways in the reflex control of gastric emptying in rats. Am J Physiol 1991; 260: G499-G504.

175 Rogers RC, McTigue DM, Hermann GE. Vagovagal reflex control of digestion: afferent modulation by neural and 'endoneurocrine' factors. Am J Physiol 1995; 268: G1-10.

176 Griffith GH, Owen GM, Kirkman S, Shields R. Measurement of rate of gastric emptying using chromium-51. Lancet 1966; 1: $1244-1245$.

177 Tollesson PO, Cassuto J, Faxen A, Bjork L. A radiologic method for the study of postoperative colonic motility in humans. Scand J Gastroenterol 1991; 26: 887-896.

178 Liu S, Chen JD. Colonic electrical stimulation regulates colonic transit via the nitrergic pathway in rats. Dig Dis Sci 2006; 51: 502-505.

179 Sanmiguel CP, Casillas S, Senagore A, Mintchev MP, Soffer EE. Neural gastrointestinal electrical stimulation enhances colonic motility in a chronic canine model of delayed colonic transit. Neurogastroenterol Motil 2006; 18: 647-653.

180 Keshavarzian A, Barnes WE, Bruninga K, Nemchausky B, Mermall H, Bushnell D. Delayed colonic transit in spinal cordinjured patients measured by indium-111 Amberlite scintigraphy. Am J Gastroenterol 1995; 90: 1295-1300.

181 Christmann V, Rosenberg J, Seega J, Lehr CM. Simultaneous in vivo visualization and localization of solid oral dosage forms in the rat gastrointestinal tract by magnetic resonance imaging (MRI). Pharm Res 1997; 14: 1066-1072.

182 Meile T, Zittel TT. Telemetric small intestinal motility recording in awake rats: a novel approach. Eur Surg Res 2002; 34: 271-274. 
183 Lynch AC, Anthony A, Dobbs BR, Frizelle FA. Anorectal physiology following spinal cord injury. Spinal Cord 2000; 38: 573-580.

184 Walter SA, Morren GL, Ryn AK, Hallbook O. Rectal pressure response to a meal in patients with high spinal cord injury. Arch Phys Med Rehabil 2003; 84: 108-111.

185 Valles M, Vidal J, Clave P, Mearin F. Bowel dysfunction in patients with motor complete spinal cord injury: clinical, neurological, and pathophysiological associations. Am J Gastroenterol 2006; 101: 2290-2299.

186 Meshkinpour H, Nowroozi F, Glick ME. Colonic compliance in patients with spinal cord injury. Arch Phys Med Rehabil 1983; 64: 111-112.

187 Mintchev MP, Sanmiguel CP, Bowes KL. Electrogastrographic impact of multi-site functional gastric electrical stimulation. $J$ Med Eng Technol 1999; 23: 5-9.

188 Huge A, Kreis ME, Jehle EC, Ehrlein HJ, Starlinger M, Becker HD et al. A model to investigate postoperative ileus with strain gauge transducers in awake rats. J Surg Res 1998; 74: 112-118.

189 Jacoby HI, Bass P, Bennett DR. In vivo extraluminal contractile force transducer for gastrointestinal muscle. J Appl physiol 1963; 18: 658-665.

190 Hubel KA, Follick M. A small strain gage for measuring intestinal motility in rats. Am J Dig Dis 1976; 21: 1076-1078.

191 Pascaud XB, Genton MJ, Bass P. A miniature transducer for recording intestinal motility in unrestrained chronic rats. $A m \mathrm{~J}$ Physiol 1978; 235: E532-E538.

192 Meile T, Glatzle J, Habermann FM, Kreis ME, Zittel TT. Nitric oxide synthase inhibition results in immediate postoperative recovery of gastric, small intestinal and colonic motility in awake rats. Int J Colorectal Dis 2006; 21: 121-129.

193 Takayama I, Seto E, Zai H, Ohno S, Tezuka H, Daigo Y et al. Changes of in vivo gastrointestinal motor pattern in pacemakerdeficient (WsRC-Ws/Ws) rats. Dig Dis Sci 2000; 45: 1901-1906.

194 Itoh Z, Honda R, Takeuchi S, Aizawa I, Takayanagi R. An extraluminal force transducer for recording contractile activity of the gastrointestinal smooth muscle in the conscious dogs: its construction and implantation. Gastroenterol Jpn 1977; 12: 275-283.

195 Enck P, Wienbeck M. Repeated noninvasive measurement of gastrointestinal transit in rats. Physiol Behav 1989; 46: 633-637.

196 Staniforth DH. Comparison of orocaecal transit times assessed by the lactulose/breath hydrogen and the sulphasalazine/ sulphapyridine methods. Gut 1989; 30: 978-982.

197 Simren M, Stotzer PO. Use and abuse of hydrogen breath tests. Gut 2006; 55: 297-303.

198 Chen CY, Chuang TY, Tsai YA, Chang H, Tai HC, Lu CL et al. Loss of sympathetic coordination appears to delay gastrointestinal transit in patients with spinal cord injury. Dig Dis Sci 2004; 49: 738-743.

199 Papasouliotis K, Gruffydd-Jones TJ, Sparkes AH, Cripps PJ. A comparison of orocaecal transit times assessed by the breath hydrogen test and the sulphasalazine/sulphapyridine method in healthy beagle dogs. Res Vet Sci 1995; 58: 263-267.

200 Papasouliotis K, Sparkes AH, Gruffydd-Jones TJ, Cripps PJ, Harper EJ. Use of the breath hydrogen test to assess the effect of age on orocecal transit time and carbohydrate assimilation in cats. Am J Vet Res 1998; 59: 1299-1302.

201 de Groat WC. Anatomy and physiology of the lower urinary tract. Urol Clin North Am 1993; 20: 383-401.

202 Chai TC, Steers WD. Neurophysiology of micturition and continence. Urol Clin North Am 1996; 23: 221-236.

203 Yoshimura N, de Groat WC. Neural control of the lower urinary tract. Int J Urol 1997; 4: 111-125.

204 Yoshimura N. Bladder afferent pathway and spinal cord injury: possible mechanisms inducing hyperreflexia of the urinary bladder. Prog Neurobiol 1999; 57: 583-606.

205 Craggs MD, Balasubramaniam AV, Chung EA, Emmanuel AV. Aberrant reflexes and function of the pelvic organs following spinal cord injury in man. Auton Neurosci 2006; 126-127: 355-370.

206 de Groat WC, Yoshimura N. Mechanisms underlying the recovery of lower urinary tract function following spinal cord injury. Prog Brain Res 2006; 152: 59-84.
207 de Groat WC. Integrative control of the lower urinary tract: preclinical perspective. Br J Pharmacol 2006; 147 (Suppl 2): S25-S40.

208 de Groat WC, Kawatani M, Hisamitsu T, Cheng CL, Ma CP, Thor $\mathrm{K}$ et al. Mechanisms underlying the recovery of urinary bladder function following spinal cord injury. J Auton Nerv Syst 1990; 30 (Suppl): S71-S77.

209 Pikov V, Gillis RA, Jasmin L, Wrathall JR. Assessment of lower urinary tract functional deficit in rats with contusive spinal cord injury. J Neurotrauma 1998; 15: 375-386.

210 Pikov V, Wrathall JR. Altered glutamate receptor function during recovery of bladder detrusor-external urethral sphincter coordination in a rat model of spinal cord injury. J Pharmacol Exp Ther 2002; 300: 421-427.

211 Smith CP, Somogyi GT, Bird ET, Chancellor MB, Boone TB. Neurogenic bladder model for spinal cord injury: spinal cord microdialysis and chronic urodynamics. Brain Res Brain Res Protoc 2002; 9: 57-64.

212 Shenot PJ, Chancellor MB, Rivas DA, Watanabe T, Kumon H, Figueroa TE. In-vivo whole bladder response to anticholinergic and musculotropic agents in spinal cord injured rats. J Spinal Cord Med 1997; 20: 31-35.

213 Pikov V, Wrathall JR. Coordination of the bladder detrusor and the external urethral sphincter in a rat model of spinal cord injury: effect of injury severity. J Neurosci 2001; 21: 559-569.

214 Chang HY, Cheng CL, Chen JJ, de Groat WC. Serotonergic drugs and spinal cord transections indicate that different spinal circuits are involved in external urethral sphincter activity in rats. Am J Physiol Renal Physiol 2007; 292: F1044-F1053.

215 Ashitomi K, Sugaya K, Miyazato M, Nishijima S, Ogawa Y. Intrathecal glutamate promotes glycinergic neuronal activity and inhibits the micturition reflex in urethane-anesthetized rats. Int J Urol 2006; 13: 1519-1524.

216 Miyazato M, Sugaya K, Nishijima S, Ashitomi K, Hatano T, Ogawa Y. Inhibitory effect of intrathecal glycine on the micturition reflex in normal and spinal cord injury rats. Exp Neurol 2003; 183: 232-240.

217 Zinck ND, Rafuse VF, Downie JW. Sprouting of CGRP primary afferents in lumbosacral spinal cord precedes emergence of bladder activity after spinal injury. Exp Neurol 2007; 204: 777-790.

218 Yoshiyama M, Nezu FM, Yokoyama O, de Groat WC, Chancellor MB. Changes in micturition after spinal cord injury in conscious rats. Urology 1999; 54: 929-933.

219 Kruse MN, de Groat WC. Consequences of spinal cord injury during the neonatal period on micturition reflexes in the rat. Exp Neurol 1994; 125: 87-92.

220 Komiyama I, Igawa Y, Ishizuka O, Nishizawa O, Andersson KE. Effects of intravesical capsaicin and resiniferatoxin on distension-induced bladder contraction in conscious rats with and without chronic spinal cord injury. J Urol 1999; 161: 314-319.

221 Yoshiyama M, deGroat WC, Fraser MO. Influences of external urethral sphincter relaxation induced by alpha-bungarotoxin, a neuromuscular junction blocking agent, on voiding dysfunction in the rat with spinal cord injury. Urology 2000; 55: 956-960.

222 Shaker H, Wang Y, Loung D, Balbaa L, Fehlings MG, Hassouna MM. Role of C-afferent fibres in the mechanism of action of sacral nerve root neuromodulation in chronic spinal cord injury. BJU Int 2000; 85: 905-910.

223 Yoshiyama M, de Groat WC. Effect of bilateral hypogastric nerve transection on voiding dysfunction in rats with spinal cord injury. Exp Neurol 2002; 175: 191-197.

224 Seki S, Sasaki K, Igawa Y, Nishizawa O, Chancellor MB, de Groat WC et al. Suppression of detrusor-sphincter dyssynergia by immunoneutralization of nerve growth factor in lumbosacral spinal cord in spinal cord injured rats. J Urol 2004; 171: 478-482.

225 Abdel-Karim AM, Abdel-Gawad M, Huynh H, Elhilali MM. Modulation of insulin-like growth factor-I system of the bladder using a somatostatin analogue in chronic spinalized rats. J Urol 2002; 168: 1253-1258.

226 Yokoyama O, Mita E, Akino H, Tanase K, Ishida H, Namiki M. Roles of opiate in lower urinary tract dysfunction associated with spinal cord injury in rats. J Urol 2004; 171: 963-967. 
227 Miyazato M, Sugaya K, Nishijima S, Ashitomi K, Morozumi M, Ogawa Y. Dietary glycine inhibits bladder activity in normal rats and rats with spinal cord injury. J Urol 2005; 173: 314-317.

228 Miyazato M, Sugaya K, Nishijima S, Kadekawa K, Ashimine S, Ogawa Y. Intrathecal or dietary glycine inhibits bladder and urethral activity in rats with spinal cord injury. J Urol 2005; 174: 2397-2400.

229 Khera M, Somogyi GT, Salas NA, Kiss S, Boone TB, Smith CP. In vivo effects of botulinum toxin A on visceral sensory function in chronic spinal cord-injured rats. Urology 2005; 66: 208-212.

230 Abdel-Karim AM, Barthlow HG, Bialecki RA, Elhilali MM. Effects of M274773, a neurokinin-2 receptor antagonist, on bladder function in chronically spinalized rats. J Urol 2005; 174: 1488-1492.

231 Zvara P, Braas KM, May V, Vizzard MA. A role for pituitary adenylate cyclase activating polypeptide (PACAP) in detrusor hyperreflexia after spinal cord injury (SCI). Ann NY Acad Sci 2006; 1070: 622-628.

232 Obara T, Matsuura S, Narita S, Satoh S, Tsuchiya N, Habuchi T. Bladder acellular matrix grafting regenerates urinary bladder in the spinal cord injury rat. Urology 2006; 68: 892-897.

233 Takahara Y, Maeda M, Nakatani T, Kiyama H. Transient suppression of the vesicular acetylcholine transporter in urinary bladder pathways following spinal cord injury. Brain Res 2007; 1137: 20-28.

234 Khera M, Boone TB, Salas N, Jett MF, Somogyi GT. The role of the prostacyclin receptor antagonist RO3244019 in treating neurogenic detrusor overactivity after spinal cord injury in rats. BJU Int 2007; 99: 442-446.

235 Cheng CL, Ma CP, de Groat WC. Effect of capsaicin on micturition and associated reflexes in chronic spinal rats. Brain Res 1995; 678: 40-48.

236 Cheng CL, de Groat WC. The role of capsaicin-sensitive afferent fibers in the lower urinary tract dysfunction induced by chronic spinal cord injury in rats. Exp Neurol 2004; 187: 445-454.

237 Kruse MN, Belton AL, de Groat WC. Changes in bladder and external urethral sphincter function after spinal cord injury in the rat. Am J Physiol 1993; 264: R1157-R1163.

238 Temeltas G, Tikiz C, Dagci T, Tuglu I, Yavasoglu A. The effects of botulinum-A toxin on bladder function and histology in spinal cord injured rats: is there any difference between early and late application? J Urol 2005; 174: 2393-2396.

239 Chang S, Mao ST, Hu SJ, Lin WC, Cheng CL. Studies of detrusorsphincter synergia and dyssynergia during micturition in rats via fractional Brownian motion. IEEE Trans Biomed Eng 2000; 47: 1066-1073.

240 Chang S, Hu SJ, Lin WC. Fractal dynamics and synchronization of rhythms in urodynamics of female Wistar rats. J Neurosci Methods 2004; 139: 271-279.

241 Kakizaki H, de Groat WC. Reorganization of somato-urethral reflexes following spinal cord injury in the rat. J Urol 1997; 158: $1562-1567$.

242 Kakizaki H, Fraser MO, de Groat WC. Reflex pathways controlling urethral striated and smooth muscle function in the male rat. Am J Physiol 1997; 272: R1647-R1656.

243 Callsen-Cencic P, Mense S. Control of the unstable urinary bladder by graded thermoelectric cooling of the spinal cord. BJU Int 1999; 84: 1084-1092.

244 Abdel-Gawad M, Dion SB, Elhilali MM. Evidence of a peripheral role of neurokinins in detrusor hyperreflexia: a further study of selective tachykinin antagonists in chronic spinal injured rats. $J$ Urol 2001; 165: 1739-1744.

245 Cruz CD, McMahon SB, Cruz F. Spinal ERK activation contributes to the regulation of bladder function in spinal cord injured rats. Exp Neurol 2006; 200: 66-73.

246 Dolber PC, Gu B, Zhang X, Fraser MO, Thor KB, Reiter JP. Activation of the external urethral sphincter central pattern generator by a 5-HT(1A) receptor agonist in rats with chronic spinal cord injury. Am J Physiol Regul Integr Comp Physiol 2007; 292: R1699-R1706.

247 Urakami S, Shiina H, Enokida H, Kawamoto K, Kikuno N, Fandel $\mathrm{T}$ et al. Functional improvement in spinal cord injuryinduced neurogenic bladder by bladder augmentation using bladder acellular matrix graft in the rat. World I Urol 2007; 25 : 207-213.

248 Kontani $\mathrm{H}$, Hayashi K. Urinary bladder response to hypogastric nerve stimulation after bilateral resection of the pelvic nerve or spinal cord injury in rats. Int J Urol 1997; 4: 394-400.

249 Kameoka H, Shiraiwa Y, Fukaya Y, Yokota T, Shishido K, Yamaguchi O. Effect of naloxone on the bladder activity of rabbits with acute spinal injury. Int J Urol 1998; 5: 588-594.

250 Walter JS, Sidarous R, Robinson CJ, Wheeler JS, Wurster RD. Comparison of direct bladder and sacral nerve stimulation in spinal cats. J Rehabil Res Dev 1992; 29: 13-22.

251 Walter JS, Wheeler JS, Cai W, Wurster RD. Direct bladder stimulation with suture electrodes promotes voiding in a spinal animal model: a technical report. J Rehabil Res Dev 1997; 34: 72-81.

252 Kerns JM, Truong TT, Walter JS, Khan T. Do direct current electric fields enhance micturition in the spinal cat? J Spinal Cord Med 1996; 19: 225-233.

253 Sugaya K, Ogawa Y, Hatano T, Koyama Y, Miyazato T, Oda M. Effect of injury to the dorsal funiculus of the thoracic spinal cord on micturition in decerebrate and freely-moving cats. Urol Int 1999; 63: 179-184.

254 Boggs JW, Wenzel BJ, Gustafson KJ, Grill WM. Spinal micturition reflex mediated by afferents in the deep perineal nerve. J Neurophysiol 2005; 93: 2688-2697.

255 Espey MJ, Downie JW. Serotonergic modulation of cat bladder function before and after spinal transection. Eur J Pharmacol 1995; 287: 173-177.

256 Sugaya K, Ogawa Y, Hatano T, Nishijima S, Nishizawa O. Micturition in thoracic spinal cord injured cats with autografting of the adrenal medulla to the sacral spinal cord. J Urol 2001; 166: $2525-2529$

257 Cheng CL, Liu JC, Chang SY, Ma CP, de Groat WC. Effect of capsaicin on the micturition reflex in normal and chronic spinal cord-injured cats. Am J Physiol 1999; 277: R786-R794.

258 Tai C, Booth AM, de Groat WC, Roppolo JR. Bladder and urethral sphincter responses evoked by microstimulation of S2 sacral spinal cord in spinal cord intact and chronic spinal cord injured cats. Exp Neurol 2004; 190: 171-183.

$259 \mathrm{Gu}$ B, Olejar KJ, Reiter JP, Thor KB, Dolber PC. Inhibition of bladder activity by 5-hydroxytryptamine1 serotonin receptor agonists in cats with chronic spinal cord injury. J Pharmacol Exp Ther 2004; 310: 1266-1272.

260 Tai C, Miscik CL, Ungerer TD, Roppolo JR, de Groat WC. Suppression of bladder reflex activity in chronic spinal cord injured cats by activation of serotonin 5-HT1A receptors. Exp Neurol 2006; 199: 427-437.

$261 \mathrm{Gu}$ B, Thor KB, Reiter JP, Dolber PC. Effect of 5-hydroxytryptamine1 serotonin receptor agonists on noxiously stimulated micturition in cats with chronic spinal cord injury. J Urol 2007; 177: 2381-2385.

262 Walter JS, Wheeler JS, Robinson CJ, Wurster RD. Surface stimulation techniques for bladder management in the spinal dog. J Urol 1989; 141: 161-165.

263 Hassouna M, Li JS, Sawan M, Duval F, Latt R, Elhilali MM. Effect of early bladder stimulation on spinal shock: experimental approach. Urology 1992; 40: 563-573.

264 Abdel-Gawad M, Boyer S, Sawan M, Elhilali MM. Reduction of bladder outlet resistance by selective stimulation of the ventral sacral root using high frequency blockade: a chronic study in spinal cord transected dogs. J Urol 2001; 166: 728-733.

265 Keirstead HS, Fedulov V, Cloutier F, Steward O, Duel BP. A noninvasive ultrasonographic method to evaluate bladder function recovery in spinal cord injured rats. Exp Neurol 2005; 194: 120-127.

266 Nout YS, Schmidt MH, Tovar CA, Culp E, Beattie MS, Bresnahan JC. Telemetric monitoring of corpus spongiosum penis pressure in conscious rats for assessment of micturition and sexual function following spinal cord contusion injury. J Neurotrauma 2005; 22: 429-441.

267 Chancellor MB, Rivas DA, Acosta R, Erhard MJ, Moore J, Salzman SK. Detrusor-myoplasty, innervated rectus muscle 
transposition study, and functional effect on the spinal cord injury rat model. Neurourol Urodyn 1994; 13: 547-557.

268 Potter PJ. Disordered control of the urinary bladder after human spinal cord injury: what are the problems? Prog Brain Res 2006; 152: $51-57$.

269 Craggs MD. Pelvic somato-visceral reflexes after spinal cord injury: measures of functional loss and partial preservation. Prog Brain Res 2006; 152: 205-219.

270 Tai C, Roppolo JR, de Groat WC. Spinal reflex control of micturition after spinal cord injury. Restor Neurol Neurosci 2006; 24: 69-78.

271 Cardenas DD, Hoffman JM, Kirshblum S, McKinley W. Etiology and incidence of rehospitalization after traumatic spinal cord injury: a multicenter analysis. Arch Phys Med Rehabil 2004; 85: 1757-1763.

272 Ondarza AB, Ye Z, Hulsebosch CE. Direct evidence of primary afferent sprouting in distant segments following spinal cord injury in the rat: colocalization of GAP-43 and CGRP. Exp Neurol 2003; 184: 373-380.

273 Vizzard MA. Neurochemical plasticity and the role of neurotrophic factors in bladder reflex pathways after spinal cord injury. Prog Brain Res 2006; 152: 97-115.

274 Wrathall JR, Emch GS. Effect of injury severity on lower urinary tract function after experimental spinal cord injury. Prog Brain Res 2006; 152: 117-134.

275 Gloeckner DC, Sacks MS, Fraser MO, Somogyi GT, de Groat WC, Chancellor MB. Passive biaxial mechanical properties of the rat bladder wall after spinal cord injury. J Urol 2002; 167: 2247-2252.

276 Nagatomi J, Gloeckner DC, Chancellor MB, deGroat WC, Sacks MS. Changes in the biaxial viscoelastic response of the urinary bladder following spinal cord injury. Ann Biomed Eng 2004; 32: 1409-1419.

277 Wilson TS, Aziz KA, Vazques D, Wuermser LA, Lin VK, Lemack GE. Changes in detrusor smooth muscle myosin heavy chain mRNA expression following spinal cord injury in the mouse. Neurourol Urodyn 2005; 24: 89-95.

278 Nagatomi J, Toosi KK, Grashow JS, Chancellor MB, Sacks MS. Quantification of bladder smooth muscle orientation in normal and spinal cord injured rats. Ann Biomed Eng 2005; 33: 1078-1089.

279 Hoang TX, Nieto JH, Tillakaratne NJ, Havton LA. Autonomic and motor neuron death is progressive and parallel in a lumbosacral ventral root avulsion model of cauda equina injury. J Comp Neurol 2003; 467: 477-486.

280 Hoang TX, Havton LA. Novel repair strategies to restore bladder function following cauda equina/conus medullaris injuries. Prog Brain Res 2006; 152: 195-204.

281 Yoshiyama M, Roppolo JR, de Groat WC. Alteration by urethane of glutamatergic control of micturition. Eur J Pharmacol 1994; 264: 417-425.

282 Buczynski AZ. Urodynamic studies in evaluating detrusor sphincter dyssynergia and their effects on the treatment. Paraplegia 1984; 22: 168-172.

283 Glick ME, Haldeman S, Meshkinpour H. The neurovisceral and electrodiagnostic evaluation of patients with thoracic spinal cord injury. Paraplegia 1986; 24: 129-137.

284 Mitsui T, Kakizaki H, Tanaka H, Shibata T, Matsuoka I, Koyanagi T. Immortalized neural stem cells transplanted into the injured spinal cord promote recovery of voiding function in the rat. J Urol 2003; 170: 1421-1425.

285 Mitsui T, Shumsky JS, Lepore AC, Murray M, Fischer I. Transplantation of neuronal and glial restricted precursors into contused spinal cord improves bladder and motor functions, decreases thermal hypersensitivity, and modifies intraspinal circuitry. J Neurosci 2005; 25: 9624-9636.

286 Mitsui T, Fischer I, Shumsky JS, Murray M. Transplants of fibroblasts expressing BDNF and NT-3 promote recovery of bladder and hindlimb function following spinal contusion injury in rats. Exp Neurol 2005; 194: 410-431.

287 Koyanagi T, Arikado K, Takamatsu T, Tsuji I. Experience with electromyography of the external urethral sphincter in spinal cord injury patients. J Urol 1982; 127: 272-276.
288 Wyndaele JJ. Urethral sphincter dyssynergia in spinal cord injury patients. Paraplegia 1987; 25: 10-15.

289 Caggiano AO, Zimber MP, Ganguly A, Blight AR, Gruskin EA Chondroitinase ABCI improves locomotion and bladder function following contusion injury of the rat spinal cord. J Neurotrauma 2005; 22: 226-239.

290 Walter JS, Wheeler JS, Cai W, King WW, Wurster RD. Evaluation of a suture electrode for direct bladder stimulation in a lower motor neuron lesioned animal model. IEEE Trans Rehabil Eng 1999; 7: 159-166.

291 Walter JS, Wheeler JS, Fitzgerald MP, McDonnell A, Wurster RD. Chronic instrumentation with model microstimulators in an animal model of the lower urinary tract. J Spinal Cord Med 2005; 28: $114-120$.

292 Walter JS, Wheeler JS, Fitzgerald MP, McDonnell A, Wurster RD. A spinal cord injured animal model of lower urinary tract function: observations using direct bladder and pelvic plexus stimulation with model microstimulators. I Spinal Cord Med 2005; 28: 246-254

293 Nout YS, Bresnahan JC, Culp E, Tovar CA, Beattie MS, Schmidt $\mathrm{MH}$. Novel technique for monitoring micturition and sexual function in male rats using telemetry. Am J Physiol Regul Integr Comp Physiol 2007; 292: R1359-R1367.

294 Giuliano F, Bernabe J, Rampin O, Courtois F, Benoit G, Rousseau JP. Telemetric monitoring of intracavernous pressure in freely moving rats during copulation. J Urol 1994; 152: 1271-1274.

295 Bernabe J, Rampin O, Sachs BD, Giuliano F. Intracavernous pressure during erection in rats: an integrative approach based on telemetric recording. Am J Physiol 1999; 276: R441-R449.

296 Giuliano F, Rossler AS, Clement P, Droupy S, Alexandre L, Bernabe J. The use of telemetry technology to test the proerectile effect of melanotan-II (MT-II) in conscious rats. Eur Urol 2005; 48: 145-151.

297 McKenna KE. The neurophysiology of female sexual function. World J Urol 2002; 20: 93-100.

298 Janig W, McLachlan EM. Organization of lumbar spinal outflow to distal colon and pelvic organs. Physiol Rev 1987; 67: 1332-1404.

299 Steers WD. Neural pathways and central sites involved in penile erection: neuroanatomy and clinical implications. Neurosci Biobehav Rev 2000; 24: 507-516.

300 McKenna KE. Neural circuitry involved in sexual function. J Spinal Cord Med 2001; 24: 148-154.

301 Johnson RD. Descending pathways modulating the spinal circuitry for ejaculation: effects of chronic spinal cord injury. Prog Brain Res 2006; 152: 415-426.

302 Ignarro LJ, Bush PA, Buga GM, Wood KS, Fukuto JM, Rajfer J. Nitric oxide and cyclic GMP formation upon electrical field stimulation cause relaxation of corpus cavernosum smooth muscle. Biochem Biophys Res Commun 1990; 170: 843-850.

303 Bush PA, Aronson WJ, Buga GM, Rajfer J, Ignarro LJ. Nitric oxide is a potent relaxant of human and rabbit corpus cavernosum. J Urol 1992; 147: 1650-1655.

304 Cellek S, Moncada S. Nitrergic neurotransmission mediates the non-adrenergic non-cholinergic responses in the clitoral corpus cavernosum of the rabbit. Br J Pharmacol 1998; 125: 1627-1629.

305 Sipski ML, Alexander CJ, Rosen RC. Physiologic parameters associated with sexual arousal in women with incomplete spinal cord injuries. Arch Phys Med Rehabil 1997; 78: 305-313.

306 Courtois FJ, Goulet MC, Charvier KF, Leriche A. Posttraumatic erectile potential of spinal cord injured men: how physiologic recordings supplement subjective reports. Arch Phys Med Rehabil 1999; 80: 1268-1272.

307 Sipski ML, Alexander CJ, Rosen R. Sexual arousal and orgasm in women: effects of spinal cord injury. Ann Neurol 2001; 49: 35-44.

308 Schmid DM, Curt A, Hauri D, Schurch B. Clinical value of combined electrophysiological and urodynamic recordings to assess sexual disorders in spinal cord injured men. Neurourol Urodyn 2003; 22: 314-321.

309 Lavoisier P, Courtois F, Barres D, Blanchard M. Correlation between intracavernous pressure and contraction of the ischiocavernosus muscle in man. J Urol 1986; 136: 936-939. 
310 Wespes E, Nogueira MC, Herbaut AG, Caufriez M, Schulman CC. Role of the bulbocavernosus muscles on the mechanism of human erection. Eur Urol 1990; 18: 45-48.

311 Holmes GM, Chapple WD, Leipheimer RE, Sachs BD. Electromyographic analysis of male rat perineal muscles during copulation and reflexive erections. Physiol Behav 1991; 49: $1235-1246$.

312 Schmidt MH, Schmidt HS. The ischiocavernosus and bulbospongiosus muscles in mammalian penile rigidity. Sleep 1993; 16: 171-183.

313 Coolen LM, Allard J, Truitt WA, McKenna KE. Central regulation of ejaculation. Physiol Behav 2004; 83: 203-215.

314 Bohlen JG, Held JP, Sanderson MO. The male orgasm: pelvic contractions measured by anal probe. Arch Sex Behav 1980; 9: 503-521.

315 Bohlen JG, Held JP, Sanderson MO, Ahlgren A. The female orgasm: pelvic contractions. Arch Sex Behav 1982; 11: 367-386.

316 McKenna KE, Chung SK, McVary KT. A model for the study of sexual function in anesthetized male and female rats. Am J Physiol 1991; 261: R1276-R1285.

317 Marson L, Cai R, Makhanova N. Identification of spinal neurons involved in the urethrogenital reflex in the female rat. J Comp Neurol 2003; 462: 355-370.

318 Gerstenberg TC, Levin RJ, Wagner G. Erection and ejaculation in man. Assessment of the electromyographic activity of the bulbocavernosus and ischiocavernosus muscles. Br J Urol 1990; 65: 395-402.

319 Kempinas WD, Suarez JD, Roberts NL, Strader L, Ferrell J, Goldman JM et al. Rat epididymal sperm quantity, quality, and transit time after guanethidine-induced sympathectomy. Biol Reprod 1998; 59: 890-896.

320 Billups KL, Tillman S, Chang TS. Ablation of the inferior mesenteric plexus in the rat: alteration of sperm storage in the epididymis and vas deferens. J Urol 1990; 143: 625-629.

321 Ricker DD, Chang TS. Neuronal input from the inferior mesenteric ganglion (IMG) affects sperm transport within the rat cauda epididymis. Int J Androl 1996; 19: 371-376.

322 Valtonen K, Karlsson AK, Siosteen A, Dahlof LG, Viikari-Juntura E. Satisfaction with sexual life among persons with traumatic spinal cord injury and meningomyelocele. Disabil Rehabil 2006; 28: 965-976.

323 Alexander MS, Bodner D, Brackett NL, Elliott S, Jackson AB, Sonksen J. Development of international standards to document sexual and reproductive functions after spinal cord injury: preliminary report. J Rehabil Res Dev 2007; 44: 83-90.

324 Brindley GS. The fertility of men with spinal injuries. Paraplegia 1984; 22: 337-348.

325 Brown DJ, Hill ST, Baker HW. Male fertility and sexual function after spinal cord injury. Prog Brain Res 2006; 152: 427-439.

326 Kafetsoulis A, Brackett NL, Ibrahim E, Attia GR, Lynne CM. Current trends in the treatment of infertility in men with spinal cord injury. Fertil Steril 2006; 86: 781-789.

327 Sipski ML. The impact of spinal cord injury on female sexuality, menstruation and pregnancy: a review of the literature. J Am Paraplegia Soc 1991; 14: 122-126.

328 Whipple B, Komisaruk BR. Sexuality and women with complete spinal cord injury. Spinal Cord 1997; 35: 136-138.

329 Frankel HL, Mathias CJ, Walsh JJ. Blood pressure, plasma catecholamines and prostaglandins during artificial erection in a male tetraplegic. Paraplegia 1974; 12: 205-211.

330 Szasz G, Carpenter C. Clinical observations in vibratory stimulation of the penis of men with spinal cord injury. Arch Sex Behav 1989; 18: 461-474.

331 Sheel AW, Krassioukov AV, Inglis JT, Elliott SL. Autonomic dysreflexia during sperm retrieval in spinal cord injury: influence of lesion level and sildenafil citrate. J Appl Physiol 2005; 99: 53-58.

332 Claydon VE, Elliott SL, Sheel AW, Krassioukov A. Cardiovascular responses to vibrostimulation for sperm retrieval in men with spinal cord injury. J Spinal Cord Med 2006; 29: 207-216.

333 Elliott S, Krassioukov A. Malignant autonomic dysreflexia in spinal cord injured men. Spinal Cord 2006; 44: 386-392.
334 Courtois FJ, Charvier KF, Leriche A, Vezina JG, Cote M, Belanger M. Blood pressure changes during sexual stimulation, ejaculation and midodrine treatment in men with spinal cord injury. BJU Int 2008; 101: 331-337.

335 Ekland MB, Krassioukov AU, McBride KE, Elliott SL. Incidence of autonomic dysreflexia and silent autonomic dysreflexia in men with SCI undergoing sperm retrieval: implications for clinical practice. J Spinal Cord Med 2008; 31: 33-39.

336 Anderson KD, Borisoff JF, Johnson RD, Stiens SA, Elliott SL. The impact of spinal cord injury on sexual function: concerns of the general population. Spinal Cord 2007; 45: 328-337.

337 Elliott SL. Problems of sexual function after spinal cord injury. Prog Brain Res 2006; 152: 387-399.

338 Giraldi A, Marson L, Nappi R, Pfaus J, Traish AM, Vardi Y et al. Physiology of female sexual function: animal models. J Sex Med 2004; 1: 237-253.

339 Linsenmeyer TA, Pogach LM, Ottenweller JE, Huang HF. Spermatogenesis and the pituitary-testicular hormone axis in rats during the acute phase of spinal cord injury. J Urol 1994; 152: 1302-1307.

340 Huang HFS, Li MT, Giglio W, Anesetti R, Ottenweller JE, Pogach LM. The detrimental effects of spinal cord injury on spermatogenesis in the rat is partially reversed by testosterone, but enhanced by follicle-stimulating hormone. Endocrinology 1999; 140: 1349-1355.

341 Wang S, Wang G, Barton BE, Murphy TF, Huang HF. Beneficial effects of vitamin $\mathrm{E}$ in sperm functions in the rat after spinal cord injury. J Androl 2007; 28: 334-341.

342 Meisel RL, Sachs BD. Spinal transection accelerates the developmental expression of penile reflexes in male rats. Physiol Behav 1980; 24: 289-292.

343 Pescatori ES, Calabro A, Artibani W, Pagano F, Triban C, Italiano G. Electrical stimulation of the dorsal nerve of the penis evokes reflex tonic erections of the penile body and reflex ejaculatory responses in the spinal rat. J Urol 1993; 149: 627-632.

344 Vargas VM, Torres D, Corona F, Vergara M, Gomez LE, DelgadoLezama $\mathrm{R}$ et al. Cholinergic facilitation of erection and ejaculation in spinal cord-transected rats. Int J Impot Res 2004; 16: 86-90.

345 Ishizuka $\mathrm{O}, \mathrm{Gu} \mathrm{BJ}$, Nishizawa O, Mizusawa H, Andersson KE. Effect of apomorphine on intracavernous pressure and blood pressure in conscious, spinalized rats. Int J Impot Res 2002; 14: $128-132$.

346 Abdel-Karim AM, Carrier S. Possible improvement of the clitoral and vaginal blood flow using a somatostatin analog in chronic spinalized Sprague-Dawley rats. J Sex Marital Ther 2002; 28 (Suppl 1): 1-9.

347 Linsenmeyer TA, Ottenweller JE, D'Imperio JS, Pogach LM, Huang HF. Epididymal sperm transport in normal and recent spinal cord injured Sprague Dawley rats. J Spinal Cord Med 1999; 22: 102-106.

348 Kim SW, Jeong SJ, Munarriz R, Kim NN, Goldstein I, Traish AM. An in vivo rat model to investigate female vaginal arousal response. J Urol 2004; 171: 1357-1361.

349 Heaton JP, Varrin SJ, Morales A. The characterization of a bio-assay of erectile function in a rat model. J Urol 1991; 145: 1099-1102.

350 Courtois FJ, Macdougall JC, Sachs BD. Erectile mechanism in paraplegia. Physiol Behav 1993; 53: 721-726.

351 Hart BL. Sexual reflexes and mating behavior in the male rat. J Comp Physiol Psychol 1968; 65: 453-460.

352 Chung SK, McVary KT, McKenna KE. Sexual reflexes in male and female rats. Neurosci Lett 1988; 94: 343-348.

353 Pfaus JG, Kippin TE, Coria-Avila G. What can animal models tell us about human sexual response? Annu Rev Sex Res 2003; 14: $1-63$.

354 Courtois FJ, Charvier KF, Leriche A, Raymond DP. Sexual function in spinal cord injury men. I. Assessing sexual capability. Paraplegia 1993; 31: 771-784.

355 Schmidt MH, Valatx JL, Schmidt HS, Wauquier A, Jouvet M. Experimental evidence of penile erections during paradoxical sleep in the rat. Neuroreport 1994; 5: 561-564. 
356 McMurray G, Casey JH, Naylor AM. Animal models in urological disease and sexual dysfunction. Br J Pharmacol 2006; 147 (Suppl 2): S62-S79.

357 Miura T, Kondo Y, Akimoto M, Sakuma Y. Electromyography of male rat perineal musculature during copulatory behavior. Urol Int 2001; 67: 240-245.

358 Sintchak G, Geer JH. A vaginal plethysmograph system. Psychophysiology 1975; 12: 113-115.

359 Laan E, Everaerd W. Physiological measures of vaginal vasocongestion. Int J Impot Res 1998; 10 (Suppl 2): S107-S110.

360 Basson R, Brotto LA. Sexual psychophysiology and effects of sildenafil citrate in oestrogenised women with acquired genital arousal disorder and impaired orgasm: a randomised controlled trial. BJOG 2003; 110: 1014-1024.

361 Vachon P, Simmerman N, Zahran AR, Carrier S. Increases in clitoral and vaginal blood flow following clitoral and pelvic plexus nerve stimulations in the female rat. Int J Impot Res 2000; 12: 53-57.

362 Giuliano F, Allard J, Compagnie S, Alexandre L, Droupy S, Bernabe J. Vaginal physiological changes in a model of sexual arousal in anesthetized rats. Am J Physiol Regul Integr Comp Physiol 2001; 281: R140-R149.

363 Mykytowycz R. The behavioural role of the mammalian skin glands. Naturwissenschaften 1972; 59: 133-139.

364 Downey JA, Chiodi HP, Darling RC. Central temperature regulation in the spinal man. J Appl Physiol 1967; 22: 91-94.

365 Guttmann L, Silver J, Wyndham CH. Thermoregulation in spinal man. J Physiol 1958; 142: 406-419.

366 Price MJ, Campbell IG. Effects of spinal cord lesion level upon thermoregulation during exercise in the heat. Med Sci Sports Exerc 2003; 35: 1100-1107.

367 Huckaba CE, Frewin DB, Downey JA, Tam HS, Darling RC, Cheh HY. Sweating responses of normal, paraplegic and anhidrotic subjects. Arch Phys Med Rehabil 1976; 57: 268-274.

368 Price MJ. Thermoregulation during exercise in individuals with spinal cord injuries. Sports Med 2006; 36: 863-879.

369 Yaggie JA, Niemi TJ, Buono MJ. Adaptive sweat gland response after spinal cord injury. Arch Phys Med Rehabil 2002; 83: 802-805.

370 Coris EE, Ramirez AM, Van Durme DJ. Heat illness in athletes: the dangerous combination of heat, humidity and exercise. Sports Med 2004; 34: 9-16.

371 Bhambhani Y. Physiology of wheelchair racing in athletes with spinal cord injury. Sports Med 2002; 32: 23-51.

372 Hagobian TA, Jacobs KA, Kiratli BJ, Friedlander AL. Foot cooling reduces exercise-induced hyperthermia in men with spinal cord injury. Med Sci Sports Exerc 2004; 36: 411-417.

373 Webborn N, Price MJ, Castle PC, Goosey-Tolfrey VL. Effects of two cooling strategies on thermoregulatory responses of tetraplegic athletes during repeated intermittent exercise in the heat. J Appl Physiol 2005; 98: 2101-2107.

374 Colachis III SC. Hypothermia associated with autonomic dysreflexia after traumatic spinal cord injury. Am J Phys Med Rehabil 2002; 81: 232-235.

375 Strain GM, Waldrop RD. Temperature and vascular volume effects on gastric ulcerogenesis after cord transection. Dig Dis Sci 2005; 50: 2037-2042.

376 Mikami Y, Ogura T, Kubo T, Kira Y, Aramaki S. Inducing peripheral sympathetic nerve activity by therapeutic electrical stimulation. J Orthop Surg (Hong Kong) 2005; 13: 167-170.

377 Argyropoulos G, Harper ME. Uncoupling proteins and thermoregulation. J Appl Physiol 2002; 92: 2187-2198.

378 Mozo J, Emre Y, Bouillaud F, Ricquier D, Criscuolo F. Thermoregulation: what role for UCPs in mammals and birds? Biosci Rep 2005; 25: 227-249.

379 Strain GM, Waldrop RD. Temperature and vascular volume effects on gastric ulcerogenesis after cord transection. Dig Dis Sci 2005; 50: 2037-2042.

380 Muraki S, Yamasaki M, Ishii K, Kikuchi K, Seki K. Relationship between core temperature and skin blood flux in lower limbs during prolonged arm exercise in persons with spinal cord injury. Eur J Appl Physiol Occup Physiol 1996; 72: 330-334.
$381 \mathrm{O}^{\prime}$ Leary DS, Johnson JM. Baroreflex control of the rat tail circulation in normothermia and hyperthermia. I Appl Physiol 1989; 66: 1234-1241.

382 Owens NC, Ootsuka Y, Kanosue K, McAllen RM. Thermoregulatory control of sympathetic fibres supplying the rat's tail. J Physiol 2002; 543: 849-858.

383 Takahashi Y, Hirayama J, Nakajima Y. Segmental regulation pattern of body surface temperature in the rat hindlimb. Brain Res 2002; 947: 100-109.

384 Vianna DM, Carrive P. Changes in cutaneous and body temperature during and after conditioned fear to context in the rat. Eur J Neurosci 2005; 21: 2505-2512.

385 Nicotra A, Young TM, Asahina M, Mathias CJ. The effect of different physiological stimuli on skin vasomotor reflexes above and below the lesion in human chronic spinal cord injury. Neurorehabil Neural Repair 2005; 19: 325-331.

386 Nicotra A, Asahina M, Young TM, Mathias CJ. Heat-provoked skin vasodilatation in innervated and denervated trunk dermatomes in human spinal cord injury. Spinal Cord 2006; 44: 222-226.

387 Hagbarth KE, Vallbo AB. Pulse and respiratory grouping of sympathetic impulses in human muscle-nerves. Acta Physiol Scand 1968; 74: 96-108.

388 Longmire DR. An electrophysiological approach to the evaluation of regional sympathetic dysfunction: a proposed classification. Pain Physician 2006; 9: 69-82.

389 Shahani BT, Halperin JJ, Boulu P, Cohen J. Sympathetic skin response - a method of assessing unmyelinated axon dysfunction in peripheral neuropathies. I Neurol Neurosurg Psychiatry 1984; 47: 536-542.

390 Cariga P, Catley M, Mathias CJ, Savic G, Frankel HL, Ellaway PH. Organisation of the sympathetic skin response in spinal cord injury. J Neurol Neurosurg Psychiatry 2002; 72: 356-360.

391 Davis MD, Genebriera J, Sandroni P, Fealey RD. Thermoregulatory sweat testing in patients with erythromelalgia. Arch Dermatol 2006; 142: 1583-1588.

392 Low VA, Sandroni P, Fealey RD, Low PA. Detection of small-fiber neuropathy by sudomotor testing. Muscle Nerve 2006; 34: 57-61.

393 Fealey RD. Thermoregulation and tests of sweating in spinal cord injury. Symposium Presentation at the 53rd Annual Conference of the American Paraplegia Society 2007, Kissimee, FL.

394 Wada M, Takagaki T. A simple and accurate method for detecting sweat. Tohoku J Exp Med 1948; 49: 284.

395 Tafari AT, Thomas SA, Palmiter RD. Norepinephrine facilitates the development of the murine sweat response but is not essential. J Neurosci 1997; 17: 4275-4281.

396 Sakamoto K, Uvelius B, Khan T, Damaser MS. Preliminary study of a genetically engineered spinal cord implant on urinary bladder after experimental spinal cord injury in rats. I Rehabil Res Dev 2002; 39: 347-357.

397 Gris D, Marsh DR, Dekaban GA, Weaver LC. Comparison of effects of methylprednisolone and anti-CD11d antibody treatments on autonomic dysreflexia after spinal cord injury. Exp Neurol 2005; 194: 541-549.

398 Gris D, Marsh DR, Oatway MA, Chen YH, Hamilton EF, Dekaban GA et al. Transient blockade of the CD11d/CD18 integrin reduces secondary damage after spinal cord injury, improving sensory, autonomic, and motor function. I Neurosci 2004; 24: 4043-4051.

399 Ditor DS, Bao F, Chen Y, Dekaban GA, Weaver LC. A therapeutic time window for anti-CD 11d monoclonal antibody treatment yielding reduced secondary tissue damage and enhanced behavioral recovery following severe spinal cord injury. J Neurosurg Spine 2006; 5: 343-352.

400 Ditor DS, John SM, Roy J, Marx JC, Kittmer C, Weaver LC. Effects of polyethylene glycol and magnesium sulfate administration on clinically relevant neurological outcomes after spinal cord injury in the rat. J Neurosci Res 2007; 85: 1458-1467.

401 Teng YD, Mocchetti I, Taveira-DaSilva AM, Gillis RA, Wrathall JR. Basic fibroblast growth factor increases long-term survival of spinal motor neurons and improves respiratory function after experimental spinal cord injury. J Neurosci 1999; 19: 7037-7047.

402 Rossignol S, Schwab M, Schwartz M, Fehlings MG. Spinal cord injury: time to move? J Neurosci 2007; 27: 11782-11792. 
403 Rowell LB. Importance of scintigraphic measurements of human splanchnic blood volume. J Nucl Med 1990; 31: 160-162.

404 Goshgarian HG, Rafols JA. The ultrastructure and synaptic architecture of phrenic motor neurons in the spinal cord of the adult rat. I Neurocytol 1984; 13: 85-109.

405 Janig W. The Integrative Action of the Autonomic Nervous System: Neurobiology of Homeostasis. Cambridge University Press: Cambridge, 2006.
406 Bharucha AE. Update of tests of colon and rectal structure and function. J Clin Gastroenterol 2006; 40: 96-103.

407 Purinton PT, Fletcher TF, Bradley WE. Gross and light microscopic features of the pelvic plexus in the rat. Anat Rec 1973; 175: 697-706.

408 Hubscher $\mathrm{CH}$, Johnson RD. Effects of acute and chronic midthoracic spinal cord injury on neural circuits for male sexual function. I. Ascending pathways. J Neurophysiol 1999; 82: 1381-1389. 